\title{
Advisory Board Italiano sulla sindrome dell'ovaio policistico (PCOS): dalle osservazioni all'esperienze cliniche sull'uso del mio-inositolo (MYO) e dell'acido alfa-lipoico (ALA) per migliorare i quadri della sindrome
}

Advisory Board Italiano sulla sindrome dell'ovaio policistico (PCOS):

Enrico M. Ferrazzi, Paolo Moghetti, Franca Fruzzetti, Alessandra Gambineri,

Anna Maria Fulghesu, Maria E. Street, Rocco Rago, Caterina Meneghini, Alessandro Dal Lago, Irene Cetin, Chiara Novielli, Chiara Mandò, Nicoletta Di Simone,

Rosanna Apa, Giovanna Noristefano, Alessandro D. Genazzani, Vincenzo De Leo

(Cite this article as: Advisory Board Italiano sulla sindrome dell'ovaio policistico (PCOS). Advisory Board Italiano sulla sindrome dell'ovaio policistico (PCOS): dalle osservazioni alle esperienze cliniche sull'uso del mio-inositolo (MYO) e dell'acido alfa-lipoico (ALA) per migliorare i quadri della sindrome. Minerva Ginecol 2020;72:000-000. DOI: 10.23736/S0026-4784.20.04575-X) 


\title{
Advisory Board Italiano sulla sindrome dell'ovaio policistico (PCOS): dalle osservazioni all'esperienze cliniche sull'uso del mioinositolo (MYO) e dell'acido alfa-lipoico (ALA) per migliorare i quadri della sindrome
}

\author{
Enrico M. FERRAZZI $1,2 *$
}

${ }^{1}$ Obstetric and Gynecologic Clinic, University of Milan, Milan, Italy; ${ }^{2}$ Fondazione IRCCS Ca' Granda Ospedale Maggiore Policlinico, Mangiagalli Center, University of Milan, Milan, Italy

*Corresponding author: Enrico M. Ferrazzi, Obstetric and Gynecologic Clinic, University of Milan, Milan, Italy.

E-mail: enrico.ferrazzi@unimi.it

\section{R I A S S U N T O}

OBIETTIVO: La complessità della sindrome dell'ovaio policistico (PCOS) spiega la non univoca presenza di linee guida e raccomandazioni internazionali e nazionali condivise. La multidisciplinarietà dei componenti dell'Advisory Board italiano dedicato alla PCOS ha posto le basi per identificare un percorso clinico-diagnostico per accompagnare la donna con PCOS durante le fasi della sua vita clinica, dall'infanzia all'adolescenza, alla premenopausa. Obiettivo del lavoro è definire e condividere le scelte ottimali per la gestione delle pazienti con PCOS identificata e valutata sulla base delle specifiche competenze ed esperienze dei centri di riferimento coinvolti.

METODI. Il panel di esperti è stato suddiviso per competenza prevalente in base alle fasi cronologiche della vita clinica delle pazienti con PCOS o per specifica competenza di popolazioni di donne con caratteristiche cliniche comuni a quelle delle pazienti con PCOS.

RISULTATI. È stata enucleata una serie di statements derivati dalla sintesi dei risultati di studi clinici e sperimentali noti in letteratura e/o condotti dai membri dell'Advisory Board inerenti i vari fenotipi di PCOS. Si è cercato di approfondire il ruolo degli attuali strumenti diagnostici soprattutto in funzione di parametri di valutazione fondamentali come l'insulinoresistenza e iperandrogenismo. Specifica attenzione è stata data all'impiego nei diversi fenotipi di PCOS di sostanze integrative ad azione nota come mioinositolo (MYO) e acido alfa-lipoico (ALA) per cercare uno strumento per approfondire aspetti clinici e, prima ancora, a livello sperimentale della PCOS.

CONCLUSIONI: L'insieme degli statements prodotti dai componenti dell'Advisory Board permetterà una migliore definizione clinica delle pazienti in funzione non solo della diagnostica ma anche della scelta terapeutica di tipo integrativo con l'uso del MYO e/o dell'ALA

PAROLE CHIAVE: Ovaio policistico, sindrome; Insulino-resistenza; Iperinsulinemia; Iperandrogenismo; Mioinositolo; Dchiro-inositolo.

$\mathrm{L}$ a sindrome dell'ovaio policistico (PCOS) è un disordine ginecologico-endocrinologico con quadri clinici eterogenei, la cui patofisiologia non è ancora del tutto compresa. ${ }^{1}$

La prevalenza della PCOS, che può variare in base ai criteri diagnostici applicati, è stata stima- ta in $15-20 \%$ secondo l'European Society of $\mathrm{Hu}-$ man Reproduction (ESHRE) e dell'Embryology/ American Society for Reproductive Medicine (ASRM). ${ }^{2}$

Pertanto, i dati epidemiologici e di ricerca di base attualmente disponibili non possono essere 
considerati un fondamento necessario per definire questa sindrome in base all'evidenza; 3 è quindi difficile stabilire un consenso globale sulla PCOS.

Del resto, quando parliamo di "sindrome" identifichiamo segni, sintomi e tratti fisiopatologici comuni di regola "down-stream" di possibili diverse patologie. Il nuovo concetto espresso dal termine esposoma, in particolari tipi di alimenti della "western diet" e stile di vita sedentario, spiega alcuni fenotipi clinici della PCOS propri della sindrome metabolica e, al contrario come alcuni profili nutrizionali e nutraceutici potrebbero essere impiegati per "trattare" il background di questi fenotipi molto frequenti in questa sindrome. Secondo questa ipotesi questi fenotipi prevalenti della PCOS subirebbero proprio uno svantaggio genomico quando esposti alla "western diet". ${ }^{4}$

L'insulino-resistenza è considerata oggi una caratteristica clinicamente rilevante della PCOS ed è correlata a un ampio spettro di comorbidità che comprende la sindrome metabolica e l'infertilità. ${ }^{1}$ Diagnosi e gestione appropriate della PCOS sono essenziali sia per risolvere le manifestazioni cliniche, ma anche per prevenire future complicanze metaboliche, endocrine e cardiovascolari. ${ }^{2}$ In particolare, esiste una chiara evidenza di un rischio cardiovascolare e disturbi del metabolismo glucidico superiore nelle pazienti con PCOS rispetto alla popolazione sana. 5

E pertanto necessario un costante aggiornamento in base all'evidenza disponibile sui criteri diagnostici che sono diversi a seconda delle varie fasi della vita delle pazienti con PCOS, ${ }^{3}$ sui trattamenti e gestione clinica complessiva nel breve, medio e lungo termine.

Il presente documento di consensus è frutto del lavoro di un Advisory Board italiano dedicato alla PCOS, la cui composizione multidisciplinare di ricerca genetica, sperimentale e clinica ha consentito, utilizzando mioinositolo (MYO) ed acido alfa-lipoico (ALA) in vari schemi terapeutici, di approfondire e integrare diversi approcci ed analizzare la malattia nell'arco della vita clinica della paziente con PCOS, dalla prima adolescenza alla menopausa.

Gli obiettivi del presente documento di con- sensus comprendono: a) approfondire i criteri diagnostici applicati nell'attuale realtà clinica italiana; b) identificare best practice di gestione di lungo termine della paziente PCOS proponendo alcuni strumenti per la pratica quotidiana; c) indicare le aree che richiedono ulteriore approfondimento di ricerca.

\section{Materiali e metodi}

Panel di esperti dell'Advisory Board

I componenti dell'Advisory Board Italiano per la PCOS sono stati scelti sulla base dell'esperienza clinica e/o scientifica non solo nazionale ma anche internazionale su questa sindrome.

La loro partecipazione è avvenuta a titolo gratuito.

Il panel di esperti è stato suddiviso per competenza prevalente in base alle fasi cronologiche della vita clinica delle pazienti con PCOS e/o per la specifica competenza su popolazioni di donne con caratteristiche cliniche comuni a quelle con quadro di PCOS:

- diagnosi;

- insulino-resistenza/iperinsulinemia;

- PCOS e adolescenza;

- PCOS e fertilità;

- terapie.

I componenti dell'Advisory Board:

- Apa Rosanna (Dipartimento di Scienze della Salute della Donna, del Bambino e di Sanità Pubblica UOC di Ginecologia e Ostetricia, Università Cattolica del Sacro Cuore, Fondazione Policlinico Universitario A. Gemelli, IRCCS, Roma);

- Cetin Irene (Ospedale Buzzi ASST Fatebenefratelli Sacco e Laboratorio di Ricerca Traslazionale Materno-Fetale "Giorgio Pardi", Dipartimento di Scienze Biomediche e Cliniche "Luigi Sacco", Università degli Studi di Milano)

- Mandò Chiara (Laboratorio di Ricerca Traslazionale Materno-Fetale "Giorgio Pardi", Dipartimento di Scienze Biomediche e Cliniche "Luigi Sacco", Università degli Studi di Milano)

- De Leo Vincenzo (Dipartimento di Medicina Molecolare e dello Sviluppo, Università degli Studi di Siena)

- Di Simone Nicoletta (Dipartimento di 
Scienze della Salute della Donna, del Bambino e di Sanità Pubblica UOC di Ginecologia e Ostetricia, Università Cattolica del Sacro Cuore Fondazione Policlinico Universitario A. Gemelli, IRCCS, Roma);

- Ferrazzi Enrico M. (Professore ordinario di Clinica Ostetrica e Ginecologica Università di Milano, Direttore UOC di Ostetricia Mangiagalli, IRCCS Ca' Granda, Policlinico di Milano;

- Fruzzetti Franca (Clinica Ostetrica e Ginecologica, Ospedale santa Chiara, Ambulatorio di Endocrinologia Ginecologica dell'Azienda Ospedaliera Pisana);

- Fulghesu Anna Maria (Dipartimento di Chirurgia, Facoltà di Medicina e Chirurgia, Università degli Studi di Cagliari);

- Gambineri Alessandra (Unità Operativa di Endocrinologia, Ospedale S. Orsola-Malpighi, Università di Bologna);

- Genazzani Alessandro D. (Centro di Ginecologia Endocrinologica Università di Modena e Reggio Emilia);

- Moghetti Paolo (Endocrinologia, Diabetologia e Malattie del Metabolismo- Università e Azienda Ospedaliera Universitaria Integrata Verona);

- Rago Rocco (Ospedale Sandro Pertini UOSD Fisiopatologia della Riproduzione e Andrologia);

- Street Maria E. (SS Endocrinologia e Diabe- tologia Pediatrica SC Pediatria - Arcispedale S. Maria Nuova - IRCCS Reggio Emilia).

\section{Metodo di lavoro dell'Advisory Board}

Dopo revisione della più recente letteratura e dell'esperienza scientifica/clinica di ogni componente del gruppo di lavoro, nelle riunioni relative sono state sviluppate e gerarchizzate le domande di ricerca che hanno costituito il driver del lavoro del Board.

Nel corso delle discussioni sono state enucleati e definiti gli statements ed identificate le aree che necessitano ulteriore sviluppo e ricerca.

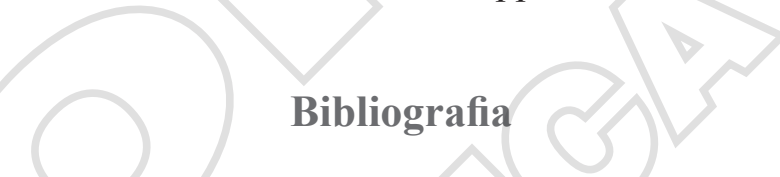

1. Facchinetti F, Bizzarri M, Benvenga S, D'Anna R, Lanzone A, Soulage C, et al. Results from the International Consensus Conference on Myo-inositol and d-chiro-inositol in Obstetrics and Gynecology: the link between metabolic syndrome and PCOS. Eur J Obstet Gynecol Reprod Biol 2015;195:72-6.

2. Sirmans SM, Pate KA. Epidemiology, diagnosis, and management of polycystic ovary syndrome. Clin Epidemiol 2013;6:1-13.

3. Lizneva D, Suturina L, Walker W, Brakta S, GavrilovaJordan L, Azziz R. Criteria, prevalence, and phenotypes of polycystic ovary syndrome. Fertil Steril 2016;106:6-15.

4. Li R, Zhang Q, Yang D, Li S, Lu S, Wu X, et al. Prevalence of polycystic ovary syndrome in women in China: a large community-based study. Hum Reprod 2013;28:2562-9.

5. Szydlarska D, Machaj M, Jakimiuk A. History of discovery of polycystic ovary syndrome. Adv Clin Exp Med 2017;26:555-8. 


\title{
Valutazioni fisiopatologiche sull'insulino-resistenza nella PCOS
}

\author{
Paolo MOGHETTI *
}

Unit of Endocrinology, Diabetology and Metabolic Diseases, University Hospital of Verona, Verona, Italy

*Corresponding author: Paolo Moghetti, Unit of Endocrinology, Diabetology and Metabolic Diseases, University Hospital of Verona, Verona, Italy. E-mail: paolo.moghetti@univr.it

\section{R I A S S UN T O}

La resistenza all'insulina e la conseguente iperinsulinemia appaiono svolgere un ruolo patogenetico chiave in una percentuale rilevante delle donne con PCOS. L'origine di questa insulinoresistenza resta indefinita, ma appare essere in larga parte indipendente dal peso, anche se aggravata dall'eventuale eccesso ponderale. L'iperinsulinemia spesso associata alla PCOS non sembra derivare tuttavia solo dall'insulinoresistenza ma anche da una ridotta clearance metabolica dell'insulina. L'iperinsulinemia può indurre in queste donne un aumento degli androgeni liberi attraverso vari meccanismi. Va peraltro tenuto presente che l'iperandrogenismo appare contribuire a sua volta alla patogenesi dell'insulinoresistenza e può verosimilmente contribuire anche ad alterare la clearance dell'insulina, con la produzione di circoli viziosi che tendono ad amplificare le relazioni fra questi aspetti. L'insulinoresistenza può essere misurata appropriatamente e direttamente utilizzando la tecnica del clamp euglicemico iperinsulinemico, che non è però applicabile nella routine clinica. Sfortunatamente, gli indici surrogati usati in questo contesto sono gravati da importanti limiti e in particolare da un elevato numero di falsi negativi. Anche per quanto riguarda l'iperandrogenismo esistono rilevanti problematiche che limitano la possibilità di misurare con precisione questi ormoni nella comune pratica clinica. In accordo con le evidenze sul ruolo importante dell'insulinoresistenza in questa sindrome, la metformina, farmaco insulino-sensibilizzante, può migliorare gli aspetti riproduttivi della sindrome in circa il $50 \%$ delle pazienti. Dati preliminari suggeriscono che anche l'inositolo possa svolgere effetti positivi sotto questo profilo, ma i dati sono ancora insufficienti e devono essere confermati da studi appropriatamente disegnati, alcuni in corso.

PAROLE ChIAVE: Ovaio policistico, sindrome; Insulinoresistenza; Iperinsulinemia; Obesità.

$\mathrm{L}$ a resistenza all'insulina ha un ruolo chiave nello sviluppo della PCOS, almeno in una percentuale rilevante di queste pazienti. 1 Questo fenomeno è presente in almeno il 70-75\% delle donne con PCOS e la sua frequenza supera il $90 \%$ fra quelle con obesità, ma è rilevabile anche in circa il $60 \%$ delle donne magre diagnosticate con questa sindrome. ${ }^{2}$

L'origine di questa insulinoresistenza resta indefinita, ma appare essere in larga parte indipendente dal peso, anche se aggravata dall'eventuale eccesso ponderale. In termini fisiopatologici, 1'iperinsulinemia associata alla PCOS può indurre un aumento degli androgeni liberi in modi diversi, in particolare attraverso la stimolazione delle ovaie, ma anche dei surreni, a produrre androgeni e attraverso la riduzione dei livelli di SHBG. 3, 4

Va peraltro tenuto presente che l'iperandroge- nismo può a sua volta contribuire a determinare insulinoresistenza. ${ }^{5}$ Inoltre, gli androgeni potrebbero favorire l'iperinsulinemia in queste pazienti anche attraverso una riduzione della clearance dell'insulina. ${ }^{6}$

L'insulinoresistenza può essere misurata appropriatamente e direttamente utilizzando la tecnica del clamp euglicemico iperinsulinemico, che misura la quantità di glucosio metabolizzata in vivo in corso di infusione a velocità costante di insulina. Questa tecnica è però complessa e non utilizzabile nella pratica clinica. Abitualmente 1'insulinoresistenza viene quindi stimata in modo indiretto attraverso indici surrogati, basati sulla misura di glicemia ed insulinemia durante un test di tolleranza orale al glucosio $o$, più comunemente, attraverso i livelli di glucosio ed insulina a digiuno. Le misure indirette comprendono il semplice rapporto tra glucosio e insulina a digiuno, 
la valutazione attraverso il modello omeostatico (HOMA), il QUICKI, il Matsuda Index e altri indicatori. ${ }^{7}$ Sfortunatamente tutti questi indici sono però inaccurati nel predire la presenza di insulinoresistenza nel singolo individuo, in particolare hanno tutti una scadente performance in termini di predittori negativi nelle donne con PCOS. ${ }^{2}$ In altri termini, mentre la presenza di iperinsulinemia e di alterazioni in questo senso di tali indici indica con buona approssimazione la presenza di insulinoresistenza, il rilevare livelli di insulina apparentemente normali e indici surrogati nella norma non consente di escludere questa alterazione metabolica.

\section{L'insulinoresistenza nella fisiopatologia della PCOS}

La PCOS è comunque una condizione assai eterogenea. Il Verona 3P (PCOS Pathophysiology and Phenotype) Study ${ }^{8}$ è uno studio osservazionale, in corso da alcuni anni, finalizzato alla fenotipizzazione accurata e sistematica delle donne con PCOS. In particolare, questo studio misura con metodiche gold standard due aspetti cruciali della fisiopatologia della sindrome, la sensibilità insulinica attraverso la tecnica del clamp e gli androgeni mediante spettrometria di massa e dialisi all'equilibrio, per la misura con tecnica appropriata del testosterone libero.

In questo studio è stato osservato che circa un terzo delle donne con PCOS che afferiscono ai nostri ambulatori hanno una sindrome metabolica, a fronte di un'età media di soli 28 anni e di un BMI medio nell'ambito del sovrappeso, circa $28,5 \mathrm{~kg} / \mathrm{m}^{2}$. Questo dato testimonia l'impatto precoce e rilevante che l'insulinoresistenza ha in questa sindrome. Tuttavia, va tenuto presente che ci sono ampie differenze, anche sotto questo profilo, da paziente a paziente 8 e che l'insulinoresistenza non è una caratteristica costante nelle donne con PCOS. In particolare, distinguendo le pazienti in fenotipi clinici in base ai criteri di diagnosi della consensus di Rotterdam, l'insulinoresistenza si riscontra con alta frequenza nel fenotipo classico, in misura minore nel fenotipo ovulatorio, ma non nelle pazienti PCOS normoandrogeniche, che hanno valori di sensibilità insulinica simili a quelli dei soggetti sani senza PCOS.
In una casistica di circa 250 pazienti, il fenotipo classico rappresentava circa il $68 \%$, mentre il fenotipo ovulatorio il $17 \%$ e quello normoandrogenico il $15 \%$ dei soggetti afferenti agli ambulatori per questi aspetti. Per quanto riguarda il BMI, le pazienti con obesità rappresentavano il $42 \%$, quelle con sovrappeso il $22 \%$ e quelle con normopeso il restante $36 \%$. In questa coorte è stata confermata una relazione tra massa grassa totale e soprattutto tronculare e l'utilizzazione del glucosio durante clamp. Questa relazione appare spiegare fino al 50\% della varianza dell'insulino-resistenza, ${ }^{9}$ ma la quota restante appare legata ad altri meccanismi.

Date le forti evidenze di un ruolo dell'insulinoresistenza nella patogenesi della PCOS, un nostro precedente studio aveva valutato la risposta al trattamento con metformina di queste pazienti. In termini di funzione riproduttiva, le pazienti responder al trattamento, che presentavano ripresa dei cicli mestruali con ovulazione, erano circa il 50-55\% del totale, ma l'altro 45$50 \%$ non rispondeva al farmaco. ${ }^{10}$ Analizzando i fattori predittivi di efficacia della metformina sulla disfunzione mestruale nelle pazienti con PCOS era stato osservato che quelle che rispondevano meglio erano quelle con un valore di insulina più alto e con livelli di androgeni (in particolare, androstenedione) più bassi. Questi dati sono in sostanziale accordo con quelli del gruppo di Legro, tratti da uno studio di confronto tra metformina e clomifene in cui gli endpoints erano comunque diversi. ${ }^{11}$ In quest'ultimo studio la risposta alla metformina era massima, in termini di bambini nati vivi nelle donne con PCOS che programmavano una gravidanza, nei soggetti con obesità di primo grado e assenza di iperandrogenismo clinico.

Per quanto riguarda le terapie insulino-sensibilizzanti con integratori, i dati sono ancora molto limitati. Una recente meta-analisi Cochrane del 2017 ha concluso che i dati disponibili non erano sufficienti per stabilire l'efficacia sugli aspetti riproduttivi dell'inositolo. ${ }^{12}$

Similmente, anche per quanto riguarda 1'uso dell'acido alfa-lipoico nella PCOS sono necessari ulteriori studi. Uno studio su una casistica molto limitata (6 soggetti) di donne con PCOS non obese, in cui la sensibilità insulinica era sta- 
ta misurata mediante clamp, ha valutato l'impiego di questo integratore per 16 settimane, riportando un incremento della sensibilità insulinica e anche del numero di cicli ovulatori, nelle sole due donne che non assumevano contraccettivi orali. ${ }^{13}$ Recentemente Genazzani et al. hanno descritto una specifica efficacia dell'acido alfalipoico sull'aspetto metabolico, valutato in termini di risposta insulinemica all'OGTT, ma non su quello endocrino-riproduttivo. ${ }^{14}$

La valutazione del rapporto fra insulinoresistenza e iperandrogenismo è un aspetto fisiopatologico rilevante in queste pazienti. Tuttavia, $\mathrm{i}$ dati sono anche in questo caso ancora limitati, soprattutto per significative criticità metodologiche nelle misure degli androgeni. A questo proposito, un recente studio condotto a Verona, in collaborazione con l'Università di Ghent, ha confrontato le misure del testosterone libero ottenute con metodica gold standard, spettrometria di massa e dialisi all'equilibrio, con quelle di routine, ottenute con una metodica in chemiluminescenza con calcolo del testosterone libero attraverso la formula di Vermeulen, a partire da testosterone totale e SHBG. ${ }^{15}$

Lo studio ha dimostrato che le metodiche abitualmente disponibili nella pratica clinica determinano una sostanziale sovrastima dei valori di testosterone ma soprattutto che una significativa quota, dell'ordine del $30 \%$, delle donne con PCOS possono essere classificate erroneamente come iperandrogenemiche o normoandrogenemiche, avendo in realtà caratteristiche ormonali opposte.

Come sopra ricordato, analoghe difficoltà esistono nell'ottenere, nella pratica clinica, valutazioni affidabili della presenza di insulinoresistenza. Pur essendoci una buona correlazione generale tra misura diretta della sensibilità insulinica mediante clamp e la sua valutazione indiretta mediante HOMA-IR, il più comune indice surrogato di insulinoresistenza, nella casistica del Verona 3P Study la distinzione fra pazienti insulino-resistenti e insulino-sensibili dava risultati molto diversi se eseguita con questi due indici. In particolare, come mostra la figura, se erano poche le donne erroneamente classificate dall'indice HOMA-IR come insulino-resistenti, molte erano invece le donne erroneamente classificate

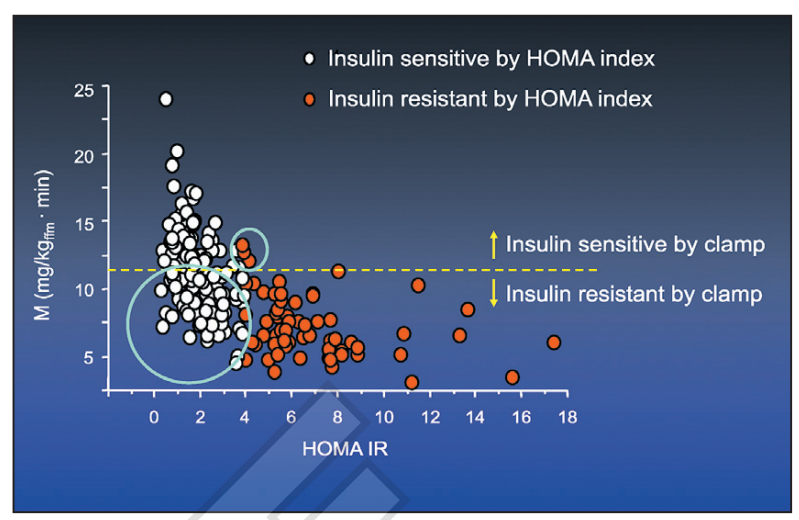

Figure 1.-Correlazione fra le misure di un indice surrogato di insulinoresistenza (HOMA-IR) e i relativi valori di riferimento (M-clamp) in un campione di donne con PCOS del Verona 3-P Study. I cerchi indicano i soggetti risultati falsi positivi e falsi negativi in termini di insulinoresistenza valutata attraverso i valori di HOMA-IR.

da questo indice come insulino-sensibili. Problemi analoghi esistono con altri indici surrogati, anche quelli che valutano la risposta glicemica e insulinemica al carico orale di glucosio. Gli indici come l'HOMA-IR possono quindi essere utili per evidenziare la presenza di insulino-resistenza ma non per escluderla (Figura 1).

\section{Protocollo dello studio IALA}

Su questi presupposti e per dare risposta alle domande ancora aperte in merito all'efficacia della terapia con integratori in queste pazienti, poggia il razionale dello studio IALA, attualmente in corso, che prevede di reclutare circa 90 donne con fenotipo PCOS classico, con BMI $<35 \mathrm{~kg} /$ $\mathrm{m}^{2}$, senza interferenza di altre patologie o farmaci. Lo studio prevede una randomizzazione in doppio cieco a tre gruppi di trattamento: mioinositolo 2 gr da solo, mioinositolo $2 \mathrm{~g}$ in associazione con acido alfa-lipoico $800 \mathrm{mg}$, o placebo per 6 mesi, ponderando la randomizzazione sulla base del BMI.

Gli endpoints previsti nello studio sono le variazioni di testosterone totale e libero, dosato con spettrometria di massa e dialisi all'equilibrio; della sensibilità insulinica, misurata mediante clamp euglicemico iperinsulinemico; della funzione ovulatoria, valutata attraverso il dosaggio seriato settimanale del pregnandiolo urinario; e di altri parametri relativi al quadro metabolico e allo stato infiammatorio. 


\section{Statements}

- Qualunque sia la causa della PCOS, nella sua patogenesi intervengono due attori fondamentali: l'insulino-resistenza e l'eccesso di androgeni. Qualunque strategia terapeutica adottata per la PCOS deve tener conto di questi due aspetti.

- La PCOS è eterogenea anche in termini metabolici. L'insulino-resistenza si riscontra con alta frequenza nel fenotipo classico, ma è meno pronunciata nel fenotipo ovulatorio e non è presente nelle pazienti PCOS normoandrogeniche, in cui i valori di sensibilità insulinica sono paragonabili a quelli dei soggetti sani.

- Insulino-resistenza e iperandrogenismo sono potenziali predittori della risposta al trattamento con metformina, ma ulteriori studi sono necessari per individuare preventivamente i responders a questa strategia, nell'ottica moderna di una medicina personalizzata.

- La valutazione dell'insulino-resistenza con indici surrogati sottostima il numero delle donne realmente insulino-resistenti.

\section{Bibliografia}

1. Diamanti-Kandarakis E, Dunaif A. Insulin resistance and the polycystic ovary syndrome revisited: an update on mechanisms and implications. Endocr Rev 2012;33:9811030 .

2. Tosi $\mathrm{F}$, Bonora $\mathrm{E}$, Moghetti P. Insulin resistance in a large cohort of women with polycystic ovary syndrome: a comparison between euglycaemic-hyperinsulinaemic clamp and surrogate indexes. Hum Reprod 2017;32:2515-21.

3. Tosi F, Negri C, Brun E, Castello R, Faccini G, Bonora $\mathrm{E}$, et al. Insulin enhances ACTH-stimulated androgen and glucocorticoid metabolism in hyperandrogenic women. Eur J Endocrinol 2011;164:197-203.

4. Moghetti P. Insulin resistance and polycystic ovary syndrome. Curr Pharm Des 2016;22:5526-34.
5. Moghetti P, Tosi F, Castello R, Magnani CM, Negri C, Brun E, et al. The insulin resistance in women with hyperandrogenism is partially reversed by antiandrogen treatment: evidence that androgens impair insulin action in women. $\mathbf{J}$ Clin Endocrinol Metab 1996;81:952-60.

6. Tosi F, Dal Molin F, Zamboni F, Saggiorato E, Salvagno GL, Fiers T, et al. Serum androgens are independent predictors of insulin clearance but not of insulin secretion in women with polycystic ovary syndrome. J Clin Endocrinol Metab 2020. [Epub ahead of print].

7. Ibáñez L, Oberfield SE, Witchel S, Auchus RJ, Chang RJ, Codner E, et al. An International Consortium Update: Pathophysiology, Diagnosis, and Treatment of Polycystic Ovarian Syndrome in Adolescence. Horm Res Paediatr 2017;88:371-95

8. Moghetti P, Tosi F, Bonin C, Di Sarra D, Fiers T, Kaufman $\mathrm{JM}$, et al. Divergences in insulin resistance between the different phenotypes of the polycystic ovary syndrome. J Clin Endocrinol Metab 2013;98:E628-37.

9. Tosi F, Di Sarra D, Kaufman JM, Bonin C, Moretta R, Bonora E, et al. Total body fat and central fat mass independently predict insulin resistance but not hyperandrogenemia in women with polycystic ovary syndrome. J Clin Endocrinol Metab 2015;100:661-9.

10. Moghetti P, Castello R, Negri C, Tosi F, Perrone F, Caputo $\mathrm{M}$, et al. Metformin effects on clinical features, endocrine and metabolic profiles, and insulin sensitivity in polycystic ovary syndrome: a randomized, double-blind, placebo-controlled 6-month trial, followed by open, long-term clinical evaluation. J Clin Endocrinol Metab 2000;85:139-46.

11. Rausch ME, Legro RS, Barnhart HX, Schlaff WD, Carr BR, Diamond MP, et al.; Reproductive Medicine Network. Predictors of pregnancy in women with polycystic ovary syndrome. J Clin Endocrinol Metab 2009;94:3458-66.

12. Morley LC, Tang T, Yasmin E, Norman RJ, Balen AH. Insulin-sensitising drugs (metformin, rosiglitazone, pioglitazone, D-chiro-inositol) for women with polycystic ovary syndrome, oligo amenorrhoea and subfertility. Cochrane Database Syst Rev 2017;11:CD003053.

13. Masharani U, Gjerde C, Evans JL, Youngren JF, Goldfine ID. Effects of controlled-release alpha lipoic acid in lean, nondiabetic patients with polycystic ovary syndrome. J Diabetes Sci Technol 2010;4:359-64.

14. Genazzani AD, Shefer K, Della Casa D, Prati A, Napolitano A, Manzo A, et al. Modulatory effects of alpha-lipoic acid (ALA) administration on insulin sensitivity in obese PCOS patients. J Endocrinol Invest 2018;41:583-90.

15. Tosi F, Fiers T, Kaufman JM, Dall'Alda M, Moretta R, Giagulli VA, et al. Implications of Androgen Assay Accuracy in the Phenotyping of Women With Polycystic Ovary Syndrome. J Clin Endocrinol Metab 2016;101:610-8. 


\title{
PCOS e rischio metabolico in adolescenza
}

\author{
Franca FRUZZETTI *
}

Clinic of Obstetrics and Gynecology, Santa Chiara Hospital, Ambulatory of Gynecological Endocrinology, University Hospital of Pisa, Pisa, Italy

*Corresponding author: Franca Fruzzetti, Clinic of Obstetrics and Gynecology, Santa Chiara Hospital, Ambulatory of Gynecological Endocrinology, University Hospital of Pisa, Pisa, Italy. E-mail: ffruzzi15@gmail.com

\section{R I A S S U N T O}

La PCOS si manifesta clinicamente in adolescenza. Nonostante la giovane età le adolescenti con PCOS possono presentare una ridotta sensibilità all'insulina, accumulo di grasso a livello addominale, alterazione del profilo lipidico con un rischio 4 volte superiore rispetto alle coetanee di sviluppare una sindrome metabolica. Fondamentale è pertanto cercare di individuare precocemente $\mathrm{i}$ soggetti a rischio. Obesità e iperandrogenemia appaiono oggi essere le condizioni che maggiormente si associano al danno metabolico. Un approccio corretto volto a identificare il profilo di rischio di ogni adolescente con PCOS contribuisce ad attuare precocemente cambiamenti nello stile di vita e scelte terapeutiche in modo da condizionare positivamente il futuro delle adolescenti con PCOS.

PARole ChIAVE: Sindrome dell'ovaio policistico; Adolescenza; Danno metabolico.

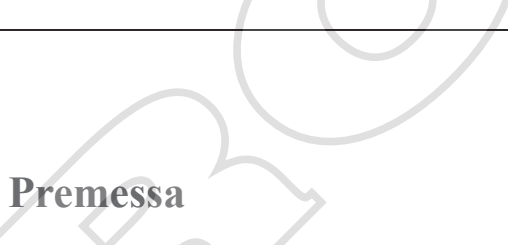

$\mathrm{U}$ no dei tanti temi di discussione attuali riguardanti la PCOS è la sua diagnosi nelle adolescenti. I criteri di Rotterdam ${ }^{1}$ sono stati elaborati per l'età adulta e, quando applicati all'adolescenza, possono essere causa di diagnosi non corrette, soprattutto per i fenotipi di PCOS come il D o il C. Al momento attuale non esistono né linee guida specifiche per l'adolescenza né criteri diagnostici validati.

\section{Definizione clinica}

La diagnosi si deve basare sulla contemporanea presenza dei 3 criteri di Rotterdam, avendo presente che l'iperandrogenismo, l'aumento delle dimensioni delle ovaie e la presenza di oligomenorrea/amenorrea hanno in questa fase della vita dei significati che possono essere completamente diversi quando presenti nell'adulto. Come segno clinico di iperandrogenismo viene incluso solo la presenza di irsutismo escludendo l'acne.

Nonostante la giovane età, le adolescenti con
PCOS hanno un danno metabolico importante che pone la base per la comparsa di patologie metaboliche e cardiovascolari nell'adulto. Le adolescenti con PCOS possono presentare una ridotta sensibilità all'insulina, un aumento della sua secrezione, un rapporto vita/fianchi alterato, una alterazione del profilo lipidico con riduzione delle HDL colesterolo e aumento dei trigliceridi (Tabella I). Il danno metabolico è simile al danno evidenziato nella PCOS dell'adulto. In alcuni casi si può arrivare a diagnosticare la presenza di una sindrome metabolica. ${ }^{2-4}$ Le adolescenti con PCOS hanno un rischio di sindrome metabolica quattro volte superiori rispetto alle coetanee non affette da questa disendocrinia.

Relativamente all'incidenza, nel nostro paese il $10 \%$ delle adolescenti con PCOS può presentare un quadro di sindrome metabolica. ${ }^{2,5}$

Per una corretta gestione della adolescente con PCOS va a questo proposito ricordato, come per la diagnosi di sindrome metabolica, la necessità di riferirsi a cut off specifici per ogni parametro riferiti all'adolescenza, e che come tali sono diversi dall'adulto. ${ }^{6}$ 
TABella I.-PCOS adolescenza: aspetti metabolici. Modificata da Fruzzetti et al. ${ }^{2}$

\begin{tabular}{lcc}
\hline Parameters & Adolescents with PCOS $(\mathrm{N} .=120)$ & Normal adolescents $(\mathrm{N} .=30)$ \\
\hline BMI $\left(\mathrm{kg} / \mathrm{m}^{2}\right)$ & $24.5 \pm 4.9$ & $23.5 \pm 2.3$ \\
WHR & $0.77 \pm 0.06^{\mathrm{a}}$ & $0.73 \pm 0.05$ \\
Total cholesterol $(\mathrm{mg} / \mathrm{dL})$ & $163.2 \pm 32$ & $164.7 \pm 18.7$ \\
LDL cholesterol $(\mathrm{mg} / \mathrm{dL})$ & $96.2 \pm 24.6$ & $99.1 \pm 15.2$ \\
HDL cholesterol $(\mathrm{mg} / \mathrm{dL})$ & $48.7 \pm 11.0^{\mathrm{b}}$ & $59.4 \pm 5.7$ \\
Triglycerides $(\mathrm{mg} / \mathrm{dL})$ & $77.9 \pm 44^{\mathrm{c}}$ & $47.3 \pm 42$ \\
Glucose $(\mathrm{mg} / \mathrm{dL})$ & $78.1 \pm 7.9^{\mathrm{d}}$ & $65.6 \pm 11.5$ \\
Insulin $(\mu \mathrm{U} / \mathrm{mL})$ & $15.2 \pm 10.5^{\mathrm{e}}$ & $7.3 \pm 2.0$ \\
HOMA-IR & $2.9 \pm 2.2^{\mathrm{e}}$ & $1.7 \pm 0.4$ \\
AUC-insulin $(\mu \mathrm{U} / \mathrm{mL} / 120 \mathrm{~min})$ & $9456 \pm 5058^{\mathrm{b}}$ & $3901 \pm 1178$ \\
\hline BM: Bod Mas
\end{tabular}

BMI: Body Mass Index; WHR: waist-to-hip ratio; HOMA-IR: homeostasis model assessment insulin resistance; AUG-insulin: area under the curve of insulin; PCOS: polycystic ovary syndrome.

$\mathrm{P}$ values are indicated for differences between groups as analyzed by Student's $t$ test for unpaired data and by ANCOVA controlling for BMI and BMI.

a $\mathrm{P}<0.05$; b $\mathrm{P}<0.001$; c $\mathrm{P}<0.01$; d $\mathrm{P}<0.0001$; $\mathrm{P}<0.005$.

Un corretto inquadramento delle alterazioni cliniche e metaboliche delle adolescenti con PCOS è fondamentale nella gestione della adolescente con PCOS e nello scegliere il trattamento più adeguato.

\section{Stratificare il rischio}

Prima di ogni approccio terapeutico, fondamentale è la valutazione del profilo metabolico e quindi la stratificazione del rischio di ciascun individuo. Da sottolineare che per attuare una stratificazione del rischio corretta è necessario che venga fatto riferimento per i diversi parametri a cut-off specifici per le adolescenti.

In generale dovrebbe essere valutato la presenza di obesità, obesità centrale con rapporto vita fianchi, la tolleranza ai carboidrati, profilo lipidico, valori della pressione arteriosa e familiarità per malattie cardiovascolari. In un recente lavoro riguardante la casistica toscana di adolescenti con PCOS non è stato riscontrato un aumento significativo dello spessore della intima, espressione di danno vascolare, in contrasto a quanto riportato dalla letteratura internazionale. ${ }^{7}$ Le differenze tra le due casistiche riguardano il BMI e quindi la presenza o meno di obesità.

La presenza di un elevato BMI contribuisce in misura significativa all'aumento del rischio metabolico anche nelle pazienti adolescenti con PCOS. Ricordiamo inoltre, che livelli elevati di testosterone sono più facilmente associati alla presenza di danno metabolico, riconoscendo nel dosaggio del testosterone un elemento importante nella stratificazione del rischio metabolico di queste adolescenti.

Iperandrogenemia, BMI e obesità sono pertanto elementi fondamentali per una corretta valutazione del rischio e per le conseguenti decisioni terapeutiche che possono comprendere sia insulino-sensibilizzanti (metformina, inositoli, acido alfa-lipoico) sia trattamenti estro-progestinici. Un approccio corretto volto a identificare il profilo di rischio di ogni singola adolescente con PCOS contribuisce alla scelta terapeutica più corretta e a condizionare positivamente il futuro delle adolescenti con PCOS.

Le scelte di un approccio farmacologico nelle adolescenti con PCOS andranno modulate diversamente a seconda dello squilibrio metabolico presente, ricordando che qualunque scelta deve tener conto anche del suo effetto sul rischio metabolico.

Dati recenti 8 indicano che la somministrazione in donne giovani per due anni di un'associazione di acido alfa-lipoico + mioinositolo $(800 \mathrm{mg}+$ $2000 \mathrm{mg} /$ die) determina un miglioramento della ciclicità mestruale valutata dopo $6(\mathrm{P}<0,001)$, 12 e 24 mesi di trattamento $(\mathrm{P}<0,01)$, associato ad un miglioramento della risposta insulinemica. Questi dati, associati alla buona tollerabilità mostrata e all'osservazione che nell'arco di due anni il peso non è aumentato, ne indicano il possibile uso anche in adolescenza. 
Quando lo scopo della terapia è il miglioramento dell'irsutismo, il trattamento estro-progestinico sarà scelto in modo da non peggiorare il problema metabolico attuando scelte che potrebbero essere meno efficaci sull'irsutismo, ma meno dannose sulla salute metabolica della adolescente con PCOS.

Prima di concludere va comunque ricordato che l'approccio a modificare lo stile di vita delle ragazze con PCOS è fondamentale in adolescenza ancor più che per le pazienti adulte. L'adolescenza è infatti un periodo determinante per la vita futura dove insegnare a modificare il proprio stile di vita mediante l'attività fisica e uso di alimentazione corretta può essere determinante per garantire un futuro migliore in termini di salute riproduttiva e rischi metabolici legati alla PCOS.

\section{Statements}

- Attualmente non esistono né linee guida specifiche per l'adolescenza né criteri diagnostici specifici validati.

- Il rischio metabolico delle pazienti adolescenti con PCOS va valutato con valori di cut-off diversi da quelli per i pazienti adulti (per esempio, valori di cut-off dell'ipertensione arteriosa).

- BMI, obesità, androgeni elevati sono elementi fondamentali per una corretta valutazione del rischio nelle pazienti adolescenti in vista delle conseguenti decisioni terapeutiche che possono comprendere sia gli insulino-sensibilizzanti, gli inositoli, l'acido alfa-lipoico, ma anche i trattamenti estro-progestinici.

- Nuovi incoraggianti risultati indicano che la somministrazione in donne giovani per due anni di acido alfa-lipoico + mioinositolo determina un miglioramento della ciclicità menstruale associato a un miglioramento della risposta insulinemica.

- Fondamentale è insegnare un corretto stile di vita che prevede regolare attività fisica e alimentazione equilibrata.

\section{Bibliografia}

1. Rotterdam ESHRE/ASRM-Sponsored PCOS Consensus Workshop Group. Revised 2003 consensus on diagnostic criteria and long-term health risks related to polycystic ovary syndrome. Fertil Steril 2004;81:19-25.

2. Fruzzetti F, Perini D, Lazzarini V, Parrini D, Genazzani AR. Adolescent girls with polycystic ovary syndrome showing different phenotypes have a different metabolic profile associated with increasing androgen levels. Fertil Steril 2009;92:626-34.

3. Silfen ME, Denburg MR, Manibo AM, Lobo RA, Jaffe R, Ferin $\mathrm{M}$, et al. Early endocrine, metabolic, and sonographic characteristics of polycystic ovary syndrome (PCOS): comparison between nonobese and obese adolescents. J Clin Endocrinol Metab 2003;88:4682-8.

4. Hart R, Doherty DA, Mori T, Huang RC, Norman RJ, Franks $\mathrm{S}$, et al. Extent of metabolic risk in adolescent girls with features of polycystic ovary syndrome. Fertil Steril 2011;95:2347-53, 2353.e1.

5. Fruzzetti F, Perini D, Lazzarini V, Parrini D, Gambacciani $\mathrm{M}$, Genazzani AR. Comparison of effects of $3 \mathrm{mg}$ drospirenone plus $20 \mu \mathrm{g}$ ethinyl estradiol alone or combined with metformin or cyproterone acetate on classic metabolic cardiovascular risk factors in nonobese women with polycystic ovary syndrome. Fertil Steril 2010;94:1793-8.

6. de Ferranti SD, Gauvreau K, Ludwig DS, Neufeld EJ, Newburger JW, Rifai N. Prevalence of the metabolic syndrome in American adolescents: findings from the Third National Health and Nutrition Examination Survey. Circulation 2004;110:2494-7.

7. Fruzzetti F, Perini D, Russo M, Bucci F, Gadducci A. Comparison of two insulin sensitizers, metformin and myoinositol, in women with polycystic ovary syndrome (PCOS). Gynecol Endocrinol 2017;33:39-42.

8. Fruzzetti F, Fidecicchi T, Palla G, Gambacciani M. Longterm treatment with $\alpha$-lipoic acid and myo-inositol positively affects clinical and metabolic features of polycystic ovary syndrome. Gynecol Endocrinol 2020;36:152-5. 


\title{
Effetto della terapia combinata mioinositolo e metformina sull'espressione fenotipica della sindrome dell'ovaio policistico
}

\author{
Alessandra GAMBINERI * \\ Operative Unit of Endocrinology, Department of Medical and Surgical Sciences, S. Orsola-Malpighi Polyclinic, \\ University of Bologna, Bologna, Italy \\ *Corresponding author: Alessandra Gambineri, Operative Unit of Endocrinology, Department of Medical and Surgical Sciences, S. \\ Orsola-Malpighi Polyclinic, University of Bologna, Bologna, Italy. E-mail: alessandra.gambineri3@unibo.it

\section{R I A S S UN T O} \\ La donna con sindrome dell'ovaio policistico (PCOS) è frequentemente affetta da insulino-resistenza (IR), soprattutto se \\ coesiste una condizione di sovrappeso-obesità ed una condizione di iperandrogenismo. \\ L'IR nella PCOS è caratteristicamente selettiva, ovvero interessa tipicamente il fegato, il tessuto adiposo e il muscolo \\ scheletrico, mentre altri tessuti quali l'ovaio, rimangono insulino sensibili e quindi esposti ad una condizione di iperin- \\ sulinemia. \\ Trattare l'IR nella PCOS comporta un miglioramento clinico, metabolico ed ovulatorio in tale patologia. L'IR nella PCOS \\ può essere trattata sia con la metformina, sia con gli inositoli. Un nostro studio, brevemente qui presentato, suggerisce \\ anche la possibilità di utilizzare la combinazione di metformina e mioinositolo nelle PCOS sovrappeso-obese. \\ PAROLE CHIAVE: Sindrome dell'ovaio policistico; Mioinositolo; Metformina.
}

$\mathrm{L}$ a sindrome dell'ovaio policistico (PCOS) è la causa più frequente di irregolarità mestruali, anovulatorietà e di infertilità nella donna. ${ }^{1-3}$ La forma classica della PCOS è caratterizzata da iperandrogenismo, oligo-anovulatorietà cronica, problemi dermatologici quali acne, irsutismo e seborrea, e un quadro ecografico pelvico di ovaie policistiche. Negli ultimi anni si è andato sempre più consolidando il concetto che la maggior parte delle donne con PCOS presentano anche una riduzione della sensibilità insulinica, che sembra essere indipendente dal peso corporeo. ${ }^{3-6} \mathrm{La}$ riduzione della sensibilità insulinica con iperinsulinemia compensatoria è stata infatti riscontrata nelle PCOS sia sovrappeso/obese ${ }^{7}$ che normopeso. $5,6,8,9$

L'insulinoresistenza (IR) e l'iperinsulinemia che ne deriva sembrano svolgere un ruolo importante nella patogenesi della PCOS. L'iperinsulinemia determina infatti un aumento della biosintesi ovarica e surrenalica degli androgeni e una riduzione della sintesi epatica della SHBG, con conseguente aumentata disponibilità tissutale degli androgeni. ${ }^{10}$ Inoltre, l'eccesso locale intraovarico degli androgeni determina una prematura atresia follicolare con conseguente anovulatorietà. ${ }^{11}$ L'iperinsulinemia in associazione all'iperandrogenemia causa inoltre un aumento dell'LH e una riduzione dell'FSH. ${ }^{12}$ La prematura esposizione delle cellule della granulosa dei follicoli immaturi ad alte concentrazioni di $\mathrm{LH}$ e di insulina contrasta lo sviluppo delle cellule stesse, determinandone una prematura luteinizzazione, e quindi un blocco della crescita follicolare e anovulatorietà. ${ }^{13}$ L'iperinsulinemia determina anche una inibizione della sintesi epatica dell'IGFBP-1 con conseguente aumentata biodisponibilità dell'IGF-1.14 L'aumento dell'IGF-1 intensifica la produzione androgenica ovarica da parte delle cellule della teca. 15

La metformina è il farmaco insulino-sensibilizzante di più largo impiego nella PCOS. Il 
meccanismo di azione è legato sia ad un effetto diretto sul recettore insulinico a livello muscolare ed adiposo (aumento della capacità di legame del recettore e stimolazione dell'attività tirosinchinasica), sia ad un effetto indiretto, mediato dalla riduzione dei livelli circolanti di glucosio. ${ }^{16}$ Quest'ultimo effetto è conseguente ad una riduzione della sintesi epatica di glucosio associata ad una aumentata utilizzazione periferica dello stesso. Il trattamento con metformina nella PCOS è in grado di determinare un miglioramento dell'iperinsulinemia e dell'iperandrogenemia con ripristino della ciclicità mestruale, dell'ovulazione e della fertilità in molte delle donne trattate sia soprappeso/obese che normopeso. ${ }^{17}$

Ad azione insulino-sensibilizzante è anche l'inositolo. I presupposti del suo impiego nella PCOS derivano dalla recente osservazione che l'insulinoresistenza nella PCOS può in parte dipendere da un difetto dell'inositolo, di cui il mioinositolo (MYO) e il d-chiroinositolo (DCI) sono stereoisomeri derivanti dalla epimerizzazione dei 6 gruppi idrossilici $(1,2,3,4,5,6$-cicloexanexolo). L'inositolo, e quindi anche il MYO e il DCI, fanno a loro volta parte di inositolfosfoglicani (IPG), mediatori del signaling insulinico intracellulare. 18,19

Dopo il legame dell'insulina al proprio recettore, viene attivato il signaling intracellulare dell'insulina in cui l'inositolo-fosfoglicano legato all'inositolo, grazie all'enzima epimerasi, si trasforma in DCI. L'insulina è fondamentale per il funzionamento dell'epimerasi.

In condizioni di IR l'insulina funziona in modo meno efficiente nell'attivare l'epimerasi, l'enzima chiave per la conversione da MYO a DCI.

Nella PCOS la IR è presente solo in alcuni tessuti, quali fegato, tessuto adiposo e muscolo scheletrico, mentre altri, quale l'ovaio, rimane insulino-sensibile, con conseguente esposizione dell'ovaio stesso ad elevati livelli di insulina compensatori alla IR. Questo sembrerebbe comportare una differente funzionalità della epimerasi nei tessuti insulino-resistenti ripetto ai tessuti insulino-sensibili con conseguente diversa concentrazione intratissutale di MYO e di DCI. ${ }^{20,21}$

Baillargeon et al. ${ }^{22}$ hanno dimostrato come la somministrazione di metformina nella PCOS, migliorando la resistenza insulinica, aumenta la produzione di DCI, attraverso la stimolazione dell'epimerasi, così che la metformina agisce almeno in parte sulla azione del MYO e sulla sua conversione a DCI. 22

\section{Studio del centro di Bologna}

Il razionale del nostro studio è stato che l'associazione tra metformina e MYO potesse avere maggiori benefici in termini metabolici ed ovulatori rispetto alla monoterapia metformina oppure MYO nelle donne con PCOS sovrappeso/obese.

Obiettivo primario dello studio era valutare l'impatto a medio termine della terapia combinata con metformina e MYO sulla IR (misurata con l'HOMA index e con l'OGTT per valutare la risposta insulinemica) nelle donne con PCOS rispetto alla monoterapia con metformina oppure con MYO.

L'obiettivo secondario dello studio era valutare l'impatto a medio termine della terapia combinata con metformina e MYO su altri aspetti della PCOS, in particolare: ciclicità mestruale ed ovulazione, iperandrogenismo clinico e biochimico ed iperandrogenemia, pattern metabolico oltre l'IR.

I criteri d'inclusione dello studio sono stati ridotti per limitare l'eterogeneità della popolazione PCOS, ed erano: razza caucasica, PCOS diagnosticata secondo i criteri NIH (oligomenorrea con anovulatorietà + irsutismo e/o iperandrogenemia), IR, età fertile, sovrappeso/obesità. L'anovulatorietà è stata diagnosticata mediante dosaggio di $\mathrm{LH}, \mathrm{FSH}, \mathrm{E} 2, \mathrm{P}$ al $7^{\circ}, 14^{\circ}, 21^{\circ}, 28^{\circ}$ giorno del ciclo mestruale in presenza di oligomenorrea lieve/moderata o at random in presenza di oligomenorrea severa/amenorrea.

I criteri di esclusione sono stati: diabete, malattie croniche renali, epatiche, cardiache, scarsa compliance, farmaci potenzialmente interferenti con il metabolismo glucidico e con gli steroidi.

Il disegno dello studio era in aperto, randomizzato, controllato con controllo attivo, a gruppi paralleli, monocentrico (Figura 1).

Le 45 donne arruolate sono state suddivise in 3 gruppi di trattamento (metformina $1700 \mathrm{mg} / \mathrm{die}$; MYO $4 \mathrm{~g} /$ die; metformina più MYO). Delle 45 donne arruolate, 39 hanno completato lo studio. 


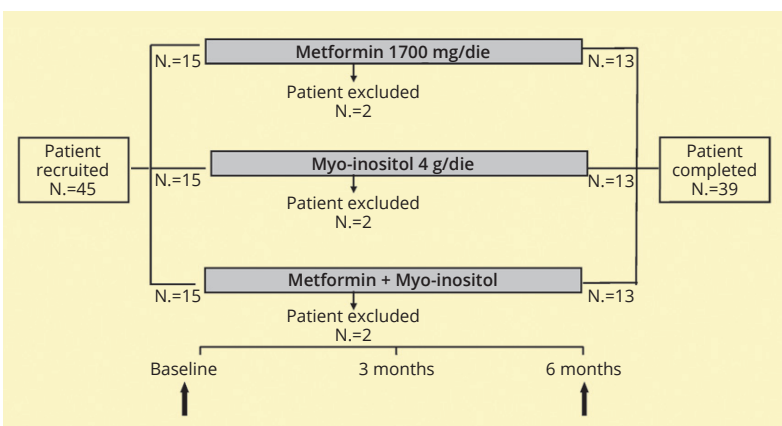

Figura 1.-Disegno dello studio; sono state reclutate 45 donne con PCOS sovrappeso/obese, randomizzate a tre bracci di trattamento (metformina, mioinositolo, metformina + mioinositolo) per 6 mesi.

Lo schema comprendeva una fase di screening di 8 settimane precedenti l'inizio del trattamento. La fine dello studio era a 6 mesi dall'inizio del trattamento durante i quali venivano eseguiti esami di valutazione dell'ovulazione, della sicurezza dei trattamenti, visita nutrizionale e di compliance, analisi ormonale e metabolica.

Il BMI e la circonferenza vita sono diminuiti in tutti e tre i gruppi di trattamento, così come è migliorato l'HOMA index. Il miglioramento del colesterolo LDL si evidenzia nel gruppo trattato con metformina e nel gruppo trattato con la combinazione metformina e MYO, mentre questo calo non si è registrato nel gruppo trattato col solo MYO. Il Free Androgen Index (FAI) ha mostrato un miglioramento nel gruppo trattato con metformina e con la combinazione metformina e MYO.

Al tempo basale queste donne erano tutte in anovularietà e, al termine del trattamento, il 60\% delle pazienti trattate sia con il solo MYO sia con la combinazione metformina e MYO ha ripristinato l'ovulazione (Figura 2).

Quindi, dai nostri dati, l'associazione tra metformina e MYO è ottimale in quanto agisce in sinergia sulla parte metabolica con la metformina e sulla funzione ovulatoria con l'azione del MYO.

\section{Statements}

- La metformina aumenta la sensibilità insulinica sia direttamente sia indirettamente riducendo la lipo-e la gluco-tossicità.

- La PCOS si caratterizza per una IR selettiva,

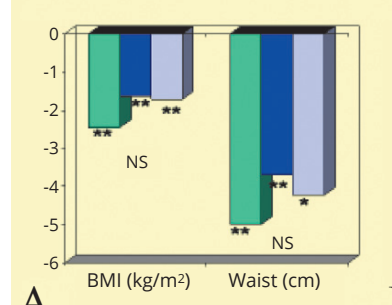

A
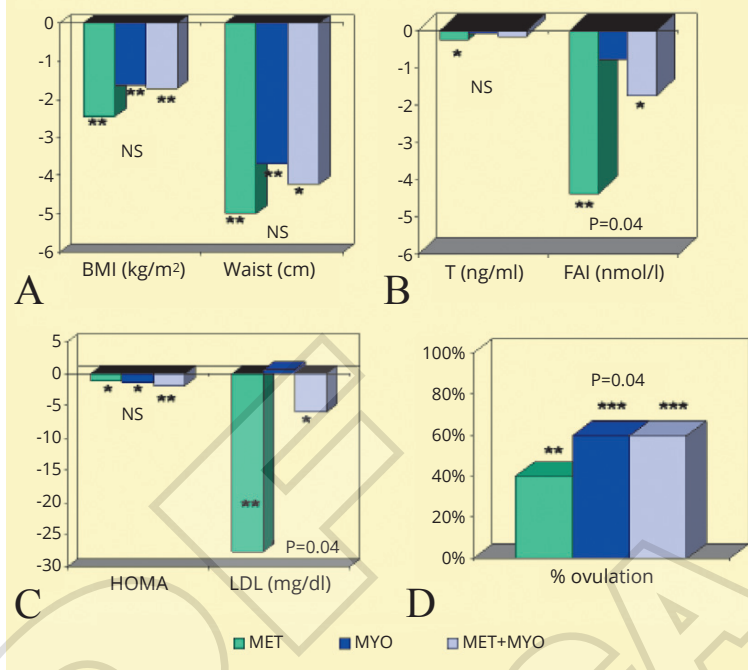

$\square \mathrm{MET}+\mathrm{MYO}$

Figura 2.-Istogrammi che rappresentano la variazione di alcuni parametri nei tre bracci di trattamento (metformina, mioinositolo, metformina + mioinositolo); gli asterischi indicano la significatività della variazione intragruppo $(* \mathrm{P}<0.05, * * \mathrm{P}<0.01, * * * \mathrm{P}<0.001)$; il valore del $\mathrm{P}$ si riferisce al confronto delle variazioni fra i tre gruppi di trattamento.

ovvero il fegato, il tessuto muscolare scheletrico e il tessuto adiposo sono IR, mentre l'ovaio mantiene una condizione di sensibilità insulinica, con conseguente esposizione ad alti livelli di insulina. Questo suggerisce una diversa espressione tissutale dell'epimerasi in presenza di IR.

- La terapia combinata metformina e MYO nella PCOS sovrappeso/obesa con IR sembra migliorare sia la componente metabolica sia la componente ovulatoria.

\section{Bibliografia}

1. Zawadsky JK, Dunaif A. Diagnostic criteria for polycystic ovary syndrome: towards a rational approach. In: Dunaif A, Givens JR, Haseltine FP, Merriam GR, editors. Current Issues in Endocrinology and Metabolism: Polycystic Ovary Syndrome. Cambridge, UK: Blackwell Scientific Publications; 1992. p. 377-84.

2. Taylor AE. Polycystic ovary syndrome. Endocrinol Metab Clin North Am 1998;27:877-902, ix.

3. The Rotterdam ESHRE/ASRM-Sponsored PCOS Consensus Workshop Group. Revised 2003 consensus on diagnostic criteria and long-term health risks related to polycystic ovary syndrome (PCOS). Hum Reprod 2004;19:41-7.

4. Baillargeon JP, Iuorno MJ, Nestler JE. Insulin sensitizers for polycystic ovary syndrome. Clin Obstet Gynecol 2003;46:325-40.

5. Genazzani AD, Battaglia C, Malavasi B, Strucchi C, Tortolani F, Gamba O. Metformin administration modulates and restores luteinizing hormone spontaneous episodic secretion 
and ovarian function in nonobese patients with polycystic ovary syndrome. Fertil Steril 2004;81:114-9.

6. Genazzani AD, Lanzoni C, Ricchieri F, Baraldi E, Casarosa E, Jasonni VM. Metformin administration is more effective when non-obese patients with polycystic ovary syndrome show both hyperandrogenism and hyperinsulinemia. Gynecol Endocrinol 2007;23:146-52.

7. Dunaif A, Segal KR, Futterweit W, Dobrjansky A. Profound peripheral insulin resistance, independent of obesity, in polycystic ovary syndrome. Diabetes 1989;38:1165-74.

8. Ciampelli M, Fulghesu AM, Cucinelli F, Pavone V, Ronsisvalle E, Guido M, et al. Impact of insulin and body mass index on metabolic and endocrine variables in polycystic ovary syndrome. Metabolism 1999;48:167-72.

9. De Leo V, la Marca A, Petraglia F. Insulin-lowering agents in the management of polycystic ovary syndrome. Endocr Rev 2003;24:633-67.

10. Nestler JE, Powers LP, Matt DW, Steingold KA, Plymate SR, Rittmaster RS, et al. A direct effect of hyperinsulinemia on serum sex hormone-binding globulin levels in obese women with the polycystic ovary syndrome. J Clin Endocrinol Metab 1991;72:83-9.

11. Utiger RD. Insulin and the polycystic ovary syndrome. N Engl J Med 1996;335:657-8.

12. Parsanezhad ME, Alborzi S, Zarei A, Dehbashi S, Omrani $\mathrm{G}$. Insulin resistance in clomiphene responders and nonresponders with polycystic ovarian disease and therapeutic effects of metformin. Int J Gynaecol Obstet 2001;75:43-50.

13. Barbieri R. Effect of insulin in polycystic ovary syndrome. In: Dunaif A, Givens J, Haseltine F, Merriam G, editors. Polycystic ovary syndrome. Boston: Blackwell; 1992; p. 249-61.

14. de Leo V, la Marca A, Morgante G, Ciotta L, Mencaglia $\mathrm{L}$, Cianci A, et al. Clomiphene citrate increases insulin-like growth factor binding protein-1 and reduces insulin-like growth factor-I without correcting insulin resistance associated with polycystic ovarian syndrome. Hum Reprod 2000;15:2302-5.

15. Stadtmauer LA, Wong BC, Oehninger S. Should patients with polycystic ovary syndrome be treated with metformin? Benefits of insulin sensitizing drugs in polycystic ovary syndrome - beyond ovulation induction. Hum Reprod 2002;17:3016-26.

16. Kirpichnikov D, McFarlane SI, Sowers JR. Metformin: an update. Ann Intern Med 2002;137:25-33.

17. Pasquali R, Gambineri A, Biscotti D, Vicennati V, Gagliardi L, Colitta D, et al. Effect of long-term treatment with metformin added to hypocaloric diet on body composition, fat distribution, and androgen and insulin levels in abdominally obese women with and without the polycystic ovary syndrome. J Clin Endocrinol Metab 2000;85:2767-74.

18. Saltiel AR. Second messengers of insulin action. Diabetes Care 1990;13:244-56.

19. Romero G, Larner J. Insulin mediators and the mechanism of insulin action. Adv Pharmacol 1993;24:21-50.

20. Baillargeon JP, Diamanti-Kandarakis E, Ostlund RE Jr, Apridonidze T, Iuorno MJ, Nestler JE. Altered D-chiro-inositol urinary clearance in women with polycystic ovary syndrome. Diabetes Care 2006;29:300-5.

21. Heimark D, McAllister J, Larner J. Decreased myo-inositol to chiro-inositol $(\mathrm{M} / \mathrm{C})$ ratios and increased $\mathrm{M} / \mathrm{C}$ epimerase activity in PCOS theca cells demonstrate increased insulin sensitivity compared to controls. Endocr J 2014;61:111-7.

22. Baillargeon JP, Iuorno MJ, Jakubowicz DJ, Apridonidze T, He N, Nestler JE. Metformin therapy increases insulinstimulated release of D-chiro-inositol-containing inositolphosphoglycan mediator in women with polycystic ovary syndrome. J Clin Endocrinol Metab 2004;89:242-9. 


\title{
Funzione endocrina e metabolismo glucidico
}

\author{
Anna Maria FULGHESU *
}

Department of Surgery, Faculty of Medicine and Surgery, University of Cagliari, Cagliari, Italy

*Corresponding author: Anna Maria Fulghesu. Department of Surgery, Faculty of Medicine and Surgery, University of Cagliari, Cagliari, Italy. E-mail: amfulghesu@unica.it

\section{R I A S S UNTO}

Lo studio presenta i risultati del trattamento con l'associazione di mioinositolo e acido alfa-lipoico in vivo, sulla risposta glicemica ed insulinemica al carico orale di glucosio in 42 giovani ragazze affette da PCOS ed iperinsulinemia. Il trattamento ha avuto una durata minima di tre mesi.

I risultati sono stati positivi nel $77 \%$ dei soggetti, con riduzioni della risposta insulinemica $>$ al $20 \%$ nel $46 \%$ dei soggetti, e tra lo 0 ed il $20 \%$ nel $31 \%$ dei soggetti. Non si sono riscontrati miglioramenti nel restante $23 \%$ dei soggetti.

L'interpretazione dei risultati non è semplice e ci porta a supporre che esistano diversi livelli di efficacia in funzione del meccanismo patogenetico di base.

L'ampliamento della casistica porterà ulteriore contributo alla comprensione delle migliori strategie terapeutiche.

PAROLE CHIAVE: Funzione endocrina; Metabolismo glucidico; Acido alfa-lipoico.

$\mathrm{N}$ el corso degli anni le azioni e gli effetti dell'acido alfa-lipoico (ALA) sono state svelate da numerosi lavori scientifici in vitro ed in vivo. ${ }^{1}$

È oggi nota la capacità di ALA di incrementare la sensibilità insulinica in vivo, di stimolare l'autofosforilazione del recettore per l'insulina e, in vitro, di aumentare l'uptake del glucosio nei miociti e negli adipociti attraverso la riduzione dell'attività dei gruppi tiolici delle proteine intracellulari. ${ }^{2}$

In uno studio del $2015^{3}$ il trattamento con ALA associato a inositolo ha dimostrato un significativo impatto positivo sul profilo metabolico anche quando il trattamento era di breve termine.

\section{Studio del centro di Cagliari}

Lo studio clinico in corso nel centro di Cagliari ha per scopo quello di verificare se la supplementazione orale con ALA e MYO possa migliorare il metabolismo glucidico, migliorando la sensibilità all'insulina in giovani pazienti affette da PCOS.

La combinazione MYO e ALA è stata impie- gata per 3-11 mesi su 42 pazienti giovani (età 1323 anni) con PCOS diagnosticata secondo i criteri di Rotterdam adattati alle adolescenti secondo Carmina,${ }^{4}$ con alterazioni del metabolismo. Di queste pazienti è stata valutata la risposta clinica, ormonale, glicemica e insulinemica alla curva da carico orale di glucosio (OGTT) e l'ultrasonografia in fase follicolare precoce.

Le pazienti sono state trattate con un'associazione di acido alfa-lipoico $400 \mathrm{mg}$, mioinositolo 0,5 g, Betaina, Acido Folico $200 \mathrm{mcg}$, Vitamina B12, Vitamina B6 e Vitamina B2 al dosaggio di una compressa due volte al giorno. Dopo un tempo minimo di tre mesi, le pazienti sono state rivalutate con curva OGTT. Delle 42 pazienti arruolate, un primo gruppo di 28 è stato valutato tra il 2013 e il 2015 mentre un secondo gruppo di 15 pazienti è stato valutato tra il 2016 e il 2017.

In 4 pazienti del primo gruppo e in 4 pazienti del secondo gruppo si è verificato un drop out per difficoltà a mantenere la compliance alla terapia dopo i primi 20 giorni. I dati clinici delle pazienti (età media: 18 anni) del primo gruppo indicano che il BMI era leggermente elevato (oltre 28) e non è aumentato durante il trattamento, 


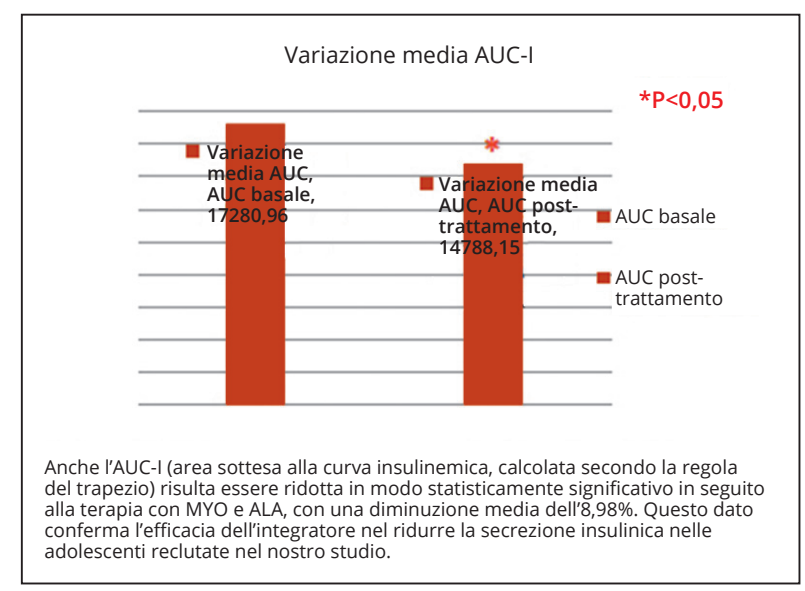

Figura 1.- Variazione media dell'area di secrezione della insulina sotto carico orale di glucosio nel primo gruppo di studio.

così come il peso, la glicemia e l'insulinemia basali. Tuttavia, l'insulina sotto carico glucidico ha registrato un decremento.

Inoltre, nel primo gruppo di pazienti, dopo il trattamento con la combinazione MYO e ALA, l'HOMA index ha avuto un leggero miglioramento con una tendenza a una riduzione del $10 \%$.

La curva insulinemica è migliorata a seguito del trattamento, anche se non in modo nettissimo, con una diminuzione tendenzialmente maggiore dell'insulinemia a 60 minuti. Inoltre, è stata osservata una variazione media del $9 \%$ circa dell'AUC dell'insulina (calcolata con la formula del trapezio), statisticamente significativa confermando così l'efficacia del trattamento nel migliorare l'azione dell'insulina e quindi ridurne la secrezione in questa casistica (Figura 1).

È stato osservato inoltre un miglioramento degli androgeni, tenendo conto che alcune pazienti avevano fatto un trattamento estro-progestinico per trattare l'irsutismo prima di entrare nel nostro studio.
Il secondo gruppo di pazienti era costituito da ragazze con età media di circa 15 anni, con peso corporeo medio leggermente inferiore a quello del primo gruppo, con BMI di 24, quasi tutte con oligomenorrea e irsutismo, con esami ormonali tipici della PCOS.

In questo gruppo con numerosità più limitata, la curva AUC pre- e post-trattamento ha avuto un miglioramento versus gruppo di controllo meno marcato di quanto osservato nel gruppo precedente.

La glicemia non ha avuto nessuna variazione tra prima e dopo trattamento; tuttavia, le pazienti non presentavano segni di sindrome metabolica o di alterazioni glicemiche data la loro giovane età (Figura 2).

Durante il trattamento l'FSH è migliorato e l'LH è rimasto stabile e l'androstenedione ha avuto una lieve flessione, sebbene non significativa, così come il 170HP.

Complessivamente, le variazioni osservate identificano tre gruppi di pazienti:

- un gruppo con riduzione della AUC-I $<20 \%$ (46\% delle pazienti);

- un gruppo con aumento della AUC-I $>20 \%$ (31\% delle pazienti);

- un gruppo senza variazione della AUC-I o con un suo aumento ( $23 \%$ delle pazienti).

In 8 casi è stata osservata una riduzione del valore iniziale dell'AUC-I fino al 40\%, mentre altri casi (meno spiegabili) hanno presentato un aumento alla fine del trattamento e altri hanno mantenuto il valore iniziale dell'insulinemia.

Solo per il secondo gruppo di pazienti i dati clinici sono stati stratificati come responder (R) e non responder (NR). Le $\mathrm{R}$ avevano più anni dal menarca in media rispetto alle NR, però BMI, glicemia e insulinemia basali e area insulinica

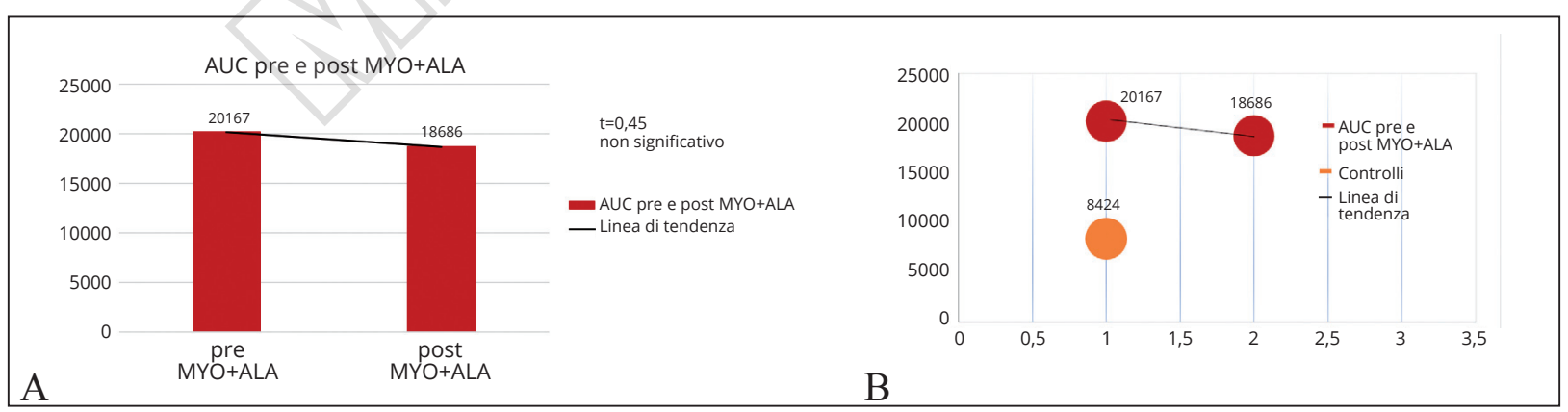

Figura 2.- Variazione media dell'area di secrezione della insulina sotto carico orale di glucosio nel secondo gruppo di studio. 
(AUC-I) erano sostanzialmente uguali. Analoghi risultati si sono osservati per gli ormoni androgeni.

Dato che la risposta al trattamento con la combinazione MYO e ALA in termini di secrezione insulinica può essere presente $\mathrm{o}$ assente $\mathrm{o}$ anche peggiore, è difficile spiegare questi risultati in considerazione del fatto che il meccanismo dell'iperinsulinismo si sviluppa con un quadro molecolare complesso e correlato con molte altre vie metaboliche.

L'ampliamento della casistica delle pazienti trattate può fornire maggior attendibilità ai risultati ed è auspicabile la stratificazione delle pazienti in base anche ad altre caratteristiche.

\section{Statements}

- L'acido alfa-lipoico ha un ruolo essenziale nei percorsi metabolici mitocondriali specifici che generano energia dal glucosio e per il suo potente effetto antiossidante.

- La variazione media dell'AUC-I si è ridotta in misura statisticamente significativa a seguito della terapia con la combinazione mioinositolo e acido alfa-lipoico con una diminuzione del $9 \%$, confermando l'efficacia dell'integratore nel ridurre la secrezione insulinica.

- Esiste la possibilità di una diversa efficacia dell'acido alfa-lipoico secondo il meccanismo alla base dell'iperinsulinismo.

- Dopo il trattamento con la combinazione mioinositolo e acido alfa-lipoico l'HOMA Index è leggermente migliorato con una tendenza a una riduzione del $10 \%$.

\section{Bibliografia}

1. Koh EH, Lee WJ, Lee SA, Kim EH, Cho EH, Jeong E, et al. Effects of alpha-lipoic Acid on body weight in obese subjects. Am J Med 2011;124:85.e1-8.

2. Cho KJ, Moon HE, Moini H, Packer L, Yoon DY, Chung AS. Alpha-lipoic acid inhibits adipocyte differentiation by regulating pro-adipogenic transcription factors via mitogen-activated protein kinase pathways. J Biol Chem 2003;278:34823-33.

3. Cianci A, Panella M, Fichera M, Falduzzi C, Bartolo M, Caruso S. d-chiro-Inositol and alpha lipoic acid treatment of metabolic and menses disorders in women with PCOS. Gynecol Endocrinol 2015;31:483-6.

4. Carmina E, Oberfield SE, Lobo RA. The diagnosis of polycystic ovary syndrome in adolescents. Am J Obstet Gynecol 2010;203:201.e1-5. 


\title{
Regolazione della sensibilità insulinica
}

\author{
Maria E. STREET*
}

Unit of Endocrinology and Pediatric Diabetology, Department of Pediatrics, Arcispedale S. Maria Nuova, AUSL of Reggio Emilia-IRCCS, Reggio Emilia, Italy

*Corresponding author: Maria E. Street, Unit of Endocrinology and Pediatric Diabetology, Department of Pediatrics, Arcispedale S Maria Nuova, AUSL of Reggio Emilia-IRCCS, Reggio Emilia, Italy. E-mail: mariaelisabeth.street@ausl.re.it

\section{R I A S S UN T O}

Insulino-resistenza, infiammazione ed infertilità sono caratteristiche della PCOS. Attualmente non vi sono validi indicatori biochimici di diagnosi nelle adolescenti. I miRNA potrebbero rappresentare un valido strumento in tal senso. Nell'ambito dell'infiammazione riveste interesse lo High Mobility Group Box 1 (HMGB1), una piccola proteina attivatrice di Nf-KB e pertanto della cascata citochinica che aumenta in condizioni di flogosi, in caso di malfunzionamento del CFTR come nella Fibrosi cistica e viene down-regolata dall'insulina. Abbiamo dimostrato che HMGB1 è aumentata in PCOS sia nel siero che nel liquido follicolare. I miR-155 e 146a sono risultati aumentati in PCOS in modo simile ad altre malattie infiammatorie croniche, e sono risultati positivamente correlati con HMGB1. Anche miR-486 è risultato aumentato nelle cellule della granulosa di donne PCOS rispetto a controlli sani, mentre è down-regolato del liquido follicolare. L'aumento di HMGB1 e le alterazioni dei miRNA sono presenti anche in modo significativo anche in adolescenti affette da PCOS. Un nostro studio pilota ha dimostrato che HMGB1 ed alcuni miRNA diminuivano tornando a concentrazioni simili ai controlli dopo trattamento per sei mesi con mioinositolo ed acido alfa-lipoico.

PAROLE CHIAVE: Sensibilità insulinica; Sindrome dell'ovaio policistico; MicroRNA.

$I_{d}^{d}$ dati riguardanti i biomarkers per la sindrome dell'ovaio policistico (PCOS), soprattutto in funzione della diagnosi nelle adolescenti, sono ancora limitati. ${ }^{1}$ I microRNA (miRNA) possono rappresentare un valido strumento a fini diagnostici; infatti il profilo di espressione di specifici miRNA del fluido follicolare sono associati a tratti fenotipici della PCOS. Pertanto, un profilo di miRNA alterato potrebbe costituire la base per nuovi metodi di valutazione e stratificazione delle pazienti con PCOS e potrebbe contribuire a spiegare in parte la natura eterogenea riscontrata nelle donne con questa sindrome. ${ }^{2}$

High Mobility Group Box 1(HMGB1) è una piccola proteina con funzioni nucleari, citosoliche ed extracellulari. In condizioni di infiammazione, HMGB1 trasloca dal nucleo al citosol e viene attivamente secreta nello spazio extracellulare e tra le altre funzioni attiva Nuclear factor kappa light chain enhancer of activated B cells (Nf-kB). HMGB1 segnala attraverso il Receptor for advanced glycation end products (RAGEs) ed attraverso i recettori della Toll like receptor family (in particolare TLR2 e TLR4). Questi recettori sono noti anche perché regolano la risposta immunitaria delle cellule della granulosa. HMGB1 svolge un ruolo anche nell'ambito dell'insulino-resistenza/iperinsulinemia in patologie, quali il diabete di tipo 2 e l'obesità ed in uno studio è stato riportato come aumentata in donne PCOS con insulino-resistenza. ${ }^{3}$

Insulino-resistenza, infiammazione ed infertilità sono caratteristiche comuni a PCOS e fibrosi cistica. La fibrosi cistica (FC) è dovuta ad un malfunzionamento/assenza del transmembrane conductance regulator (CFTR). Abbiamo precedentemente dimostrato nella FC che HMGB1 aumentava all'esordio del diabete legato alla FC e che in vitro il silenziamento del CFTR determinava un aumento di HMGB1 che diminuiva in seguito a somministrazione di insulina. In aggiunta, in vitro, si osservava una riduzione di FOXO-1, compatibile con ridotta sensibilità insulinica. 
Abbiamo riscontrato queste stesse caratteristiche in cellule della granulosa di donne PCOS, ottenute da liquido follicolare in corso di Procreazione Medicalmente Assistita. ${ }^{3}$

\section{Studi del centro di Reggio Emilia}

Nel centro di Reggio Emilia sono allo studio la proteina HMGB1 e alcuni miRNA selezionati. In particolare, i tre studi riguardano:

- la proteina HMGB1 nel liquido follicolare e nelle cellule della granulosa del corpo luteo in donne con e senza la sindrome dell'ovaio policistico (PCOS);

- sulla stessa casistica di pazienti, sono allo studio miRNA regolatori della sensibilità insulinica nel liquido follicolare e nelle cellule della granulosa del corpo luteo in donne con e senza PCOS;

- la valutazione dei livelli di HMGB1 e di miRNA circolanti nel siero di adolescenti e giovani donne con PCOS e loro modificazioni in seguito a trattamento con acido alfa-lipoico (ALA) e mioinositolo (MYO).

\section{Marker d'infiammazione}

La proteina HMGB1 rappresenta un valido indicatore ed è considerato un marcatore d'infiammazione. ${ }^{4}$ Presente nel citosol e secreto nel comparto extracellulare, la HMGB1 è coinvolta nella produzione di NF-kB e, di conseguenza, delle citochine pro-infiammatorie.

In base a precedenti studi condotti su modelli di fibrosi cistica è risultato che la HMGB1 è legata all'infiammazione sistemica ed aumenta per il malfunzionamento del regolatore della conduttanza transmembrana (CFTR), in condizioni di iperinsulinismo, iperglicemia ed in condizioni di obesità. Il CFTR, implicato anche nel normale sviluppo del follicolo ovarico, è down-regolato o mal funziona in modelli animali con PCOS. ${ }^{5}$ Quando silenziato, il CFTR si accompagna a una ridotta espressione di $\mathrm{FOXO}^{6}$ che è un importante mediatore intracellulare legato al recettore dell'insulina che è indispensabile per la regolazione della sensibilità insulinica. Quindi, affinché il signaling dell'insulina sia efficiente deve essere ben efficiente anche il FOXO1. Questo in presenza dell'insulina viene fosforilato, si stacca dal DNA, favorisce la lipogenesi e inibisce la gluconeogenesi. HMGB1 aumenta in vitro se il CFTR viene silenziato e viene abbassato dalla somministrazione di insulina. È stato in precedenza osservato che in pazienti con Fibrosi cistica, il diabete si associa a un peggioramento delle condizioni cliniche ed infiammatorie e ad aumento di HMGB1 che correla con il calo di insulina, l'insorgenza del diabete. ${ }^{3}$

È stato quindi ipotizzato che HMGB1 fosse alterato nella PCOS. 3

Nel primo studio condotto nel centro di Reggio Emilia sono state reclutate 30 pazienti con PCOS e 50 soggetti controllo. Nelle donne con PCOS, 1'HMGB1 era significativamente più elevato rispetto ai controlli nel liquido follicolare, mentre l'estradiolo sierico era più elevato. Nei controlli l'HMGB1 e i livelli di estrogeni erano significativamente correlati, mentre tale correlazione non era presente nelle donne con PCOS. Inoltre, l'HMGB1 non correlava con l'età cronologica né con il BMI e col numero di follicoli trovato dopo stimolazione. ${ }^{7}$

Nel secondo studio l'HMGB1 era correlato positivamente ai livelli di miRNA-155 nelle cellule della granulosa e sono stati osservati rapporti molto chiari anche con il miRNA146a (Figura 1). ${ }^{8}$

L'aumento del miRNA155 si riscontra in molte patologie infiammatorie e croniche come la fibrosi cistica e l'obesità. L'aumento di questi miRNA è descritto in malattie cardiovascolari, che sono complicanze nella donna adulta con PCOS in condizioni di IR e di diabete. In studi condotti sul-

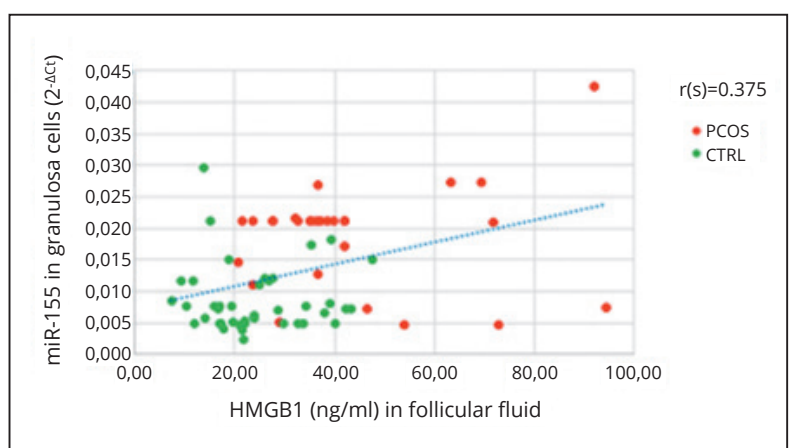

Figura 1.-HMGB1 nel liquido follicolare e miR-155 nelle cellule della granulosa sono risultati positivamente correlati sia in donne PSOS che nei controlli. I livelli di entrambi sono più elevati nelle pazienti con PCOS.

Modificata da Cirillo et al. ${ }^{8}$ 
la fibrosi cistica, il miRNA-155 è predetto essere regolatore di FOXO1 ed è stato identificato come uno dei fattori della down-regulation di FOXO1. ${ }^{3}$ I dati di espressione genica, normalizzati rispetto ai controlli, evidenziano down- e up-regolazioni molto significative nelle pazienti PCOS.

Questi stessi miRNA, regolatori della sensibilità insulinica sono stati precedentemente studiati in diversi momenti della vita in pazienti con fibrosi cistica in relazione alla tolleranza glucidica ed all'esordio del diabete legato alla fibrosi cistica (CFRD), alcuni sono regolatori di FOXO1. ${ }^{9}$

Abbiamo pertanto ipotizzato nello studio in PCOS che i microRNA selezionati potessero essere coinvolti nel controllo della funzionalità ovarica e della sensibilità insulinica e, viceversa, che i microRNA responsabili della regolazione della sensibilità insulinica possano influire in qualche modo sulla funzionalità ovarica. I miRNA146, miRNA155 e miRNA486 sono downregolati nel liquido follicolare, mentre troviamo un quadro opposto quando questi stessi microRNA sono stati dosati nelle cellule della granulosa nelle pazienti con PCOS rispetto ai controlli. ${ }^{8}$

Oltre all'HMGB1, che è un marker sensibile e discriminante, un altro possibile marker d'infiammazione avrebbe potuto essere la IL-6 che però, in accordo con alcuni dati in letteratura, non presenta variazioni nei liquidi follicolari delle donne con PCOS poiché verosimilmente riflette altre funzioni tra cui l'impianto embrionale ed il prosieguo della gravidanza. ${ }^{7}$

Nel terzo studio sono state reclutate 25 adolescenti con PCOS classificate con i criteri di Rotterdam e 15 soggetti come controlli, con età media di 16-18 anni, con valori di BMI nella norma. Nel siero di queste pazienti 1'HMBG1 era molto più elevata rispetto ai controlli; le concentrazioni di HMGB1 erano inversamente correlate alle concentrazioni sieriche di estradiolo e al rapporto trigliceridi/HDL (Figura 2). ${ }^{10}$

Dopo 6 mesi di trattamento con la combinazione di ALA e MYO il livello di HMGB1 è risultato nettamente diminuito con valori molto più simili a quelli dei controlli.

I miRNA320, miRNA155, miRNA146a e miRNA93 erano down-regolati rispetto ai controlli prima del trattamento ed erano up-regolati in modo significativo dopo 6 mesi di trattamento.

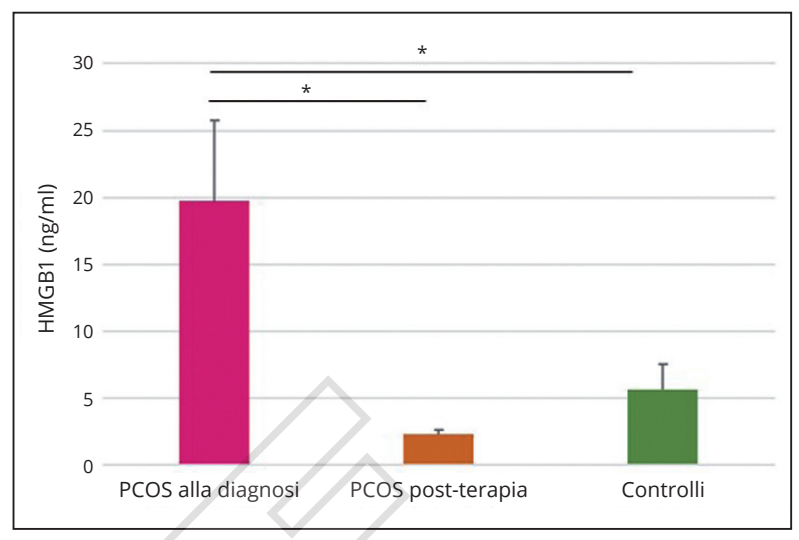

Figura 2.-L'HMGB1 risulta significativamente aumentato nel siero di ragazze adolescenti affette da PCOS e diminuisce e torna a concentrazioni simili ai controlli dopo 6 mesi di trattamento con mioinositolo ed acido alfa-lipoico (MYO+ALA).

Modificata da Cirillo et al. ${ }^{10}$

Per esempio, il miRNA370 non era misurabile al momento della diagnosi di PCOS mentre dopo trattamento è significativamente aumentato. Quindi, i dati di questo studio indicano una normalizzazione dei livelli dei miRNA analizzati. ${ }^{8}$

\section{Ipotesi del meccanismo d'azione dell'associazione acido alfa-lipoico e mioinositolo}

L'associazione ALA e MYO nella PCOS riduce gli aumentati livelli di HMGB1sierici, normalizza le concentrazioni di miRNA e aumenta la concentrazione di FOXO1 (Figura 3).

I nostri dati confermano l'ipotesi che da un lato l'associazione ALA e MYO riduce l'infiammazione e dall'altro migliora la sensibilità insulinica dell'ovaio.

\section{Statements}

- La proteina HMGB1, che rispecchia lo stato infiammatorio, è aumentata in condizioni di iperinsulinismo, iperglicemia e in condizioni di obesità.

- La HMGB1, dosata nei liquidi follicolari di pazienti con PCOS, è significativamente più alta rispetto ai controlli.

- I livelli di HMGB1 sono inversamente correlati a quelli dell'insulina nei liquidi follicolari.

- Il livello di HMGB1 può riflettere la quantità d'insulina o la sensibilità insulinica a livello 


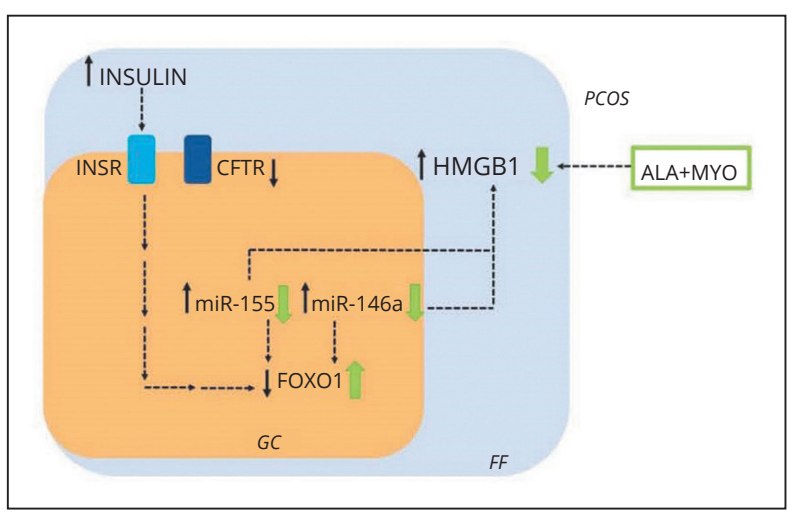

Figura 3.-Schema riassuntivo delle modificazioni presenti nell'ovaio di adolescenti PCOS e del possibile effetto del trattamento combinato con mioinositolo ed acido alfa-lipoico (MYO+ALA).

Nella PCOS, nelle cellule della granulosa, vi è una riduzione dell'espressione del CFTR ed una riduzione di FOXO1, compatibile con insulino-resistenza, un aumento di HMGB1, di miR-155 e di miR-146 compatibili con infiammazione ed insulino-resistenza. Il mioinositolo associato all'acido alfalipoico determina una riduzione di HMGB1, miR-155, miR146a e un aumento di FOXO1.

dell'ovaio e rispecchiare l'infiammazione presente nella PCOS.

- L'HMGB1 è diminuita nel siero di adolescenti con PCOS dopo trattamento con acido alfa-lipoico e mioinositolo per 6 mesi.

- I miR146, miR155 e miR486, sono downregolati nel liquido follicolare, mentre sono upregolati all'interno delle cellule della granulosa nelle pazienti PCOS rispetto ai controlli.

- In base ai dati i livelli di miRNA si sono normalizzati nelle pazienti con PCOS trattate con mioinositolo e acido alfa-lipoico per 6 mesi.

- L'associazione tra mioinositolo e acido alfalipoico riduce l'infiammazione e migliora la sensibilità insulinica dell'ovaio.

\section{Bibliografia}

1. Ibáñez L, Oberfield SE, Witchel S, Auchus RJ, Chang $\mathrm{RJ}$, Codner E, et al. An international consortium update: pathophysiology, diagnosis, and treatment of Polycystic Ovarian Syndrome in adolescence. Horm Res Paediatr 2017;88:371-95.

2. Sørensen AE, Wissing ML, Englund AL, Dalgaard LT. MicroRNA species in follicular fluid associating with polycystic ovary syndrome and related intermediary phenotypes. J Clin Endocrinol Metab 2016;101:1579-89.

3. Montanini L, Cirillo F, Smerieri A, Pisi G, Giardino I, d'Apolito M, et al. HMGB1 Is Increased by CFTR Loss of Function, Is Lowered by Insulin, and Increases In Vivo at Onset of CFRD. J Clin Endocrinol Metab 2016;101:1274-81.

4. Nativel B, Marimoutou M, Thon-Hon VG, Gunasekaran MK, Andries J, Stanislas G, et al. Soluble HMGB1 is a novel adipokine stimulating IL-6 secretion through RAGE receptor in SW872 preadipocyte cell line: contribution to chronic inflammation in fat tissue. PLoS One 2013;8:e76039.

5. Chen H, Guo JH, Zhang XH, Chan HC. Defective CFTRregulated granulosa cell proliferation in polycystic ovarian syndrome. Reproduction 2015;149:393-401.

6. Smerieri A, Montanini L, Maiuri L, Bernasconi S, Street ME. FOXO1 content is reduced in cystic fibrosis and increases with IGF-I treatment. Int J Mol Sci 2014;15:18000-22.

7. Cirillo F, Catellani C, Sartori C, Lazzeroni P, Morini D. CFTR and foxol gene expression are reduced and high mobility group box1 (HMGB1) is increased in the ovaries and serum of women with polycystic ovarian syndrome. Gynecol Endocrinol 2019;35:842-6.

8. Cirillo F, Catellani C, Lazzeroni P, Sartori C, Nicoli A, Amarri $\mathrm{S}$, et al. MiRNAs Regulating Insulin Sensitivity Are Dysregulated in Polycystic Ovary Syndrome (PCOS) Ovaries and Are Associated With Markers of Inflammation and Insulin Sensitivity. Front Endocrinol (Lausanne) 2019;10:879.

9. Montanini L, Smerieri A, Gullì M, Cirillo F, Pisi G, Sartori C, et al. miR-146a, miR-155, miR-370, and miR708 Are CFTR-Dependent, Predicted FOXO1 Regulators and Change at Onset of CFRDs. J Clin Endocrinol Metab 2016;101:4955-63.

10. Cirillo F, Catellani C, Lazzeroni $P$, Sartori C, Tridenti G, Vezzani C, et al. HMGB1 is increased in adolescents with polycystic ovary syndrome (PCOS) and decreases after treatment with myo-inositol (MYO) in combination with alpha-lipoic acid (ALA). Gynecol Endocrinol 2020;1-6. [Epub ahead of print] 


\title{
La supplementazione di mioinositolo e acido alfa-lipoico in donne infertili con sindrome dell'ovaio policistico
}

\author{
Rocco RAGO, Caterina MENEGHINI, Alessandro DAL LAGO *
}

Operative Unit of Reproductive Pathophysiology and Andrology, Sandro Pertini Hospital, Rome, Italy

*Corresponding author: Alessandro Dal Lago, Operative Unit of Reproductive Pathophysiology and Andrology, Sandro Pertini Hospital, Rome, Italy. E-mail: alessandro.dallago@aslroma2.it

\section{R I A S S UNTO}

Obiettivo del trattamento dell'infertilità nelle pazienti con sindrome dell'ovaio policistico (PCOS) è ridurre il peso corporeo, ripristinare l'ovulazione, migliorare la qualità dell'endometrio e, in corso di tecniche di fecondazione assistita, evitare la iperstimolazione ovarica e le gravidanze plurigemellari. Nelle paziente con PCOS la riduzione del 5-10\% del peso corporeo, mediante dieta ipocalorica ipoglucidica associata ad una corretta attività fisica, consente di riprendere una fisiologica ovulazione aumentando la possibilità di gravidanza spontanea. Ma quando si presenta insulino-resistenza è necessario associare farmaci ipoglicemizzanti orali usati abitualmente per il diabete mellito e definiti insulinosensibilizzanti. Questi hanno la capacità di aumentare la sensibilità dell'insulina sulle cellule bersaglio diminuendo pertanto il fenomeno della cosidetta "insulino-resistenza". Nell'ambito degli insulino-sensibilizzanti è recente l'associazione tra mioinositolo e acido alfa-lipoico: il loro sinergismo terapeutico è in grado di migliorare sia il profilo clinico-metabolico che l'outcome riproduttivo delle donne affette da PCOS.

PARole Chiave: Mioinositolo; Acido alfa-lipoico; Sindrome dell'ovaio policistico.

$\mathrm{L}$ a sindrome dell'ovaio policistico è un'endocrinopatia che determina irregolarità mestruali e riduce la capacità ovulatoria. È infatti la più comune causa di disturbo ovulatorio e di infertilità femminile manifestandosi nel 5-10\% delle donne in età riproduttiva e frequentemente associata ad insulino-resistenza.

La sindrome dell'ovaio policistico (PCOS) si accompagna anche ad una ridotta probabilità di esito positivo a seguito di tecniche di fecondazione assistita, nel corso delle quali le donne con PCOS manifestano un aumentato rischio di iperstimolazione ovarica (OHSS) tanto da meritare particolare attenzione.

La patogenesi di questa sindrome è ancora non risolta, anche se nelle ultime decadi numerosi ricercatori hanno focalizzato la loro attenzione sul ruolo dell'insulina-resistenza che è presente nel $30-40 \%$ delle pazienti con PCOS. L'insulina gioca un ruolo nella patogenesi dell'iperandrogeni- smo: stimola le cellule tecali ovariche a produrre androgeni sia direttamente che indirettamente, mentre elevati livelli di glicemia, inibendo la sintesi epatica della SHBG, generano incremento delle concentrazioni di androgeni liberi.

È chiaro quindi che la sindrome dell'ovaio policistico presenta due aspetti patologici: uno di tipo metabolico e uno di tipo riproduttivo. Questa associazione ha portato a studiare la relazione tra insulina e funzione gonadica inducendo numerosi clinici a verificare l'effetto di farmaci insulinosensibilizzanti nel trattamento delle donne affette da PCOS. Numerose evidenze scientifiche hanno dimostrato che il trattamento con insulino-sensibilizzanti (metformina e/o inositoli) determina un miglioramento dell'outcome riproduttivo sia in termini di induzione spontanea dell'ovulazione sia nei trattamenti di Procreazione Medicalmente Assistita (PMA). Si è osservato infatti che trattare donne infertili affette da PCOS con 
farmaci insulino-sensibilizzanti determina una riduzione delle unità di gonadotropine necessarie per indurre la follicologenesi ed una riduzione del numero di giorni di stimolazione; allo stesso tempo è evidente un miglioramento della qualità oocitaria generando pertanto un incremento della pregnancy rate..$^{1-5}$

Lo studio randomizzato controllato di Colazingari ${ }^{6}$ evidenzia come il trattamento combinato di mioinositolo e D-chiro-inositolo determina un miglioramento della qualità oocitaria in donne di età superiore a 35 anni sottoposte a trattamento PMA, confermando allo stesso tempo la riduzione sia delle unità di gonadotropine utilizzate sia del numero di oociti immaturi.

\section{Associazione Acido alfa-lipoico/ mioinositolo e qualità degli oociti}

Nell'ambito degli insulino-sensibilizzanti, più recente è l'associazione tra mioinositolo (MYO) e acido alfa-lipoico (ALA). L'ALA, potente antiossidante e cofattore enzimatico della catena respiratoria mitocondriale, è in grado di incrementare la sensibilità insulinica migliorando il controllo della glicemia in pazienti con diabete di tipo II.
L'attività antiossidante di ALA trova un razionale impiego anche nelle donne con PCOS in cui è documentato l'aumento dello stress ossidativo e quindi dei livelli di ROS a livello del compartimento follicolare, responsabili del decadimento della qualità oocitaria. Inoltre, l'ALA migliora il metabolismo energetico del muscolo scheletrico migliorando la biogenesi mitocondriale mediata da AMPK-PGC-1 $\alpha$ come risulta da studi in vitro.

Ad oggi gli studi presenti in letteratura che utilizzano l'ALA non sono numerosi.

Nel nostro studio ${ }^{7}$ sono state arruolate 65 donne con PCOS non obese e sono state escluse le donne con patologie endocrine legate alla PCOS, eliminando pertanto il fattore metabolico confondente. Lo studio aveva l'obiettivo di valutare l'eventuale azione antiossidante dell'ALA sulla qualità oocitaria. Le donne sono state randomizzate in due gruppi di trattamento: uno trattato con la combinazione di MYO e ALA, e uno trattato con il solo MYO (Tabella I).

In entrambi i gruppi, al tempo 0 e dopo 3 mesi di trattamento, non sono state evidenziate variazioni significative dei valori metabolici (colesterolo, trigliceridi ecc.) ma nel gruppo trattato con l'associazione MYO e ALA abbiamo osservato

TABELLA I.-Caratteristiche metaboliche, ormonali e cliniche di 37 donne trattate con mioinositolo e con l'associazione mioinositolo e acido alfa-lipoico. Riprodotta con permesso da Rago et al. ${ }^{7}$

\begin{tabular}{|c|c|c|c|c|c|c|}
\hline \multirow[t]{2}{*}{ Characteristic $(\mathrm{N} .=37)$} & \multirow{2}{*}{\multicolumn{2}{|c|}{ T0 }} & \multirow[b]{2}{*}{$P$ value } & \multicolumn{3}{|c|}{ MYO plus ALA } \\
\hline & & & & T0 & $\mathrm{T} 3$ & $\mathrm{P}$ value \\
\hline Age (years) & $36.3 \pm 2.8$ & & / & $37.1 \pm 2.7$ & / & / \\
\hline Duration of infertility (years) & $2.5 \pm 1.0$ & & / & $3.5 \pm 0.9$ & / & / \\
\hline BMI $(\mathrm{kg} / \mathrm{m} 2)$ & $21.9 \pm 1.5$ & $21.2 \pm 1.3$ & 0.41 & $22.3 \pm 1.5$ & $21.2 \pm 1.6$ & $<0.01$ \\
\hline Total cholesterol (mg/dl) & $181.8 \pm 31.5$ & $180.2 \pm 30.0$ & 0.69 & $179.7 \pm 27.1$ & $177.4 \pm 27.8$ & 0.51 \\
\hline $\mathrm{HDL}(\mathrm{mg} / \mathrm{dl})$ & $51.9 \pm 12.4$ & $51.8 \pm 12.6$ & 0.58 & $51.5 \pm 11.4$ & $53.0 \pm 11.1$ & 0.08 \\
\hline $\mathrm{LDL}(\mathrm{mg} / \mathrm{dl})$ & $99.7 \pm 15.8$ & $98.9 \pm 14.7$ & 0.06 & $99.0 \pm 12.1$ & $97.2 \pm 10.2$ & 0.39 \\
\hline Triglycerides (mg/dl) & $97.9 \pm 39.9$ & $98.3 \pm 40.5$ & 0.84 & $98.5 \pm 35.8$ & $95.4 \pm 33.3$ & 0.16 \\
\hline Basal glycemia $(\mathrm{mg} / \mathrm{dl})$ & $85.3 \pm 10.2$ & $84.4 \pm 8.7$ & 0.32 & $84.5 \pm 8.9$ & $83.3 \pm 8.5$ & 0.32 \\
\hline Basal insulin $(\mathrm{mU} / \mathrm{ml})$ & $6.5 \pm 2.9$ & $6.5 \pm 2.6$ & 0.81 & $6.6 \pm 2.9$ & $6.0 \pm 2.4$ & $<0.01$ \\
\hline Basal FSH (mIU/ml) & $6.2 \pm 1.9$ & $5.7 \pm 1.0$ & 0.18 & $5.6 \pm 1.4$ & $6.0 \pm 1.9$ & 0.24 \\
\hline Basal LH (mIU/ml) & $7.1 \pm 1.8$ & $7.1 \pm 1.7$ & 0.97 & $7.0 \pm 1.8$ & $6.7 \pm 1.9$ & 0.30 \\
\hline $17 \beta-\mathrm{E} 2(\mathrm{pg} / \mathrm{ml})$ & $45.1 \pm 17.8$ & $44.1 \pm 16.3$ & 0.68 & $46.6 \pm 16.1$ & $44.7 \pm 14.5$ & 0.60 \\
\hline PRL (ng/ml) & $11.9 \pm 4.8$ & $11.4 \pm 4.6$ & 0.67 & 1 3. $1 \pm 5.4$ & $12.4 \pm 4.3$ & 0.51 \\
\hline TSH (ml U/l) & $1.6 \pm 0.5$ & $1.6 \pm 0.5$ & 0.32 & $1.6 \pm 0.4$ & $1.71 \pm 0.3$ & 0.26 \\
\hline FT3 (pg/ml) & $2.7 \pm 0.5$ & $2.9 \pm 0.7$ & 0.22 & $2.7 \pm 0.6$ & $2.7 \pm 0.5$ & 0.92 \\
\hline FT4 (ng/dl) & $1.2 \pm 0.3$ & $1.2 \pm 0.4$ & 0.79 & $1.2 \pm 0.3$ & $1.3 \pm 0.4$ & 0.17 \\
\hline Ovarian volume $\left(\mathrm{cm}^{3}\right)$ & $10.6 \pm 0.5$ & $10.3 \pm 1.2$ & 0.19 & $10.9 \pm 1.0$ & $9.5 \pm 0.8$ & $<0.001$ \\
\hline Ovarian reserve (N. follicles) & $27.7 \pm 3.8$ & $26.4 \pm 3.5$ & 0.06 & $27.8 \pm 3.6$ & $26.1 \pm 1.6$ & 0.06 \\
\hline
\end{tabular}

Values are reported as mean $\pm \mathrm{SD}$.

BMI: Body Mass Index; HDL: high-density lipoprotein; LDL: low-density lipoprotein; FSH: follicle-stimulating hormone; LH: luteinizing hormone; 17 $\beta$-E2: 17 $\beta$-estradiol; PRL: prolactin; TSH: thyroid stimulating hormone; FTJ: free triiodothyronine; FT4: free thyroxine. 
una riduzione significativa del BMI, del valore di insulinemia, sia basale che in corso di OGTT, e del volume ovarico. Anche questo studio conferma la riduzione della quantità di gonadotropina FSH necessaria per l'induzione della follicologenesi. Nel gruppo con trattamento combinato la qualità oocitaria è inversamente correlata alla diminuzione del BMI ma non con la riduzione dei livelli d'insulinemia; la stimolazione ha però dato esito ad un maggior recupero di oociti maturi MII generando poi embrioni di classe I e II. Tutto ciò ha determinato di fatto un aumento del tasso di gravidanza (Figura 1, Tabella II).

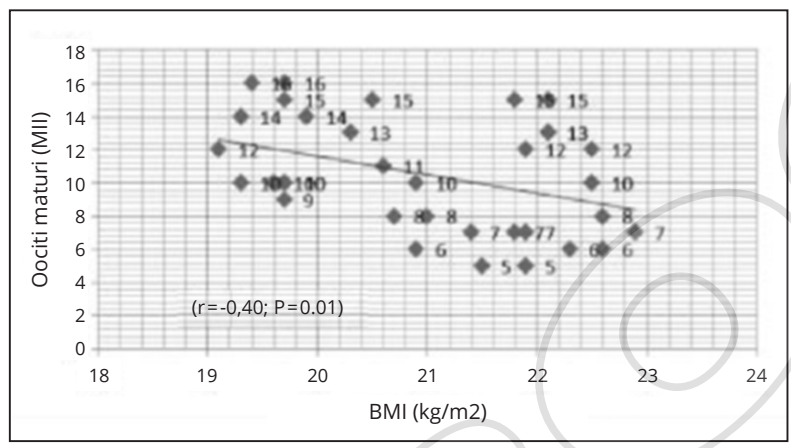

Figura 1.-Correlazione tra BMI e oociti maturi MII.

Test parametrico di Pearson: $0<\mathrm{r}<0.3$ correlazione debole; $0.3<\mathrm{r}<0.7$ correlazione moderata; $\mathrm{r}>0.7$ correlazione forte. Riprodotta con permesso da Rago et al.

TABELla II. - Risultati del trattamento con mioinositolo e con l'associazione mioinositolo e acido alfa-lipoico. Riprodotta con permesso da Rago et al. ${ }^{7}$

\begin{tabular}{lccc}
\hline $\begin{array}{l}\text { Characteristic } \\
\text { (N.=37) }\end{array}$ & MYO & MYO plus ALA & P value \\
\hline $\begin{array}{l}\text { Stimulation (days) } \\
\text { FSH (IU) }\end{array}$ & $11.6 \pm 0.6$ & $10.8 \pm 0.6$ & 0.06 \\
administration & $1501.9 \pm 676.4$ & $1498.0 \pm 698.4$ & 0.96 \\
N. of retrieved & $11.5 \pm 4.2$ & $12.0 \pm 4.8$ & 0.06 \\
oocytes & $9.4 \pm 3.9$ & $10.9 \pm 4.6$ & 0.17 \\
N. of MII oocytes & $0.81 \pm 0.9$ & $0.87 \pm 0.9$ & $<0.05$ \\
MIT/total retrieved & & $0.2 \pm 0.4$ & $<0.001$ \\
oocytes (\%) & $1.01 \pm 1.5$ & $83.4 \%$ & 0.53 \\
N. of GV+DEG & $78.9 \%$ & $95.5 \%$ & 1.0 \\
Fertilization rate & $95.9 \%$ & $2.7 \pm 0.4$ & 0.62 \\
Cleavage rate & $2.6 \pm 0.7$ & $75.7 \%$ & $<0.05$ \\
No. of embryos & $57.7 \%$ & $18.4 \%$ & $<0.01$ \\
transferred & $27.8 \%$ & $7.7 \%$ & 0.11 \\
Embryo grade 1 & $14.4 \%$ & & \\
Embryo grade 2 & & & \\
Embryo grade 3 & & & \\
\hline Values are means \pm SD or percentage. & & \\
MII: metaphase II; DEG: degenerate oocytes, GV: germinal vesicles.
\end{tabular}

\section{Regime dietetico}

Successivamente abbiamo valutato l'associazione MYO e ALA in donne con PCOS in sovrappeso/obesità di grado $1^{\circ}$, iperinsulinemiche e con oligo-amenorrea.

Abbiamo seguito 273 donne che soddisfacevano a tre dei sei criteri di inclusione (Tabella III) e suddivise in due gruppi in relazione al trattamento ricevuto: un gruppo ha osservato solo un regime dietetico normocalorico, un secondo gruppo ha associato, al regime dietetico, terapia combinata MYO e ALA. Tutte le pazienti, come da pratica clinica, sono state valutate a 3 e a 6 mesi dopo l'inizio del trattamento e monitorate per circa un anno. Al termine dei 6 mesi abbiamo evidenziato una riduzione del valore di BMI in entrambi i gruppi ma più significativa nel gruppo trattato anche con MYO e ALA (Tabella IV).

Un risultato analogo è stato rilevato valutando l'HOMA-IR index. Il miglioramento dei dati endocrino-metabolici, del volume ovarico e la regolarizzazione del ciclo mestruale è stato significativo a partire del $3^{\circ}$ mese di terapia nel gruppo trattato.

Durante il periodo di follow-up abbiamo osservato un incremento significativo della percentuale di gravidanze nelle donne trattate con associazione MYO e ALA rispetto alle donne sottoposte al solo regime dietetico (Tabella V).

Tutte le donne incluse nello studio presentavano una condizione di sindrome da insulinoresistenza: dopo 6 mesi di trattamento con l'associazione MYO e ALA, pur non evidenziandosi variazioni significative dei livelli ematici di glucosio, abbiamo osservato una riduzione statisticamente significativa dell'HOMA-IR index e dei livelli d'insulinemia. La riduzione significativa

TABELla III.--Regime dietetico: criteri di inclusione ed esclusione.

\begin{tabular}{|c|c|}
\hline Criteri di inclusione & Criteri di esclusione \\
\hline $\begin{array}{l}\text { - Infertilità di coppia da fattore } \\
\text { endocrino-ovulatorio (PCOS } \\
\text { criteri Rotterdam) }\end{array}$ & $\begin{array}{l}\text { - Precedente chirurgia } \\
\text { pelvica }\end{array}$ \\
\hline $\begin{array}{l}\text { - Età 18-40 aa } \\
\text { - Diagnosi di PCOS } \\
\text { - HOMA }>2,5-\text { BMI } \leq 30 \mathrm{~kg} / \mathrm{m} 2 \\
\text { - Iperinsulinemia basale } \\
\text { - Oligomenorrea/amenorrea }\end{array}$ & $\begin{array}{l}\text { - Fattore maschile severo } \\
\text { - Fattore utero-tubarico } \\
\text { - Anomalie genetiche }\end{array}$ \\
\hline
\end{tabular}


TABELLA IV.-Caratteristiche metaboliche, ormonali e cliniche delle donne con PCOS in condizioni basali ed in corso di trattamento.

\begin{tabular}{|c|c|c|c|c|}
\hline & \multicolumn{2}{|c|}{ Dieta - Gruppo A } & \multicolumn{2}{|c|}{ Mioinositolo + acido alfa-lipoico - Gruppo B } \\
\hline & $\mathrm{T}_{0}$ & $\mathrm{~T}_{6}$ & $\mathrm{~T}_{0}$ & $\mathrm{~T}_{6}$ \\
\hline Età donna $(\mathrm{aa})$ & $32,3 \pm 2,8$ & / & $33,1 \pm 2,7$ & / \\
\hline Durata di infertilità (aa) & $1,8 \pm 1,0$ & / & $2,1 \pm 0,9$ & / \\
\hline $\mathrm{BMI} \mathrm{kg} / \mathrm{m}^{2}(\mathrm{mU} / \mathrm{ml})$ & $27,5 \pm 3,6$ & $25,5 \pm 2,7$ & $27,0 \pm 3,8$ & $23,9 \pm 3,2$ \\
\hline Colesterolo totale $(\mathrm{mg} / \mathrm{dl})$ & $185,8 \pm 33,5$ & $184,2 \pm 32,0$ & $189,7 \pm 29,1$ & $1774,4 \pm 27,8$ \\
\hline HDL (mg/dl) & $50,1 \pm 11,2$ & $50,8 \pm 12,6$ & $51,1 \pm 12,4$ & $50 \pm 11,8$ \\
\hline $\mathrm{LDL}(\mathrm{mg} / \mathrm{dl})$ & $101,7 \pm 15,6$ & $99,9 \pm 14,1$ & $100,0 \pm 12,0$ & $96,2 \pm 10,4$ \\
\hline Trigliceridi (mg/dl) & $95,9 \pm 37,9$ & $94,3 \pm 39,5$ & $100,5 \pm 37,8$ & $95,9 \pm 31,3$ \\
\hline Glicemia basale (mg/dl) & $98,1 \pm 5,9$ & $95,8 \pm 5,4$ & $96,4 \pm 9,4$ & $88,6 \pm 7,8$ \\
\hline Insulinemia basale $(\mathrm{mU} / \mathrm{ml})$ & $20,4 \pm 6,4$ & $18,8 \pm 6,2$ & $21,6 \pm 5,4$ & $13,3 \pm 5,7$ \\
\hline HOMA index & $4,8 \pm 1,6$ & $3,4 \pm 0,9$ & $4,9 \pm 1,5$ & $2,9 \pm 0,6$ \\
\hline FSH basale $(\mathrm{mIU} / \mathrm{ml})$ & $6,9 \pm 2,6$ & $6,3 \pm 1,5$ & $6,6 \pm 1,49$ & $6,1 \pm 1,9$ \\
\hline LH basale $(\mathrm{mIU} / \mathrm{ml})$ & $7,5 \pm 1,9$ & $7,4 \pm 2,1$ & $7,09 \pm 1,8$ & $6,3 \pm 1,9$ \\
\hline $\mathrm{E}_{2}(\mathrm{pg} / \mathrm{ml})$ & $44,3 \pm 15,8$ & & $48,4 \pm 18,1$ & $45,7 \pm 13,5$ \\
\hline AMH (ng/ml) & $6,9 \pm 2,5$ & & $5 \pm 3,9$ & $3,8 \pm 1,9$ \\
\hline PRL (ng/ml) & $12,9 \pm 5,8$ & $12,4 \pm 5,6$ & $12,9 \pm 5,4$ & $12,7 \pm 3,5$ \\
\hline TSH (mIU/l) & $1,58 \pm 0,5$ & $1,54 \pm 0,5$ & $1,63 \pm 0,5$ & $1,51 \pm 0,3$ \\
\hline Testosterone (ng/dl) & $12,5 \pm 3,4$ & $12,1 \pm 2,8$ & $12,2 \pm 3,1$ & $10,1 \pm 2,2$ \\
\hline SHBG nmol/1 & $34,10 \pm 12,1$ & $37,08 \pm 10,2$ & $35,06 \pm 11,5$ & $42,08 \pm 12,2$ \\
\hline DHEA-S ng/ml & $3048,84 \pm 87$ & $2818,64 \pm 57$ & $133,44 \pm 58$ & $2478,44 \pm 47$ \\
\hline Androstenedione $\mathrm{ng} / \mathrm{ml}$ & $2,61 \pm 0,5$ & $2,4 \pm 0,8$ & $2,8 \pm 0,7$ & $1,8 \pm 0,5$ \\
\hline Volume ovarico $\left(\mathrm{cm}^{3}\right)$ & $10,7 \pm 0,5$ & $10,2 \pm 0,9$ & $10,9 \pm 1,0$ & $8,5 \pm 0,8$ \\
\hline $\mathrm{AFC}\left(\mathrm{n}^{\circ}\right.$ follicoli) & $27,8 \pm 3,1$ & $26,3 \pm 3,1$ & $26,1 \pm 4,7$ & $20,0 \pm$ \\
\hline Ciclo ovarico (gg) & $48,8 \pm 13,1$ & $46,58 \pm 15,1$ & $47,6 \pm 18,5$ & $32,2 \pm 9,1$ \\
\hline \multicolumn{5}{|c|}{ TABELLA V.-Outcome clinico-riproduttivo. } \\
\hline & \multicolumn{2}{|c|}{ Gruppo A (follow-up) } & o B & Gruppo B (follow-up) \\
\hline Ciclo (gg) & \multirow{3}{*}{\multicolumn{2}{|c|}{$\begin{array}{c}46.58 \pm 15.1 \\
1.8 \pm 0.1 \\
7 / 150\end{array}$}} & $47.6 \pm 18.5$ & $32.2 \pm 9.1$ \\
\hline $\mathrm{N}^{\circ}$ ovulazioni & & & $1.3 \pm 0.4$ & $3.0 \pm 0.1$ \\
\hline Gravidanza & & & $0 / 197$ & $35 / 194$ \\
\hline
\end{tabular}

del BMI ha probabilmente rappresentato il fattore principale per la regolarizzazione del ciclo mestruale in donne oligomenorroiche e il ritorno del ciclo mestruale nelle donne amenorroiche.

Questo studio conferma che l'associazione MYO e ALA in pazienti PCOS migliora l'outcome riproduttivo sia spontaneo che con tecniche di PMA.

\section{Statements}

- Le donne con PCOS hanno un'attività ovulatoria ridotta e pertanto una minor probabilità di gravidanza anche dopo tecniche di fecondazione assistita.

- Nel gruppo delle donne con PCOS sottoposte a trattamento con mioinositolo e acido alfalipoico abbiamo osservato una riduzione statisticamente significativa del BMI, del valore di insulinemia basale e del volume ovarico rispetto ai valori iniziali.

- Nelle donne con sindrome da insulino-resistenza, dopo trattamento con l'associazione mioinositolo e acido alfa-lipoico abbiamo evidenziato una riduzione fortemente significativa per quanto riguarda sia l'HOMA-IR index sia i livelli ematici d'insulinemia.

- La supplementazione con MYO e ALA, nelle donne con PCOS sottoposte a PMA, determina, a fronte di una diminuzione di oociti immaturi e/o degenerati, un maggiore recupero di oociti di classe MII che a loro volta sono in grado di generare embrioni di classe I e II.

- Nelle donne con PCOS in sovrappeso e/o obese, il solo regime dietetico determina una riduzione del BMI, ma in maniera più evidente nel gruppo trattato con l'associazione mioinositolo e acido alfa-lipoico. 
- Le donne trattate con l'associazione MYO e ALA hanno generato una percentuale significativamente superiore di gravidanze rispetto alle donne sottoposte al solo regime dietetico nell'arco di 12 mesi.

\section{Bibliografia}

1.Cheang KI, Baillargeon JP, Essah PA, Ostlund RE Jr, Apridonize T, Islam L, et al. Insulin-stimulated release of D-chiroinositol-containing inositolphosphoglycan mediator correlates with insulin sensitivity in women with polycystic ovary syndrome. Metabolism 2008;57:1390-7.

2. Papaleo E, Unfer V, Baillargeon JP, Fusi F, Occhi F, De Santis L. Myo-inositol may improve oocyte quality in intracytoplasmic sperm injection cycles. A prospective, controlled, randomized trial. Fertil Steril 2009;91:1750-4.

3. Ciotta L, Stracquadanio M, Pagano I, Carbonaro A, Pa- lumbo M, Gulino F. Effects of myo-inositol supplementation on oocyte's quality in PCOS patients: a double blind trial. Eur Rev Med Pharmacol Sci 2011;15:509-14.

4. Palomba S, Falbo A, Carrillo L, Villani MT, Orio F, Russo $\mathrm{T}$, et al.; METformin in High Responder Italian Group. Metformin reduces risk of ovarian hyperstimulation syndrome in patients with polycystic ovary syndrome during gonadotropin-stimulated in vitro fertilization cycles: a randomized, controlled trial. Fertil Steril 2011;96:1384-1390.e4.

5. Tang T, Lord JM, Norman RJ, Yasmin E, Balen AH. Cochrane Database Syst Rev 2012.

6. Colazingari S, Treglia M, Najjar R, Bevilacqua A. The combined therapy myo-inositol plus D-chiro-inositol, rather than D-chiro-inositol, is able to improve IVF outcomes: results from a randomized controlled trial. Arch Gynecol Obstet 2013;288:1405-11.

7. Rago R, Marcucci I, Leto G, Caponecchia L, Salacone P, Bonanni P, et al. Effect of myo-inositol and alpha-lipoic acid on oocyte quality in polycystic ovary syndrome non-obese women undergoing in vitro fertilization: a pilot study. J Biol Regul Homeost Agents 2015;29:913-23. 


\title{
Funzione ovarica in donne obese
}

\author{
Irene CETIN 1,2, Chiara NOVIELLI 1,2, Chiara MANDÒ 1,2*
}

1Ospedale dei Bambini Buzzi, ASST Fatebenefratelli Sacco, Milan, Italy; ${ }^{2}$ Dipartimento di Scienze Biomediche e Cliniche Luigi Sacco, Laboratorio di Ricerca Translazionale Materno-Fetale "Giorgio Pardi”, Università degli Studi di Milano, Milan, Italy

*Corresponding author: Chiara Mandò, Dipartimento di Scienze Biomediche e Cliniche Luigi Sacco, Laboratorio di Ricerca Translazionale Materno-Fetale “Giorgio Pardi”, Università degli Studi di Milano, Milan, Italy. E-mail: chiara.mando@unimi.it

\section{RI A S SUNTO}

L'obesità si associa ad un maggior rischio di infertilità, con aumento di stress ossidativo a livello delle cellule ovariche. I mitocondri sono sede della produzione di specie reattive dell'ossigeno, che se non correttamente inattivate da enzimi endogeni, possono modificare lo stato ossidativo della cellula. Disfunzioni mitocondriali sono state riportate nell'ovocita di modelli murini di obesità, e nella placenta di gravidanze umane di donne obese. In questo studio pilota abbiamo analizzato gli effetti in vivo dell'associazione tra acido alfa-lipoico (ALA), mioinositolo (MYO) e acido folico in donne obese infertili senza PCOS rispetto a donne normopeso, sottoposte a fecondazione assistita. Abbiamo valutato il contenuto di DNA mitocondriale (mtDNA, una misura del numero di mitocondri e dello stress ossidativo) nelle cellule della granulosa, che circondano e nutrono l'ovocita nel follicolo ovarico, e la sua associazione con la qualità ovocitaria e gli esiti clinici.

Abbiamo osservato una riduzione, seppur non significativa, del mtDNA (indice di stress ossidativo) nelle cellule della granulosa delle pazienti obese supplementate con la combinazione ALA + MYO + acido folico, rispetto a quelle supplementate con solo acido folico. C'era inoltre una correlazione significativa inversa tra i livelli di mtDNA ed il numero di ovociti prelevati a seguito di stimolazione ovarica, ed una diminuzione degli ovociti degenerati nelle pazienti obese supplementate. I risultati preliminari di questo studio pilota suggeriscono che l'acido alfa-lipoico associato a mioinositolo potrebbe contribuire a diminuire lo stress ossidativo nell'ambiente ovocitario, concorrendo al miglioramento dell'esito della fecondazione assistita in donne obese senza PCOS.

PAROLE CHIAVE: Funzione ovarica; Obesità; Donna.

È noto che l'obesità sia un fattore di rischio d'infertilità. L'obesità infatti si associa a disfunzione ovarica, minor tasso di concepimento e modificazioni della qualità ovocitaria, con minore capacità di sviluppo nella blastocisti. ${ }^{1-7}$

Robker et al. in una review del $2011^{2}$ riportano i principali meccanismi lipotossici attraverso cui l'eccesso di lipidi intracellulari può condurre a disfunzioni a livello delle cellule ovariche. L'infiammazione, lo stress ossidativo e lo stress del reticolo endoplasmatico sono tra i principali responsabili di queste alterazioni, con meccanismi che si amplificano a vicenda.

\section{Obesità e stress ossidativo}

In alcune condizioni a rischio o patologiche della gravidanza umana, lo stress ossidativo è stato as- sociato all'alterazione del contenuto e della funzione mitocondriale. ${ }^{8-11}$

Presso il Laboratorio di Ricerca Traslazionale Materno-Fetale "Giorgio Pardi" di Milano, lo studio dei meccanismi molecolari sottostanti la modifica della funzione ovarica dovuti all'obesità si è focalizzato sullo stress ossidativo. Esso si esprime con un eccessivo rilascio, a livello dei mitocondri, dei ROS (Reactive Oxygen Species: specie reattive dell'ossigeno) normalmente prodotti lungo la catena respiratoria ma che, se non inattivati da enzimi endogeni, si accumulano determinando una eccessiva ossidazione di proteine e lipidi, inducendo un danno alle membrane intracellulari e al DNA, e apoptosi cellulare.

È noto che i mitocondri rivestano un ruolo fondamentale nella maturazione dell'ovocita e nello sviluppo embrionale. Un recente studio ${ }^{12}$ 


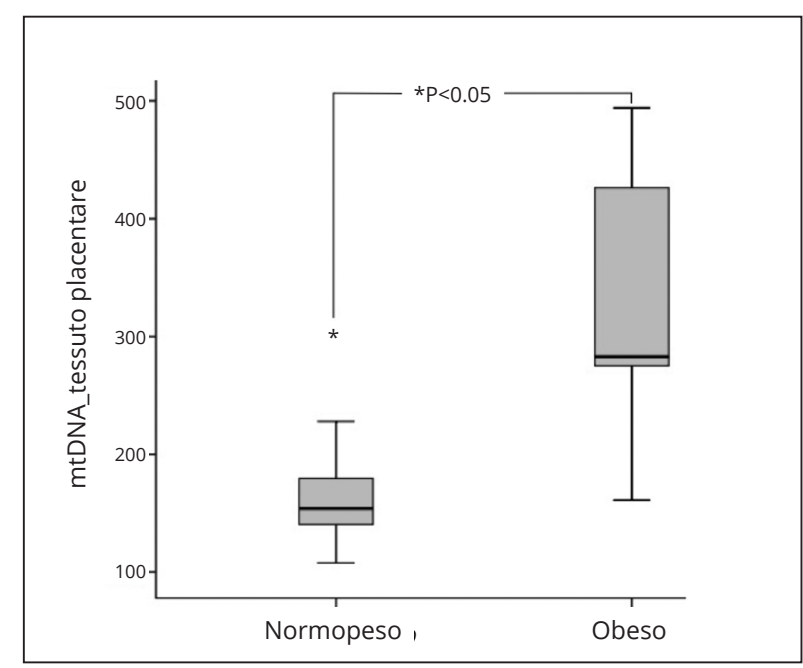

Figura 1.- Livelli di DNA mitocondriale in placente di donne con BMI pregravidico normopeso e obeso. Modificata da Mandò et al. ${ }^{10}$

ha dimostrato che un eccesso di DNA mitocondriale nella blastocisti si associa al fallimento dell'impianto dell'ovocita.

La quantità di DNA mitocondriale (mtDNA), proporzionale al numero di mitocondri nella cellula, è utilizzata per quantificare i mitocondri ed è proporzionale anche ai livelli di stress ossidativo della cellula. Abbiamo recentemente riportato che la quantità di mtDNA nelle placente e nel sangue materno al terzo trimestre di gravidanza (dove si ritrovano molte cellule placentari) di donne obese è significativamente superiore a quella riscontrata in donne normopeso, e il contenuto di mtDNA correla con il BMI pregravidico (Figura 1). 10,11

Lo studio di Grindler e Moley (2013) ${ }^{13}$ su un modello animale ha dimostrato il ruolo chiave dei mitocondri dell'ovocita nello sviluppo dei difetti riproduttivi legati all'obesità. Nel topo obeso, che presenta minore fertilità rispetto al normopeso, si è osservata infatti una diversa distribuzione dei mitocondri nell'ovocita e anche una diversa morfologia mitocondriale, insieme ad un aumento di ROS.

È da stabilire se: 1) le alterazioni mitocondriali trovate nella placenta e nel sangue materno di donne obese si ritrovino già anche nell'ovocita di queste donne; 2) le problematiche dell'ovocita nelle donne obese, che portano all'aumentato rischio di infertilità, possano essere migliorate da un prodotto antiossidante associato a una sostanza insulino-sensibilizzante.

\section{Studio pilota osservazionale}

Lo studio pilota osservazionale attualmente in corso ha lo scopo di analizzare gli effetti in vivo dell'associazione tra acido alfa-lipoico (ALA) e mioinositolo (MYO) in donne infertili obese senza PCOS. L'outcome primario dello studio è la quantità di DNA mitocondriale nelle cellule della granulosa (che circondano e nutrono l'ovocita nel follicolo ovarico) per valutare lo stress ossidativo nell'ambiente ovocitario di pazienti con diversi BMI e diversi tipi di supplementazione. Gli outcomes secondari sono la qualità ovocitaria e gli outcomes clinici.

L'ALA è stato scelto per la sua nota capacità di migliorare la funzione mitocondriale e di diminuire la concentrazione di ROS, e per i relativi effetti antiossidanti ed antinfiammatori.

Le pazienti infertili sono state arruolate presso il Centro di Procreazione Medicalmente Assistita dell'Ospedale Sacco (Milano). Le pazienti sono state divise in 3 gruppi: 1) pazienti normopeso, supplementate con solo acido folico (400 mcg/die); 2) pazienti obese, supplementate con solo acido folico (400 mcg/die); 3 ) pazienti obese, supplementate con acido alfa-lipoico $(800 \mathrm{mg} / \mathrm{die})+$ mioinositolo ( $2 \mathrm{~g} /$ die $)+$ acido folico $(400 \mathrm{mcg} / \mathrm{die})$.

I criteri d'inclusione comprendevano: donne normopeso (BMI $>18$ e $<25)$ e obese $(B M I \geq 28)$; infertilità non per causa ovarica (tubarica, coppie discordanti); stesso tipo di stimolazione ovarica (FSH+ GnRH antagonista); assunzione dei supplementi da almeno 2 mesi prima della stimolazione ovarica.

I criteri di esclusione erano: PCOS, diabete o altre patologie metaboliche e cardiovascolari; pazienti con ridotta riserva ovarica; prescrizione di diete specifiche.

Al momento del prelievo degli ovociti, a due settimane dalla stimolazione ovarica, il liquido follicolare antrale è stato centrifugato per ottenere le cellule della granulosa. Il mtDNA è stato misurato nelle cellule della granulosa attraverso la quantificazione dell'espressione di un gene del DNA mitocondriale, il citocromo B (cytB), normalizzato con un gene nucleare in singola copia (RNAseP), per ottenere il numero di molecole di DNA circolare mitocondriale in ogni cellula, proporzionale al numero di mitocondri ed al livello di stress ossidativo della cellula. 
L'età della donna non era significativamente diversa tra i gruppi in esame.

Non è stata trovata differenza statisticamente significativa nei livelli di mtDNA. Tuttavia, il mtDNA tendeva ad essere maggiore nelle cellule della granulosa delle donne obese supplementate con solo acido folico rispetto alle normopeso con lo stesso tipo di supplementazione e alle donne obese supplementate anche con ALA + MYO. Inoltre, il numero totale di ovociti ottenuti al prelievo correlava in modo significativo e inverso con il mtDNA; quindi, considerando il mtDNA come indice di stress ossidativo, tanto minore stress ossidativo era presente nelle cellule della granulosa tanto maggiore era il numero di ovociti ottenuti al prelievo.

Non è stata trovata correlazione tra quantità di mtDNA ed età della paziente, suggerendo quindi che l'età non rappresenti un fattore confondente.

Le pazienti obese supplementate con acido folico avevano una percentuale di ovociti degenerati maggiore rispetto alle pazienti obese supplementate con la combinazione ALA + MYO e acido folico.

Inoltre, benché non significativamente (è possibile ipotizzare per ragioni di dimensione del campione), il tasso di successo della gravidanza era minore nelle obese supplementate col solo acido folico $(11,1 \%)$ rispetto alle normopeso $(36,8 \%)$, e rispetto alle obese supplementate con la combinazione ALA + MYO e acido folico $(28,6 \%)$.

In conclusione, si è osservato: 1) riduzione, sia pur non significativa, del mtDNA (indice di stress ossidativo) nelle cellule della granulosa delle pazienti obese supplementate con la combinazione ALA + MYO + acido folico rispetto a quelle supplementate con il solo acido folico; 2) correlazione significativa inversa tra livelli di mtDNA ed il numero di ovociti prelevati a seguito di stimolazione ovarica. Per quanto riguarda gli outcomes secondari, si è osservata una diminuzione degli ovociti degenerati in pazienti obese supplementate con la combinazione MYO + ALA rispetto a quelle non supplementate.

Questi risultati suggeriscono che l'azione di ALA in sinergia con il MYO potrebbe avere degli effetti positivi per ridurre i livelli di stress os- sidativo e migliorare gli esiti della fecondazione assistita in pazienti obese infertili. ${ }^{14}$

Attualmente sono in corso un ampliamento della casistica e le analisi di altri markers di stress ossidativo e di infiammazione nel liquido follicolare, i cui risultati saranno a breve valutati.

\section{Statements}

- L'obesità si associa a stress ossidativo, infiammazione e stress del reticolo endoplasmatico, meccanismi lipotossici attraverso i quali l'eccesso di lipidi intracellulare può portare a disfunzione ovarica.

- Difetti mitocondriali sembrano avere un ruolo chiave nello sviluppo di difetti riproduttivi legati all'obesità.

- L'analisi del mtDNA è un sistema per quantificare il contenuto di mitocondri nella cellula, misura dello stress ossidativo, ed è stato riportato che la quantità di mtDNA nelle placente e nel sangue materno al terzo trimestre di gravidanza di donne obese è significativamente superiore a quella riscontrata in donne normopeso.

- In questo studio pilota osservazionale, i livelli di mtDNA correlano inversamente con il numero di ovociti prelevati da pazienti sottoposte a fecondazione assistita, due settimane dopo la stimolazione ovarica.

- Si è osservata una diminuzione degli ovociti degenerati in pazienti obese supplementate con la combinazione mioinositolo + acido alfa-lipoico + acido folico rispetto a quelle supplementate con solo acido folico.

- I risultati preliminari di questo studio pilota suggeriscono che l'acido alfa-lipoico associato a mioinositolo potrebbe contribuire a diminuire lo stress ossidativo nell'ambiente ovocitario, concorrendo al miglioramento dell'esito della fecondazione assistita.

\section{Bibliografia}

1. Sim KA, Dezarnaulds GM, Denyer GS, Skilton MR, Caterson ID. Weight loss improves reproductive outcomes in obese women undergoing fertility treatment: a randomized controlled trial. Clin Obes 2014;4:61-8.

2. Robker RL, Wu LL, Yang X. Inflammatory pathways linking obesity and ovarian dysfunction. J Reprod Immunol 2011;88:142-8.

3. van der Steeg JW, Steures P, Eijkemans MJ, Habbema JD, Hompes PG, Burggraaff JM, et al. Obesity affects spontane- 
ous pregnancy chances in subfertile, ovulatory women. Hum Reprod 2008;23:324-8.

4. Wu LL, Dunning KR, Yang X, Russell DL, Lane M, Norman RJ, et al. High-fat diet causes lipotoxicity responses in cumulus-oocyte complexes and decreased fertilization rates. Endocrinology 2010;151:5438-45.

5. Esinler I, Bozdag G, Yarali H. Impact of isolated obesity on ICSI outcome. Reprod Biomed Online 2008;17:583-7.

6. Zhang D, Zhu Y, Gao H, Zhou B, Zhang R, Wang T, et al. Overweight and obesity negatively affect the outcomes of ovarian stimulation and in vitro fertilisation: a cohort study of 2628 Chinese women. Gynecol Endocrinol 2010;26:325-32.

7. Metwally M, Li TC, Ledger WL. The impact of obesity on female reproductive function. Obes Rev 2007;8:515-23.

8. Mandò C, De Palma C, Stampalija T, Anelli GM, Figus M, Novielli $\mathrm{C}$, et al. Placental mitochondrial content and function in intrauterine growth restriction and preeclampsia. Am J Physiol Endocrinol Metab 2014;306:E404-13.

9. Novielli C, Mandò C, Tabano S, Anelli GM, Fontana L, Antonazzo P, et al. Mitochondrial DNA content and methylation in fetal cord blood of pregnancies with placental insufficiency. Placenta 2017;55:63-70.
10. Mandò C, Anelli GM, Novielli C, Panina-Bordignon $P$, Massari M, Mazzocco MI, et al. Impact of Obesity and Hyperglycemia on Placental Mitochondria. Oxid Med Cell Longev 2018;2018:2378189.

11. Anelli GM, Cardellicchio M, Novielli C, Antonazzo P, Mazzocco MI, Cetin I, et al. Mitochondrial content and hepcidin are increased in obese pregnant mothers. J Matern Fetal Neonatal Med 2018;31:2388-95.

12. Ravichandran K, McCaffrey C, Grifo J, Morales A, Perloe M, Munne S, et al. Mitochondrial DNA quantification as a tool for embryo viability assessment: retrospective analysis of data from single euploid blastocyst transfers. Hum Reprod 2017;32:1282-92.

13. Grindler NM, Moley KH. Maternal obesity, infertility and mitochondrial dysfunction: potential mechanisms emerging from mouse model systems. Mol Hum Reprod 2013;19:486-94.

14. Mandò C, Savasi V, Anelli GM, Novielli C, Massari M, Parrilla $\mathrm{B}$, et al. Mitochondrial DNA in granulosa cells of obese infertile women undergoing IVF.Society for Reproductive Investigation (SRI) - 62nd Annual Meeting; San Francisco/CA, U.S.A. - March 25th-28th 2015. 


\title{
Abortività spontanea ricorrente: ruolo dell'inflammasoma
}

\author{
Nicoletta DI SIMONE *
}

Unit of Obstetrics and Gynecology, Department of Women's and Children's Health and of Public Health, IRCCS A. Gemelli University Polyclinic Foundation, Sacred Heart Catholic University, Rome, Italy

*Corresponding author: Nicoletta Di Simone, Unit of Obstetrics and Gynecology, Department of Women's and Children's Health and of Public Health, IRCCS A. Gemelli University Polyclinic Foundation, Sacred Heart Catholic University, Rome, Italy.

E-mail: disimone@unicatt.it

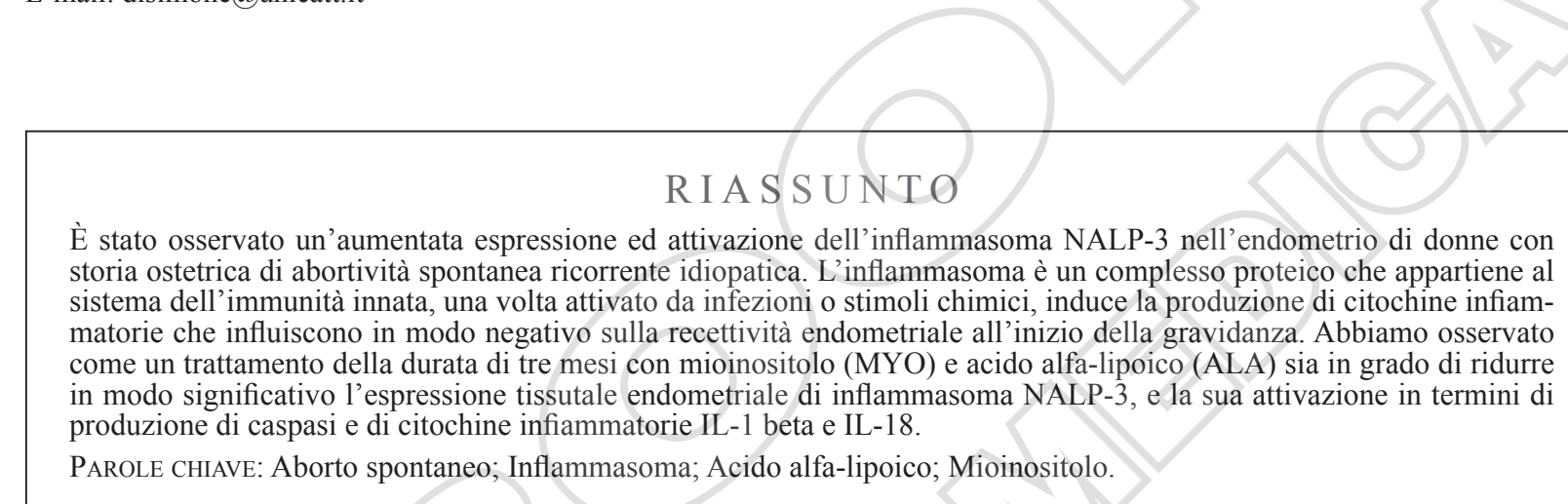

$\mathrm{L}$ 'abortività spontanea ricorrente rappresenta una problematica clinica in aumento negli ultimi anni.

Nello studio qui presentato ed effettuato a Roma, presso il Dipartimento di Scienze della Salute della Donna e del Bambino, Area Salute Donna, Fondazione Policlinico Universitario A. Gemelli IRCCS, Università Cattolica del Sacro Cuore sono state esaminate pazienti con abortività ricorrente idiopatica, ossia sine causa. In tali pazienti è stata effettuata una valutazione della funzionalità endometriale, in termini infiammatori (inflammasoma) escludendo le condizioni di infezione endometriale e/o endometrite. ${ }^{1}$

L'inflammasoma è un complesso proteico appartenente al sistema dell'immunità innata ed è un indicatore di condizione infiammatoria. In particolare, il NALP-3, l'inflammasoma più noto, una volta attivato attiva la pro-caspasi-1 in caspasi e una serie di citochine infiammatorie, trasformando i precursori in forme attive.

Nello studio che è stato condotto con l'associazione di mioinositolo (MYO) e acido alfalipoico (ALA) sono state arruolate 40 donne con abortività ricorrente idiopatica. ${ }^{2}$ Sono state escluse: pazienti con PCOS e insulino-resistenza; pazienti che utilizzavano contraccettivi e/o dispositivi intrauterini negli ultimi 6 mesi antecedenti lo studio, farmaci antinfiammatori, antibiotici, sensibilizzanti per insulina; donne con anomalie anatomiche dell'utero, deficit della fase luteale, aumentati livelli prolattinemia; pazienti con infezioni vaginali, con evidenza isteroscopica/istologica di endometrite; sono state escluse coppie con anomalie del cariotipo parentale, precedenti anomalie cromosomiche del prodotto di concepimento, disordini trombofilici, patologie autoimmuni. Il gruppo di controllo, 15 pazienti, era costituito da donne con precedenti gravidanze fisiologiche.

Tutte le pazienti sono state sottoposte a isteroscopia diagnostica con biopsia endometriale ed esame istologico. L'isteroscopia diagnostica 
è stata ripetuta dopo 3 mesi di trattamento con MYO e ALA nelle pazienti con abortività ricorrente idiopatica.

È stata studiata l'espressione tissutale e l'attivazione del NALP-3.

È emerso che il NALP-3 era presente in stato di attivazione nelle donne con abortività ricorrente prima del trattamento integrativo con MYO e ALA. Abbiamo osservato una riduzione del NAPL-3 dopo il trattamento con raggiungimento di livelli simili a quelli del gruppo di controllo.

L'analisi quantitativa e immunoistochimica riguardante il NALP-3 ha messo in evidenza che, dopo il trattamento con MYO e ALA, la colorazione più intensa, indice della presenza di NALP-3 a livello endometriale, è risultata ridotta in modo significativo nel gruppo di pazienti con abortività spontanea idiopatica. L'analisi di caspasi-1 e interleuchine ha confermato l'osservazione sul NALP-3.

Inoltre, $\mathrm{i}$ frammenti di tessuto endometriale di queste pazienti sono stati incubati in coltura con ALA e MIO per valutare quale dei due principi farmacologici fosse in grado di ridurre l'attivazione del NALP-3. L'ALA riduceva l'at- tivazione nel NALP-3 in modo dose-dipendente e quindi l'attività della caspasi e la secrezione di interleuchine.

\section{Statements}

- L'inflammasoma NALP-3, presente nell'endometrio di donne con abortività ricorrente, si riduce in misura significativa dopo trattamento con mioinositolo e acido alfa-lipoico raggiungendo un'espressione tissutale simile a quella di una popolazione di controllo (pazienti fertili).

- In pazienti con abortività ricorrente idiopatica trattate con mioinositolo e acido alfa-lipoico si è raggiunta un'incidenza di gravidanze a termine del 50-60\% (bimbi in braccio).

\section{References}

1. D'Ippolito S, Tersigni C, Marana R, Di Nicuolo F, Gaglione R, Rossi ED, et al. Inflammosome in the human endometrium: further step in the evaluation of the "maternal side". Fertil Steril 2016;105:111-8.e1, 4.

2. Di Nicuolo F, D'Ippolito S, Castellani R, Rossi ED, Masciullo V, Specchia M, et al. Effect of alpha-lipoic acid and myoinositol on endometrial inflammasome from recurrent pregnancy loss women. Am J Reprod Immunol 2019;82:e13153. 


\title{
Insulino-sensibilizzanti in pazienti con sindrome dell'ovaio policistico
}

\author{
Rosanna APA *, Giovanna NOTARISTEFANO
}

Unit of Obstetrics and Gynecology, Department of Women's and Children's Health and of Public Health, IRCCS A. Gemelli University Polyclinic Foundation, Sacred Heart Catholic University, Rome, Italy

*Corresponding author: Rosanna Apa, Unit of Obstetrics and Gynecology, Department of Women's and Children's Health and of Public Health, IRCCS A. Gemelli University Polyclinic Foundation, Sacred Heart Catholic University, Rome, Italy.

E-mail: rosanna.apa@policlinicogemelli.it

$$
\begin{aligned}
& \text { R I A S S U N T O } \\
& \text { I composti nutraceutici sono stati oggetto, negli ultimi anni, di numerosi studi nell'ambito della PCOS, volti alla scoperta } \\
& \text { di efficaci alternative terapeutiche ai farmaci, quali metformina ed estroprogestinici, spesso causa di effetti collaterali } \\
& \text { non tollerati soprattutto dalle pazienti più giovani. Tra i vari composti i più utilizzati sono stati il mioinositolo (MYO), } \\
& \text { con il suo stereoisomero d-chiroinositolo, e l'acido alfa-lipoico (ALA), i quali si sono dimostrati efficaci nel migliorare } \\
& \text { le caratteristiche della PCOS. Le pazienti con PCOS mostrano, infatti, significativi miglioramenti clinici ed endocrino- } \\
& \text { metabolici, sia dopo il trattamento combinato con MYO-ALA che con i composti presi singolarmente. Il meccanismo } \\
& \text { d'azione di tali composti non è ancora del tutto chiaro. Nel frattempo, sono necessari ulteriori studi su popolazioni più } \\
& \text { ampie per confermare questi risultati al fine di poter proporre il mioinositolo e l'acido alfa-lipoico come valida alternativa } \\
& \text { terapeutica ai farmaci tradizionali. } \\
& \text { PAROLE chIAVE: Sindrome dell'ovaio policistico; Acido alfa-lipoico; Mioinositolo. }
\end{aligned}
$$

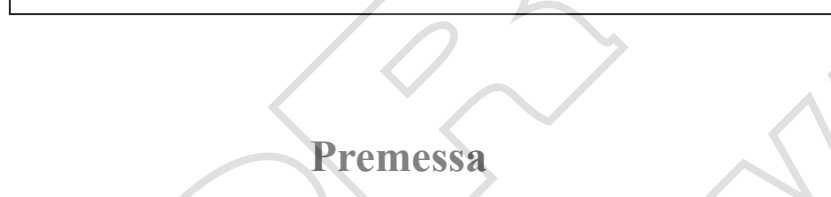

$\mathrm{L}$ a sindrome dell'ovaio policistico (PCOS) è caratterizzata dalla varia combinazione di anovulazione cronica, iperandrogenismo, disturbi mestruali, sterilità e obesità. Oltre alla disfunzione ormonale e all'insulinoresistenza, sono stati suggeriti come fattori chiave della patogenesi e dello sviluppo della PCOS l'infiammazione cronica di basso grado e lo stress ossidativo, derivanti dall'aumento della produzione di radicali liberi in presenza di difese antiossidanti limitate. ${ }^{1}$

Nell'ultimo decennio sono stati condotti numerosi studi sull'effetto dei composti nutraceutici sulla PCOS, in particolare del mioinositolo (MYO) e del suo stereoisomero d-chiroinositolo. Il mioinositolo svolge un importante ruolo come base strutturale dei secondi messaggeri che sono coinvolti in processi intracellulari insulino-dipendenti ed è stato dimostrato che il trattamento con questo composto migliora le caratteristiche endocrine della PCOS. ${ }^{2-4}$

L'acido alfa-lipoico (ALA) è un composto organico che agisce come un potente fattore antiossidante e antinfiammatorio. Esso è un cofattore per l'alfa-cheto-deidrogenasi mitocondriale e nelle cellule è ridotto ad acido diidrolipoico, che è generalmente considerato la forma più bioattiva dell'ALA responsabile della maggior parte degli effetti antiossidanti. ${ }^{5}$ Numerose evidenze mostrano le sue capacità di migliorare il controllo del glucosio nei pazienti con diabete di tipo 2, presumibilmente aumentando l'assorbimento del glucosio e la sensibilità all'insulina e riducendo lo stress ossidativo. ${ }^{6}$

Tutto ciò mira alla scoperta di efficaci alternative terapeutiche ai farmaci, quali metformina ed estroprogestinici, spesso causa di effetti collaterali non tollerati soprattutto dalle pazienti più giovani.

Finora, studi condotti sull'uso di mioinositolo, 
d-chiro-inositolo e acido alfa-lipoico, variamente combinati tra loro, si sono dimostrati efficaci nel migliorare le caratteristiche della PCOS, senza effetti collaterali.

\section{Gli effetti della combinazione mioinsoitolo + acido alfa-lipoico nelle pazienti con PCOS}

In un nostro studio pilota ${ }^{7}$ sono state arruolate 40 pazienti con PCOS diagnosticata secondo i criteri di Rotterdam, in sovrappeso ma normoinsulinemiche, e trattate per 6 mesi con l'associazione MYO e ALA.

E stato osservato un miglioramento del BMI, WHR e FG score. Il numero di cicli è aumentato da 2 a 5 in 6 mesi e tutti i parametri di iperandrogenismo (SHBG, DHEAS) sono migliorati, associati ad una riduzione dell'AMH, del volume ovarico e della conta dei follicoli antrali (Tabella I). L'unico ormone non modificato è stato il 17-idrossi-progesterone che è un indicatore della funzione surrenalica (dati non mostrati). Tuttavia, non sono state osservate differenze statisticamente significative delle caratteristiche metaboliche tenendo però conto del fatto che le pazienti non avevano parametri metabolici particolarmente anomali in condizioni di base, confermando l'osservazione per cui maggiori sono le alterazioni pre-trattamento, maggiori sono le differenze che si possono osservare dopo trattamento con 1'associazione MYO e ALA. Pertanto, la combinazione MYOALA è in grado di migliorare le caratteristiche cliniche e ormonali nelle donne con PCOS sovrappeso-obese attraverso un meccanismo che, anche se non chiarito, potrebbe essere indipendente dall'insulina e mirato all'ovaio stesso. ${ }^{7}$

TABELla I.-Caratteristiche cliniche delle pazienti con PCOS prima e dopo sei mesi di trattamento con l'associazione mioinositolo e acido alfa-lipoico.

\begin{tabular}{lcc}
\hline Caratteristiche & Pre & Post \\
\hline Age (years) & $25,57 \pm 5,72$ & \\
BMl (kg/m2) & $30,03 \pm 4,47$ & $28,60 \pm 5,56^{* *}$ \\
WHR & $0,80 \pm 0,10$ & $0,79 \pm 0,08$ \\
FG score & $12,19 \pm 4,33$ & $10,19 \pm 3,31$ \\
Cycles in 6 months & $2,29 \pm 1,82$ & $5,24 \pm 1,37 * *$ \\
\hline$* \mathrm{P}<0,05 ; * * \mathrm{P}<0,01$. & & \\
\hline
\end{tabular}

Acido alfa-lipoico in pazienti con PCOS normo- o iperinsulinemiche

Nello studio condotto al Policlinico Gemelli di Roma (dipartimento di Ginecologia Disfunzionale) sono state arruolate 60 donne con diagnosi di PCOS secondi i criteri di Rotterdam, di età compresa tra 18 e 34 anni, normo- $(\mathrm{N} .=30)$ o iperinsulinemiche $(\mathrm{N} .=30)$. Le pazienti sono state trattate per 6 mesi con acido alfa-lipoico $800 \mathrm{mg} /$ die e valutate dal punto di vista clinico, metabolico ed antropometrico sia in condizioni basali che al termine della terapia.

La Tabella II mostra le caratteristiche cliniche, ormonali e antropometriche delle pazienti prima e dopo 6 mesi di trattamento. È stato osservato un aumento statisticamente significativo dei cicli mestruali, parallelamente ad una riduzione di testosterone e ITL con aumento dei livelli medi di SHBG. La secrezione di insulina ha subito una significativa modifica durante 1'OGTT, con riduzione dell'AUC-I (Figura 1).

Il gruppo delle pazienti normoinsulinemiche

TABELLA II.-Caratteristiche cliniche, antropometriche e ormonali di tutte le pazienti studiate $(N .=60)$ prima e dopo sei mesi di trattamento con acido alfa-lipoico.

\begin{tabular}{|c|c|c|}
\hline Caratteristiche & Pre & Post \\
\hline Cicli & $2,35 \pm 1,72$ & $4,00 \pm 1,88^{* *}$ \\
\hline FSH & $6,19 \pm 2,03$ & $6,86 \pm 1,76$ \\
\hline LH & $9,3 \pm 6,97$ & $9,50 \pm 5,69$ \\
\hline E2 & $44,35 \pm 11,58$ & $45,30 \pm 12,79$ \\
\hline PRL & $8,35 \pm 3,69$ & $8,29 \pm 3,31$ \\
\hline A & $2,71 \pm 1,18$ & $2,62 \pm 0,98$ \\
\hline $\mathrm{T}$ tot & $0,41 \pm 0,12$ & $0,36 \pm 0,09 *$ \\
\hline ITL & $3,20 \pm 2,15$ & $2,54 \pm 1,48^{*}$ \\
\hline DHEAS & $3574,67 \pm 1063,37$ & $2451,25 \pm 1075,77$ \\
\hline SHBG & $61,25 \pm 38,46$ & $72,58 \pm 29,87^{*}$ \\
\hline $\mathrm{AMH}$ & $7,44 \pm 2,59$ & $7,43 \pm 3,10$ \\
\hline 17-OHP & $0,79 \pm 0,36$ & $0,70 \pm 0,28$ \\
\hline Glicemia 0’ & $80,96 \pm 6,82$ & $79,26 \pm 7,16$ \\
\hline AUC glicemia & $12.817,17 \pm 1947,38$ & $12.936,52 \pm 2262,09$ \\
\hline Insulinemia $0{ }^{\prime}$ & $9,76 \pm 7,35$ & $9,70 \pm 6,79$ \\
\hline AUC insulina & $8445,50 \pm 4400,17$ & $6613,44 \pm 4058,24 *$ \\
\hline HOMA-IR & $1,91 \pm 1,57$ & $1,90 \pm 1,38$ \\
\hline Età, anni & $22,20 \pm 5,05$ & $22,92 \pm 5,13$ \\
\hline Peso, kg & $64,49 \pm 13,19$ & $63,85 \pm 11,32$ \\
\hline Altezza, cm & \multicolumn{2}{|c|}{$163,50 \pm 6,86$} \\
\hline BMI, kg/m² & $26,86 \pm 10,07$ & $24,32 \pm 4,63$ \\
\hline LAG & $58,50 \pm 13,05$ & $63,00 \pm 13,27$ \\
\hline
\end{tabular}




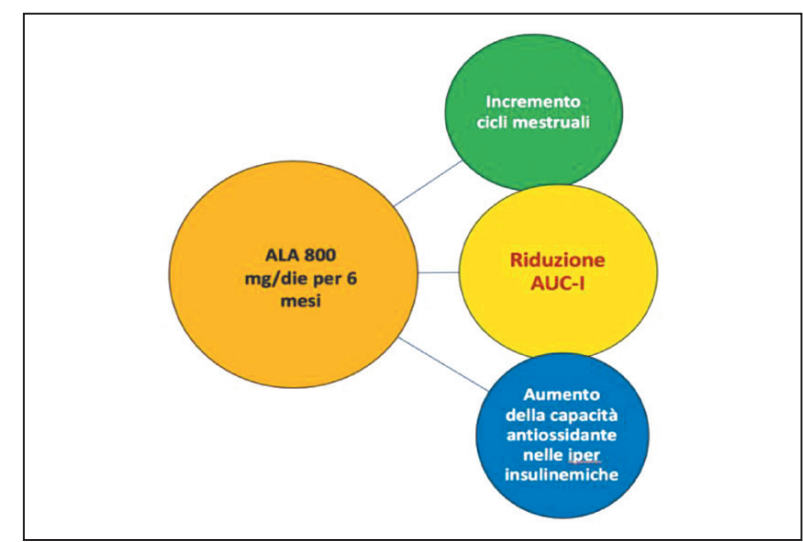

Figura 1.-Risultati ottenuti dopo sei mesi di trattamento con acido alfa-lipoico.

(Tabella III) ha mostrato un aumento di SHBG e nessun altro cambiamento ormonale significativo, ad eccezione di una riduzione del DHEAS. Anche in queste pazienti abbiamo riscontrato un aumento significativo dei cicli mestruali, ma nessun cambiamento nella capacità antiossidante. Ciò che è rilevante è che queste pazienti hanno mostrato una riduzione significativa del BMI.

$\mathrm{Nel}$ gruppo delle pazienti iperinsulinemiche

TABELLA III.-Caratteristiche cliniche, antropometriche e ormonali delle pazienti normoinsulinemiche $(N .=30)$ prima e dopo sei mesi di trattamento con acido alfa-lipoico.

\begin{tabular}{lcc}
\hline Caratteristiche & Pre & Post \\
\hline Cicli & $2,40 \pm 2,07$ & $4,20 \pm 2,29^{*}$ \\
FSH & $6,76 \pm 1,98$ & $7,37 \pm 1,86$ \\
LH & $8,40 \pm 6,65$ & $9,57 \pm 5,72$ \\
E2 & $48,30 \pm 9,99$ & $47,20 \pm 14,52$ \\
PRL & $8,46 \pm 5,01$ & $8,21 \pm 3,93$ \\
A & $2,53 \pm 0,95$ & $2,23 \pm 0,93$ \\
Ttot & $0,39 \pm 0,16$ & $0,35 \pm 0,13$ \\
ITL & $2,75 \pm 1,80$ & $2,27 \pm 1,98$ \\
DHEAS & $2302,00 \pm 781,62$ & $2032,00 \pm 714,64^{*}$ \\
SHBG & $70,50 \pm 50,79$ & $83,00 \pm 49,17 *$ \\
AMH & $8,30 \pm 2,39$ & $6,92 \pm 3,89$ \\
17-OHP & $0,67 \pm 0,26$ & $0,53 \pm 0,23$ \\
Glicemia 0 & $79,90 \pm 5,26$ & $76,60 \pm 7,41$ \\
AUC glicemia & $12.084,00 \pm 1688,71$ & $11.808,05 \pm 2008,18$ \\
Insulinemia 0 & $5,62 \pm 2,17$ & $7,85 \pm 5,29$ \\
AUC insulina & $4042,05 \pm 803,87$ & $4207,05 \pm 1199,40$ \\
HOMA-IR & $1,13 \pm 0,51$ & $1,47 \pm 0,93$ \\
Età, anni & $24,10 \pm 4,01$ & $24,90 \pm 4,28$ \\
Peso, kg & $59,40 \pm 8,09$ & $59,82 \pm 8,21$ \\
Altezza, cm & & $166,67 \pm 5,57$ \\
BMI, kg/m ${ }^{2}$ & $26,72 \pm 3,29$ & $21,74 \pm 1,82^{*}$ \\
LAG & $61,60 \pm 9,17$ & $64,20 \pm 12,88$ \\
\hline
\end{tabular}

I dati sono presentati come media \pm DS $* \mathrm{P}<0,05$.
(Tabella IV) dopo 6 mesi di terapia abbiamo osservato un aumento statisticamente significativo dei cicli mestruali e di SHBG e una modifica significativa della secrezione di insulina durante l'OGTT, con conseguente diminuzione dell'AUC-I. La capacità antiossidante totale si è dimostrata significativamente aumentata nei pazienti iperinsulinemici $(\mathrm{P}<0,05)$.

\section{Statements}

- Nelle pazienti con PCOS sottoposte a trattamento combinato con mioinositolo e acido alfalipoico si possono osservare maggiori risultati quanto più gravi sono le alterazioni prima del trattamento stesso.

- L'associazione mioinositolo e acido alfa-lipoico è efficace nel migliorare il profilo clinico e anche le caratteristiche ormonali di pazienti con PCOS in sovrappeso attraverso un meccanismo che, sebbene non sia del tutto chiarito, potrebbe essere insulino-indipendente e mirato direttamente all'ovaio.

TABELLA IV.-Caratteristiche cliniche, antropometriche e ormonali delle pazienti iperinsulinemiche $(N .=30)$ prima e dopo sei mesi di trattamento con acido alfalipoico.

\begin{tabular}{lcc}
\hline Caratteristiche & Pre & Post \\
\hline Cicli & $2,31 \pm 1,49$ & $3,85 \pm 1,57^{* *}$ \\
FSH & $5,79 \pm 2,04$ & $6,50 \pm 1,66$ \\
LH & $9,68 \pm 7,42$ & $9,45 \pm 5,90$ \\
E2 & $41,31 \pm 12,16$ & $43,84 \pm 11,69$ \\
PRL & $8,26 \pm 2,60$ & $8,35 \pm 2,96$ \\
A & $2,86 \pm 1,35$ & $2,92 \pm 0,94$ \\
Ttot & $0,41 \pm 0,10$ & $0,37 \pm 0,06$ \\
ITL & $3,53 \pm 2,38$ & $2,73 \pm 1,86$ \\
DHEAS & $2768,43 \pm 1216,38$ & $2750,71 \pm 1209,19$ \\
SHBG & $54,64 \pm 26,79$ & $65,14 \pm 31,55^{*}$ \\
AMH & $6,84 \pm 2,66$ & $7,79 \pm 2,54$ \\
17-OHP & $0,89 \pm 0,39$ & $0,83 \pm 0,24$ \\
Glicemia 0 & $81,77 \pm 7,94$ & $81,30 \pm 6,49$ \\
AUC glicemia & $13.381,15 \pm 2005,29$ & $13.804,62 \pm 2116,35$ \\
Insulinemia 0 & $12,95 \pm 8,38$ & $11,12 \pm 7,65$ \\
AUC insulina & $11.590,82 \pm 2870,17$ & $8332,29 \pm 4528,36^{*}$ \\
HOMA-IR & $2,47 \pm 1,82$ & $1,21 \pm 1,59$ \\
Età, anni & $20,86 \pm 5,40$ & $21,50 \pm 5,36$ \\
Peso, kg & $69,08 \pm 15,51$ & $67,48 \pm 12,87$ \\
Altezza, cm & \multicolumn{2}{c}{$160,78 \pm 7,05$} \\
BMI, kg/m² & $26,98 \pm 5,36$ & $26,64 \pm 5,23$ \\
LAG & $56,00 \pm 15,57$ & $64,26 \pm 13,87^{*}$ \\
\hline I &
\end{tabular}

I dati sono presentati come media $\pm \mathrm{DS}$.

$* \mathrm{P}<0,05 ; * * \mathrm{P}<0,01$. 
- Le pazienti con PCOS normo- o iperinsulinemiche, trattate con acido alfa-lipoico per 6 mesi hanno mostrato un miglioramento significativo della ciclicità mestruale, con riduzione degli androgeni ed aumento dell'SHBG. Le pazienti normoinsulinemiche hanno mostrato una riduzione significativa del BMI. Nelle pazienti iperinsulinemiche è stata osservata una significativa riduzione dei livelli di AUC-I dopo 6 mesi di trattamento con ALA. La PCOS, inoltre, è ormai riconosciuta come condizione di aumentato stress ossidativo. Lo sviluppo di tale studio ha compreso la misurazione della capa-cità antiossidante totale pre- e post-terapia, che è risultata aumentata in modo significativo nelle pazienti iperinsulinemiche.

- I meccanismi di azione sull'ovaio, insulino-dipendenti o indipendenti, dei composti nutraceutici devono ancora essere chiariti. Nel frattempo, sono necessari ulteriori studi su popolazioni più ampie per confermare questi risultati al fine di poter proporre il mioinositolo e l'acido alfa-lipoico come valida alternativa terapeutica ai farmaci tradizionali.

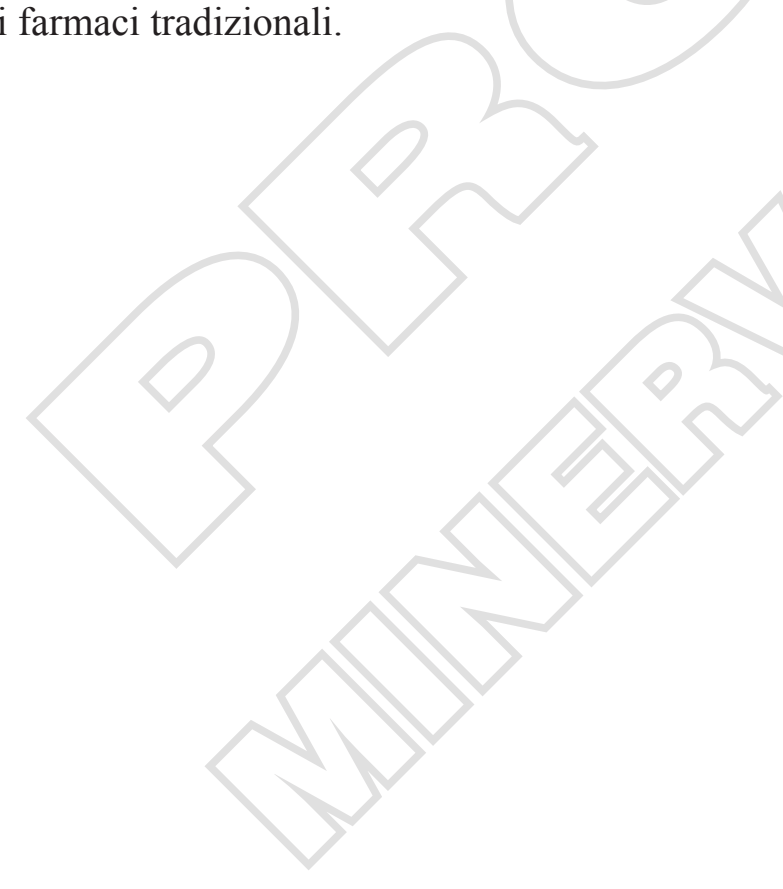

\section{References}

1. Artimani T, Karimi J, Mehdizadeh M, Yavangi M, Khanlarzadeh E, Ghorbani M, et al. Evaluation of pro-oxidant-antioxidant balance (PAB) and its association with inflammatory cytokines in polycystic ovary syndrome (PCOS). Gynecol Endocrinol 2018;34:148-52.

2. Iuorno MJ, Jakubowicz DJ, Baillargeon JP, Dillon P, Gunn RD, Allan G, et al. Effects of d-chiro-inositol in lean women with the polycystic ovary syndrome. Endocr Pract 2002;8:417-23.

3. Genazzani AD, Lanzoni C, Ricchieri F, Jasonni VM. Myoinositol administration positively affects hyperinsulinemia and hormonal parameters in overweight patients with polycystic ovary syndrome. Gynecol Endocrinol 2008;24:139-44.

4. Galazis N, Galazi M, Atiomo W. D-Chiro-inositol and its significance in polycystic ovary syndrome: a systematic review. Gynecol Endocrinol 2011;27:256-62.

5. Haghighatdoost F, Hariri M. The effect of alpha-lipoic acid on inflammatory mediators: a systematic review and meta-analysis on randomized clinical trials. Eur J Pharmacol 2019;849:115-23.

6. Zhang Y, Han P, Wu N, He B, Lu Y, Li S, et al. Amelioration of lipid abnormalities by $\alpha$-lipoic acid through antioxidative and anti-inflammatory effects. Obesity (Silver Spring) 2011;19:1647-53.

7. De Cicco S, Immediata V, Romualdi D, Policola C, Tropea A, Di Florio C, et al. Myoinositol combined with alpha-lipoic acid may improve the clinical and endocrine features of polycystic ovary syndrome through an insulin-independent action. Gynecol Endocrinol 2017;33:698-701. 


\title{
Criteri di scelta della integrazione con inositolo e acido lipoico nelle pazienti con sindrome dell'ovaio policistico
}

\begin{abstract}
Alessandro D. GENAZZANI *
Department of Gynecology and Obstetrics, University of Modena and Reggio Emilia, Modena, Italy

*Corresponding author: Alessandro D. Genazzani, Center of Gynecologic Endocrinology, Department of Obstetrics and Gynecology, University of Modena and Reggio Emilia, Modena, Italy. E-mail: algen@unimo.it

RIAS S UNTO

La Sindrome dell'Ovaio Policistico (PCOS) trova nella alterazione metabolica un suo importante marker. Oltre ai classici sintomi di anovulazione, iperandrogenismo e aspetto ecografico di ovaie, la insulino resistenza (IR) e la ridotta insulino sensibilità sono gli elementi da cercare nelle pazienti con PCOS al fine di migliorare sia il quadro clinico e la fertilità sia ridurre la prospettiva di un crescente rischio di malattia (diabete, rischio cardio vascolare, rischio oncologico). L'esecuzione del test da carico orale di glucosio (OGTT) permette di identificare la IR che in genere è assai più frequente nelle PCOS con familiarità diabetica.

L'uso integrativo degli inositoli e dell'acido lipoico (ALA) ha evidenziato che questi in modo specifico possono migliorare la sensibilità all'insulina in specie nelle pazienti con predisposizione familiare al diabete che hanno una ridotta espressione della epimerasi e LASY (Lipoic Acid SYntase). Dati clinici confermano che l'uso combinato di myo-inositolo (MYO) con ALA, permette un buon controllo della insulino resistenza aumentando la insulino sensibilità in tutte le pazienti PCOS, in particolare in quelle con familiarità diabetica.

PAROlE ChIAVE: Sindrome dell'ovaio policistico; Acido alfa-lipoico; Mioinositolo.
\end{abstract}

\section{Premessa}

$\mathrm{N}$ ell'approccio clinico-pratico delle pazienti con sindrome dell'ovaio policistico (PCOS), in presenza o in assenza di obesità, occorre considerare che l'inositolo, oltre alla sua implicazione nell'insulino-sensibilità e nei livelli ormonali, è anche il messaggero di altre strutture ormonali proteiche (TSH, FSH) e che, inoltre, l'acido alfa-lipoico (ALA) segue il proprio percorso metabolico partendo dai mitocondri. ${ }^{1}$

Il lavoro svolto nel centro di Modena attraverso lo studio sull'inositolo ha contribuito a costruire un modello concettuale per l'approccio delle pazienti con PCOS.

Il livello di conversione del glucosio-6-fosfato a D-chiro-inositolo per opera dell'epimerasi ${ }^{2}$ a livello ematico potrebbe essere superiore a quella che avviene nel tessuto ovarico dove la quantità di glucosio-6-fosfato è ridotta rispetto agli altri tessuti e organi.

Era stato osservato in precedenza che il grado di miglioramento dell'iperinsulinismo con l'inositolo era proporzionale al livello di iperinsulinismo riscontrato di base, ${ }^{3}$ e che l'effetto sulle gonadotropine è stato riscontrato in modo marcato solo nelle pazienti che erano realmente iperinsulinemiche.

Le pazienti con PCOS non obese avevano risposte dell'insulina all'OGTT borderline ma, seppur con valori di LH un poco elevati, l'insulina basale era normale. Con la somministrazione di mioinositolo (MYO) la risposta all'insulina sotto carico orale di glucosio si riduceva. Quindi, nelle pazienti con PCOS non obese sembra esistere una variabile non legata al peso corporeo. ${ }^{4}$ 
TABELLA I.-Caratteristiche ormonali nelle pazienti PCOS con insulina basale $<12 \mu \mathrm{U} / \mathrm{ml}$ (gruppo A) o con insulina basale $>12 \mu \mathrm{U} / \mathrm{ml}$ (gruppo B) prima e dopo trattamento con mioinositolo. Modificata da Genazzani et al. ${ }^{5}$

\begin{tabular}{|c|c|c|c|c|c|c|c|c|c|c|}
\hline Gruppo & $\begin{array}{c}\mathrm{LH} \\
\mathrm{mIU} / \mathrm{ml}\end{array}$ & $\begin{array}{c}\mathrm{FSH} \\
\mathrm{mIU} / \mathrm{ml}\end{array}$ & $\begin{array}{c}\mathrm{E} 2 \\
\mathrm{pg} / \mathrm{ml}\end{array}$ & $\begin{array}{c}\mathrm{A} \\
\mathrm{ng} / 100 \mathrm{ml}\end{array}$ & $\begin{array}{c}\mathrm{T} \\
\mathrm{ng} / 100 \mathrm{ml}\end{array}$ & $\begin{array}{l}17 \mathrm{OHP} \\
\mathrm{ng} / \mathrm{ml}\end{array}$ & $\begin{array}{c}\text { Cortisolo } \\
\mu \mathrm{g} / 100 \mathrm{ml}\end{array}$ & Insulina $\mu \mathrm{U} / \mathrm{ml}$ & Glu-to-ins. ratio & BMI \\
\hline \multicolumn{11}{|l|}{$\begin{array}{l}\text { Gruppo A } \\
(\mathrm{N} .=15)\end{array}$} \\
\hline Basale & $12,4 \pm 2,5$ & $5,9 \pm 1,1$ & $82 \pm 20$ & $234,3 \pm 29,6$ & $64,7 \pm 8,4$ & $1,1 \pm 0,1$ & $10,4 \pm 1,5$ & $7,1 \pm 0,9$ & $14,2 \pm 1,9$ & $28 \pm 1,1$ \\
\hline $\begin{array}{l}\text { In trattamento } \\
\text { (8 sett.) }\end{array}$ & $7,7 \pm 1,2 * *$ & $4,9 \pm 0,9$ & $79,5 \pm 20,5$ & $180 \pm 36,2 *$ & $60 \pm 8,8$ & $1,4 \pm 0,3$ & $11,6 \pm 1,2$ & $5,9 \pm 1,1$ & $16,9 \pm 2$ & $26,3 \pm 1,3 *$ \\
\hline \multicolumn{11}{|l|}{$\begin{array}{l}\text { Gruppo B } \\
(\mathrm{N} .=27)\end{array}$} \\
\hline Basale & $10 \pm 0,2$ & $4,8 \pm 0,3$ & $67 \pm 10$ & $330 \pm 17,6$ & $63,6 \pm 3,3$ & $1,03 \pm 0,1$ & $14,5 \pm 1,2$ & $20,3 \pm$ & $5,5 \pm 0,5 \S$ & $34,3 \pm 2,1 \S$ \\
\hline $\begin{array}{l}\text { In trattamento } \\
\text { (8 sett.) }\end{array}$ & $7,1 \pm 0,9 * *$ & $3,9 \pm 0,2^{*}$ & $73,4 \pm 8,7$ & $250 \pm 25,5 * * *$ & $57,5 \pm 3,5^{*}$ & $1,1 \pm 0,2$ & $14,2 \pm 0,7$ & $12,9 \pm 1,8 * * * * \S$ & $9,0 \pm 1,2 * * * \S$ & $31,2 \pm 1,3 * \S$ \\
\hline
\end{tabular}

LH: luteinizing hormone; FSH: follicle-stimulating hormone; E2: estradiol; A: androstenedione; T: testosterone; 170HP: 17-hydroxyprogesterone; BMI: Body Mass Index.

$* \mathrm{P}<0,05 ; * * \mathrm{P}<0,03 ; * * * \mathrm{P}<0,01 ; * * * * \mathrm{P}<0,00001$ versus basale; $\S \mathrm{P}<0.02$ versus Gruppo $\mathrm{A}$.

L'analisi delle pazienti obese trattate con inositolo ha evidenziato un miglioramento della risposta insulinica massima sotto carico di glucosio orale rispetto al basale. Inoltre, le pazienti con parenti diabetici non hanno mostrato modificazioni significative del picco glicemico, mentre le pazienti senza parenti glicemici presentavano una riduzione più marcata del picco glicemico.

In uno studio precedente 5 (e confermato da altri lavori) è stato identificato il valore di cutoff dei livelli d'insulina di base di $12 \mu \mathrm{U} / \mathrm{ml}$ al di sopra dei quali una paziente è classificabile come fortemente a rischio di essere iperinsulinemica alla curva di carico di glucosio con una probabilità del $90 \%$. Di fatto, le pazienti con valori d'insulina uguali o al di sopra di questo cutoff avevano una risposta migliore al trattamento con inositolo e proporzionale al valore d'insulina superiore ai $12 \mu \mathrm{U} / \mathrm{ml}$ (Tabella I).

\section{Familiarità con il diabete}

Lo studio di Larner et al. (2010) aveva dimostrato che la familiarità con il diabete cambia la quota di D-chiro-inositolo prodotta perchè il MYO non si trasforma del tutto in D-chiroinositolo per una ridotta espressione/funzione dell'enzima epimerasi, con conseguenti implicazioni sulla sensibilità all'insulina.

L'ALA ha un ruolo nella funzione antiossidante mitocondriale. In modelli sperimentali di diabete di tipo 2 è stato dimostrato che la LASY, enzima che sintetizza 1'ALA a livello mitocondriale, è ridotta e che la somministrazione d'insulina non è sufficiente per determinare l'uptake di glucosio necessario all'interno dei tessuti; quindi nella paziente diabetica si produce meno ALA inducendo così uno stimolo alla insulinoresistenza. Questo accade perché 1'ALA stimola in modo indipendente dall'inositolo la AKT citoplasmatica la quale attiva la GLUT4 e il successivo uptake del glucosio. ${ }^{6}$

Dato che inositolo e ALA agiscono su vie distinte e all'interno dei mitocondri, la familiarità col diabete, in particolare per via materna, assume un'importanza rilevante.

In un altro studio, la somministrazione combinata di MYO e ALA a 30 donne obese con PCOS (distinte per presenza o assenza di familiarità al diabete di tipo 1 o di tipo 2$)^{7}$ ha migliorato la sensibilità all'insulina di base nelle pazienti con familiarità al diabete e con tendenza alla riduzione dell' $\mathrm{LH}$, ossia dei parametri riproduttivi di base. Quando è stato eseguito dopo il trattamento, il miglioramento della risposta insulinica all'OGTT era significativamente migliorato sia nel gruppo di pazienti con familiarità, sia nel gruppo di pazienti senza familiarità al diabete, a differenza di quanto osservato dopo il trattamento col solo MYO. In pratica nel gruppo delle PCOS con la familiarità al diabete e quindi con una maggiore inefficienza della LASY e della epimerasi, l'abbinamento dell'ALA e 


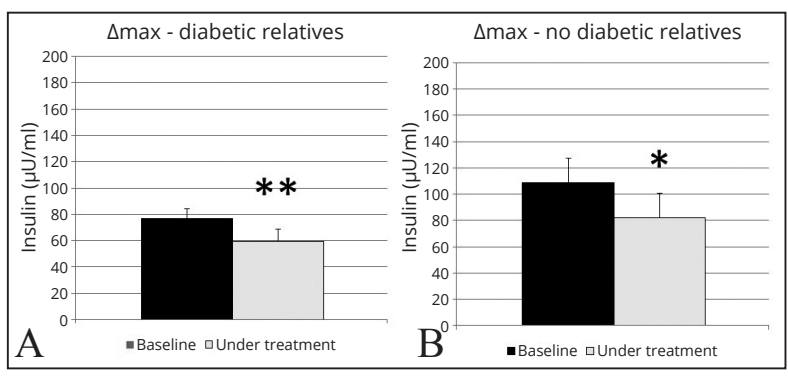

Figura 1.-Massima risposta dell'insulina all'OGTT prima e dopo trattamento con MYO+ALA.

Modificata da Genazzani et al. ${ }^{8}$

MYO riattiva in modo marcato lo stimolo sulla GLUT4 e quindi migliora la insulino-sensibilità8 (Figura 1).

Le variazioni significative si sono riscontrate anche quando un altro gruppo di pazienti sono state trattate con solo ALA (400 mg/die). ${ }^{9} \mathrm{Le}$ pazienti sono state suddivise per presenza/assenza di familiarità al diabete. Quindi, il trattamento con solo ALA ha determinato una buona risposta in tutte le pazienti trattate, in particolare, in quelle con familiarità al diabete.

In tutte le pazienti trattate (Tabella II) (indipendentemente dalla presenza o assenza del diabete familiare) si sono verificati i miglioramenti metabolici, ma non si sono riscontrate variazioni degli indici della riproduzione (androgeni, LH, FSH, etc.), anche se l'oligomenorrea è stata corretta e il peso si è ridotto in una parte di queste pazienti. Quindi, gli equilibri metabolici ricostituiti hanno in qualche modo influito positivamente sugli aspetti riproduttivi (Tabella II). ${ }^{9}$ Questa ipotesi è stata recentemente confer- mata confrontando 3 gruppi di pazienti PCOS obese trattate con solo MYO, con solo ALA o con la combinazione ALA+MYO. ${ }^{8}$

Come conclusione si può affermare che l'associazione MYO e ALA è un trattamento chiave perché il MYO ha un effetto sia sulla insulinosensibilità sia sugli altri ormoni, in particolare sul segnale post-recettoriale dell'FSH, mentre l'ALA migliora il profilo metabolico e la sensibilità insulinica.

\section{Statements}

- Il miglioramento dell'iperinsulinismo con inositolo nelle pazienti con PCOS è stato riscontrato solo nelle pazienti che erano realmente iperinsulinemiche.

- Dopo trattamento con mioinositolo, le pazienti con PCOS e con parenti diabetici non hanno mostrato modificazioni significative della risposta insulina all' OGTT, mentre le pazienti con PCOS e senza parenti diabetici presentavano una riduzione più marcata della risposta insulinica.

- La somministrazione combinata di mioinositolo e acido alfa-lipoico a PCOS obese ha indotto un miglioramento degli indici ormonali e della sensibilità all'insulina di base in specie nelle pazienti con familiarità al diabete.

- Il mioinositolo è integrato nel segnale post-recettoriale dell'FSH, mentre l'acido alfalipoico migliora il profilo metabolico e l'iperinsulinemia.

TABella II.-Trattamento con ALA in PCOS obese senza (gruppo A) e con (gruppo B) familiarità al diabete. ALA non modifica l'aspetto ormonale riproduttivo, ma modifica quello metabolico.

\begin{tabular}{|c|c|c|c|c|c|c|c|c|c|c|c|}
\hline PCOS patients & $\underset{\mathrm{mIU} / \mathrm{ml}}{\mathrm{LHIU} / \mathrm{ml}}$ & $\begin{array}{c}\text { Estradiolo } \\
\mathrm{pg} / \mathrm{ml}\end{array}$ & $\underset{\mathrm{ng} / \mathrm{ml}}{\mathrm{A}}$ & $\underset{\mathrm{ng} / \mathrm{ml}}{\mathrm{T}}$ & $\begin{array}{l}\text { Insulina } \\
\mu \mathrm{U} / \mathrm{ml}\end{array}$ & $\begin{array}{c}\text { Glucosio } \\
\mathrm{mg} / \mathrm{dl}\end{array}$ & $\begin{array}{l}\text { Trigliceridi } \\
\mathrm{mg} / \mathrm{dl}\end{array}$ & $\begin{array}{c}\text { GOT } \\
\mathrm{U} / 1\end{array}$ & $\begin{array}{c}\mathrm{GPT} \\
\mathrm{U} / 1\end{array}$ & BMI & $\begin{array}{l}\text { HOMA } \\
\text { Index }\end{array}$ \\
\hline \multicolumn{12}{|c|}{ Con parentela diabetica $(\mathrm{N} .=20)$} \\
\hline Basale & $9,2 \pm 1,15,7 \pm 0,5$ & $51,1 \pm 19,0$ & $281,6 \pm 58,1$ & $0,33 \pm 0,06$ & $15,5 \pm 2,9$ & $92,6 \pm 3,3$ & $91,5 \pm 17,52$ & $23,4 \pm 2,2$ & $27,5 \pm 4,1$ & $35,5 \pm 1,5$ & $53,2 \pm 0,6$ \\
\hline $\begin{array}{l}\text { In trattamento } \\
\text { con ALA }\end{array}$ & $08,9 \pm 1,5 \quad 5,5 \pm 0,4$ & $65,1 \pm 15,0$ & $277 \pm 37,2$ & $0,3 \pm 0,03$ & $10,3 \pm 1,6$ & $588,9 \pm 2,2$ & $75,7 \pm 7,6$ & $18,8 \pm 1,2$ & $22,9 \pm 4,9$ & $32,5 \pm 2,2$ & $22,2 \pm 0,3$ \\
\hline P vs. basale & & & & & $\mathrm{P}<0,01$ & & $\mathrm{P}<0,01$ & $\mathrm{P}<0,02$ & & $\mathrm{P}<0,002$ & $2 \mathrm{P}<0,03$ \\
\hline \multicolumn{12}{|c|}{ Senza parentela diabetica $(\mathrm{N} .=12)$} \\
\hline Basale & $8,7 \pm 1,64,9 \pm 0,4$ & $49,8 \pm 15,3$ & $428 \pm 113$ & $0,4 \pm 0,06$ & $14 \pm 3,3$ & $95 \pm 3,8$ & $89,3 \pm 18,6$ & $19 \pm 1,4$ & $19,5 \pm 2,4$ & $30,1 \pm 3$ & $3,3 \pm 0,7$ \\
\hline $\begin{array}{l}\text { In trattamento } \\
\text { con ALA }\end{array}$ & $13,6 \pm 4 \quad 5 \pm 0,5$ & $80 \pm 35,2$ & $391,6 \pm 106$ & $0,4 \pm 0,08$ & $8,8 \pm 1,1$ & $82,8 \pm 3,2$ & $85,8 \pm 5,4$ & $18,8 \pm 2,6$ & $16,6 \pm 3$ & $27,3 \pm 1,9$ & $91,8 \pm 0,2$ \\
\hline P vs. basale & & & & & $\mathrm{P}<0,5$ & $\mathrm{P}<0,009$ & & & & $\mathrm{P}<0,05$ & $\mathrm{P}<0,04$ \\
\hline
\end{tabular}




\section{Bibliografia}

1. Genazzani AD. Inositol as putative integrative treatment for PCOS. Reprod Biomed Online 2016;33:770-80.

2. Larner J, Brautigan DL, Thorner MO. D-chiro-inositol glycans in insulin signaling and insulin resistance. Mol Med 2010;16:543-52.

3. Genazzani AD, Lanzoni C, Ricchieri F, Jasonni VM. Myoinositol administration positively affects hyperinsulinemia and hormonal parameters in overweight patients with polycystic ovary syndrome. Gynecol Endocrinol 2008;24:139-44.

4. Genazzani AD, Santagni S, Ricchieri F, Campedelli A, Rattighieri E, Chierchia E, et al. Myo-inositol modulates insulin and luteinizing hormone secretion in normal weight patients with polycystic ovary syndrome. J Obstet Gynaecol Res 2014;40:1353-60.

5. Genazzani AD, Prati A, Santagni S, Ricchieri F, Chierchia E, Rattighieri E, et al. Differential insulin response to myo- inositol administration in obese polycystic ovary syndrome patients. Gynecol Endocrinol 2012;28:969-73.

6. Padmalayam I, Hasham S, Saxena U, Pillarisetti S. Lipoic acid synthase (LASY): a novel role in inflammation, mitochondrial function, and insulin resistance. Diabetes 2009;58:600-8.

7. Genazzani AD, Despini G, Santagni S, Prati A, Rattighieri E, Chierchiaand E, et al. Effects of a Combination of Alpha Lipoic Acid and Myo-Inositol on Insulin Dynamics in Overweight/ Obese Patients with PCOS. Endocrinol Metab Syndr 2014;3:3.

8. Genazzani AD, Prati A, Marchini F, Petrillo T, Napolitano A, Simoncini T. Differential insulin response to oral glucose tolerance test (OGTT) in overweight/obese polycystic ovary syndrome patients undergoing to myo-inositol (MYO), alpha lipoic acid (ALA), or combination of both. Gynecol Endocrinol 2019;35:1088-93.

9. Genazzani AD, Shefer K, Della Casa D, Prati A, Napolitano A, Manzo A et al. Modulatory effects of alpha-lipoic acid (ALA) administration on insulin sensitivity in obese PCOS patients. J Endocrinol Invest 2018;41:583-90. 


\title{
Associazione metformina, mioinositolo e acido alfa-lipoico: riduzione della dose di metformina in paziente PCOS obesa
}

\author{
Vincenzo DE LEO * \\ Department of Molecular and Developmental Medicine, University of Siena, Siena, Italy
}

*Corresponding author: Vincenzo De Leo, Department of Molecular and Developmental Medicine, University of Siena, Siena, Italy. E-mail: vincenzo.deleo@unisi.it

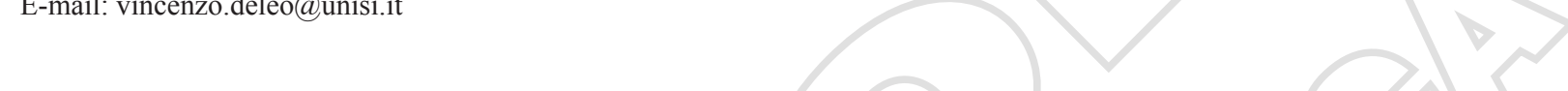 \\ R I A S S U T O \\ Il trattamento dell'insulino-resistenza nella sindrome dell'ovaio micropolicistico si basa sull'utilizzo di farmaci quali la metformina, le cui azioni sono da tempo conosciute. Comunemente tale farmaco ad alte dosi può indurre effetti indesiderati a livello gastroenterico. Il presente studio confronta due protocolli terapeutici in pazienti affette da ovaio micropolicistico, obese e iperandrogeniche, il Gruppo A trattato con sola meftormina ad alte dosi ed il Gruppo B trattato con associazione tra metformina a dosi più basse, myo-inositolo $2 \mathrm{~g}$ e acido alfa-lipoico $800 \mathrm{mg}$ al giorno. Il Gruppo $\mathrm{B}$ ha mostrato risultati migliori in termini di riduzione dell'HOMA index, quadro androgenico e parametri riproduttivi. L'associazione metformina, inositolo e acido lipoico si è dimostrata una scelta meglio tollerata dalle pazienti ed adeguata per le donne PCO, obese e infertili che cercano la normalizzazione dei parametri ovulatori e l'ottenimento della gravi- danza. \\ PAROLE CHIAVE: Sindrome dell'ovaio policistico; Metformina; Acido alfa-lipoico; Mioinositolo.}

\section{Premessa}

$\mathrm{N}$ elle donne con sindrome dell'ovaio policistico (PCOS) e resistenza insulinica, la scoperta dell'alterazione del metabolismo degli inositoli, che comporta un ridotto signaling dell'insulina, è stato un altro passo avanti fondamentale per la comprensione della patogenesi di questa malattia. ${ }^{1}$

La metformina ha diversi effetti sul metabolismo glucidico ed è intervenuta in misura innovativa per curare le disfunzioni endocrine di pertinenza dell'endocrinologia ginecologica. ${ }^{2}$

L'impiego dell'acido alfa-lipoico (ALA) è fondamentale in quanto possiede un'azione antiossidante, è un cofattore enzimatico della catena respiratoria, e un fattore di regolazione del metabolismo glucidico e lipidico. L'ALA contribuisce al controllo della glicemia in pazienti con diabete mellito di tipo 2 e, inoltre, esercita un effetto di controllo sull'appetito e, quindi, sull'assunzione di cibo. ${ }^{3}$
Associazione tra metformina, mioinositolo e acido alfa-lipoico

L'azione di metformina è dose-dipendente, quindi nel centro di Siena, la metformina è sempre stata impiegata a dosi fino a $1000 \mathrm{mg}$ per 3 volte/die; tuttavia, ad alte dosi metformina può determinare considerevoli effetti collaterali.

Nello studio di Cappelli et al. ${ }^{4}$ è stata utilizzata una dose ridotta di metformina associata a mioinositolo (MYO; con azione insulinosensibilizzante) e ALA. Sono state arruolate 45 donne con PCOS e suddivise in due gruppi di trattamento: un primo gruppo di pazienti trattate con metformina ad alte dosi in monoterapia e un secondo gruppo di pazienti trattate con l'associazione tra metformina a dose più bassa $(850$ $\mathrm{mg}$ ) per 2 volte/die, mioinositolo $1000 \mathrm{mg}$ per due volte/die e acido alfa-lipoico $400 \mathrm{mg}$ per 2 volte/die. L'associazione tra metformina, MYO e ALA ha determinato risultati migliori rispetto a metformina in monoterapia in base a diversi 


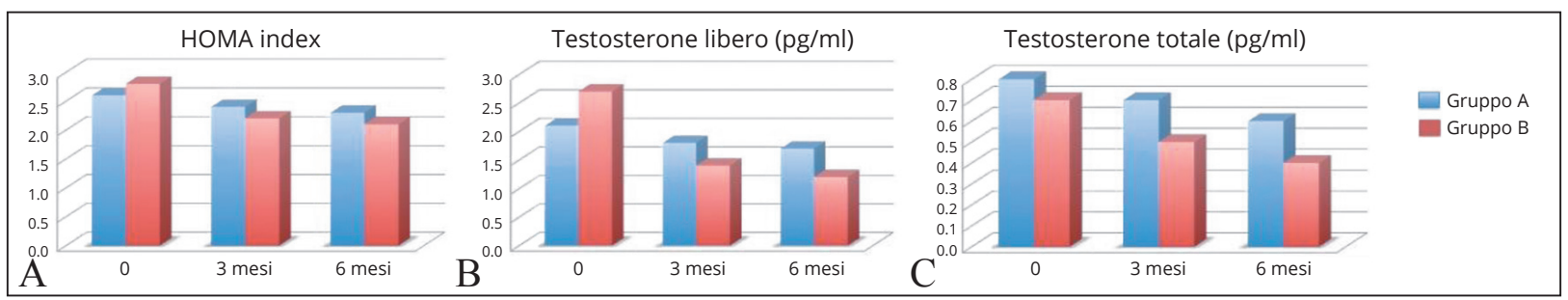

Figura 1.- Le azioni dei due differenti protocolli terapeutici sull'HOMA index (A), sul testosterone libero (B) e sul testosterone totale (C). Riprodotto con permesso di Cappelli et al. ${ }^{4}$

Tabella I.-Dati dello studio di Cappelli et al. ${ }^{4}$

\begin{tabular}{llccc}
\hline Parametri & Gruppo & 0 & 3 mesi & 6 mesi \\
\hline Ciclo & Gruppo A & $45 \pm 20$ & $36 \pm 8$ & $32 \pm 5$ \\
& Gruppo B & $48 \pm 16$ & $32 \pm 4$ & $30 \pm 4$ \\
BMI, kg/m ${ }^{2}$ & Gruppo A & $31 \pm 2$ & $28 \pm 2$ & $27 \pm 1$ \\
\multirow{2}{*}{ Ferriman-Gallwey Score } & Gruppo B & $32 \pm 3$ & $26 \pm 1$ & $25 \pm 1$ \\
& Gruppo A & $14 \pm 2$ & $12 \pm 2$ & $10 \pm 1$ \\
& Gruppo B & $15 \pm 3$ & $10 \pm 1$ & $7 \pm 1$ \\
\hline
\end{tabular}

parametri valutati nel corso dello studio (Tabella I, Figura 1).

Quindi, l'associazione "metformina, MYO e ALA" è una possibile scelta terapeutica da proporre a donne con PCOS obese e fertili che non vogliono assumere contraccettivi orali. Inoltre, questa associazione può essere somministrata a donne con PCOS sottoposte a vari trattamenti ormonali dato che MYO contrasta la IR e, in associazione con ALA, i fenomeni dell'infiammazione.

Nello studio di Cappelli et al. ${ }^{4}$ è emerso che la somministrazione di metformina comporta un'iper-azione o iperstimolazione del D-chiro-inositolo fosfoglicano (DCI-IPG) e un maggior consumo di inositolo. Pertanto, la supplementazione con inositolo durante il trattamento delle donne con PCOS determina un effetto sinergico. 5,6

Dato che uno dei meccanismi con cui agisce la metformina è la stimolazione della produzione del DCI-IPG, l'associazione con il MYO trova un'indicazione idonea.

Occorre considerare anche il fatto che tutte le pazienti con iperinsulinemia e/o iperglicemia consumano grosse quantità endogene di inositolo; la carenza endogena che ne deriva può essere quindi corretta con la supplementazione di MYO e ALA.

\section{Statements}

- L'associazione "metformina, mioinositolo e acido alfa-lipoico" è una scelta terapeutica idonea da proporre alle donne con PCOS obese e fertili che non vogliono assumere contraccettivi orali.

- Uno dei meccanismi con cui agisce metformina passa attraverso la stimolazione della produzione del DCI-IPG e, pertanto, l'associazione dell'inositolo trova indicazione.

- Tutte le pazienti con iperinsulinemia e/o iperglicemia consumano grosse quantità endogene di inositolo; la carenza endogena che ne deriva può essere quindi corretta con la supplementazione con mioinositolo e acido alfa-lipoico.

\section{Bibliografia}

1. Nestler JE. Role of hyperinsulinemia in the pathogenesis of the polycystic ovary syndrome, and its clinical implications. Semin Reprod Endocrinol 1997;15:111-22.

2. Diamanti-Kandarakis E, Economou F, Palimeri S, Christakou C. Metformin in polycystic ovary syndrome. Ann N Y Acad Sci 2010;1205:192-8.

3. Ziegler D, Ametov A, Barinov A, Dyck PJ, Gurieva I, Low PA, et al. Oral treatment with alpha-lipoic acid improves symptomatic diabetic polyneuropathy: the SYDNEY 2 trial. Diabetes Care 2006;29:2365-70.

4. Cappelli V, Di Sabatino A, Musacchio MC, De Leo V. [Evaluation of a new association between insulin-sensitizers and $\alpha$-lipoic acid in obese women affected by PCOS]. Minerva Ginecol 2013;65:425-33. Italian.

5. Baillargeon JP, Diamanti-Kandarakis E, Ostlund RE Jr, Apridonidze T, Iuorno MJ, Nestler JE. Altered D-chiro-inositol urinary clearance in women with polycystic ovary syndrome. Diabetes Care 2006;29:300-5.

6. Heimark D, McAllister J, Larner J. Decreased myoinositol to chiro-inositol (M/C) ratios and increased $\mathrm{M} / \mathrm{C}$ epimerase activity in PCOS theca cells demonstrate increased insulin sensitivity compared to controls. Endocr J 2014;61:111-7. 


\title{
Advisory Board italiano sulla sindrome dell'ovaio policistico: conclusioni
}

\author{
Enrico M. FERRAZZI 1,2 *, Paolo MOGHETTI ${ }^{3}$, Franca FRUZZETTI 4, \\ Alessandra GAMBINERI 5, Anna M. FULGHESU 6, Maria E. STREET 7, Rocco RAGO 8, \\ Caterina MENEGHINI 8, Alessandro DAL LAGO ${ }^{8}$, Irene CETIN 9, 10, Chiara NOVIELLI 9, 10, \\ Chiara MANDÒ 9, 10, Nicoletta DI SIMONE 11, Alessandro D. GENAZZANI 12, Rosanna APA 11, \\ Giovanna NOTARISTEFANO ${ }^{11}$, Vincenzo DE LEO ${ }^{13}$
}

${ }^{1}$ Obstetric and Gynecologic Clinic, University of Milan, Milan, Italy; ${ }^{2}$ Maggiore Polyclinic Hospital, IRCCS Ca' Granda Foundation, Padiglione Mangiagalli, University of Milan, Milan, Italy; 3 Department of Endocrinology, Diabetology and Metabolic Diseases, University Hospital of Verona, Verona, Italy; ${ }^{4}$ Clinic of Obstetrics and Gynecology, Ambulatory of Gynecological Endocrinology, Santa Chiara Hospital, Pisa, Italy; 5 Operative Unit of Endocrinology, Department of Medical and Surgical Sciences, S. Orsola-Malpighi Polyclinic, University of Bologna, Bologna, Italy; ${ }^{6}$ Department of Surgery, Faculty of Medicine and Surgery, University of Cagliari, Cagliari, Italy; ${ }^{7}$ Unit of Endocrinology and Pediatric Diabetology, Department of Pediatrics, Arcispedale S. Maria Nuova, AUSL of Reggio Emilia-IRCCS, Reggio Emilia, Italy; ${ }^{8}$ Operative Unit of Reproductive Pathophysiology and Andrology, Sandro Pertini Hospital, Rome, Italy; ${ }^{9}$ Giorgio Pardi Maternal-Fetal Translational Research Laboratory, Buzzi Hospital, ASST Fatebenefratelli Sacco, Milan, Italy; ${ }^{10}$ Luigi Sacco Department of Biomedical and Clinical Sciences, University of Milan, Milan, Italy; ${ }^{11}$ Unit of Obstetrics and Gynecology, Department of Women's and Children's Health and of Public Health, IRCCS A. Gemelli University Polyclinic Foundation, Sacred Heart Catholic University, Rome, Italy; ${ }^{12}$ Center of Endocrinologic Gynecology, Obstetrics and Gynecology Clinic, University of Modena and Reggio Emilia, Modena, Italy; ${ }^{13}$ Department of Molecular and Developmental Medicine, University of Siena, Siena, Italy

*Corresponding author: Enrico M. Ferrazzi, Obstetric and Gynecologic Clinic, University of Milan, Milan, Italy. E-mail: enrico.ferrazzi@unimi.it

$\mathrm{Q}$ uanto emerge dalle discussioni e dalle valutazioni clinico-sperimentali dei componenti dell Advisory Board altro non fa che suggerire quanto la valutazione clinica e dei dati laboratoristici delle pazienti con quadri di sindrome dell'ovaio policistico (PCOS) sia importante per la definizione della procedura terapeutica.

Le molte esperienze cliniche dei componenti dell'Advisory discusse e confrontate durante gli incontri hanno portato alla stesura di indicazioni/ raccomandazioni ritenute rilevanti per la diagnosi, la gestione e per la scelta del trattamento delle pazienti con PCOS:

- nella PCOS la insulino resistenza (IR) è frequente nel fenotipo classico, è parziale nel fenotipo ovulatorio mentre non è presente nelle pazienti normoandrogeniche;

- è frequente considerare come insulino-sensibile la paziente con PCOS solo perché non si è valutato 1' Homeostatic Model Assessment
(HOMA) Index o la risposta insulinica all'OGTT; - i livelli di High Mobility Group 1 (HMGB1) aumentano in condizioni d'iperinsulinismo e iperglicemia. I livelli di HMGB1 sono inversamente correlati a quelli dell'insulina nei liquidi follicolari e sono aumentati nelle pazienti con PCOS;

- i livelli di HMGB1 e di miRNA, marker d'infiammazione in pazienti con PCOS, diminuiscono dopo trattamento integrativo con la combinazione mioinositolo e acido alfa-lipoico;

- il rischio metabolico delle pazienti adolescenti con PCOS deve essere valutato con indici e valori di cut-off diversi da quelli normalmente usati per le pazienti adulte;

- BMI e obesità sono elementi da considerare come fondamentali per una corretta valutazione del rischio metabolico e riproduttivo nelle adolescenti con PCOS proprio per le specifiche decisioni terapeutiche da consigliare e che pos- 
sono comprendere sia gli insulino-sensibilizzanti (metformina), sia il mioinositolo, sia trattamenti estro-progestinici, o combinazioni varie di questi;

- la supplementazione con combinazione di mioinositolo e acido alfa-lipoico in pazienti con PCOS sottoposte a procreazione medicalmente assistita induce un miglioramento che si realizza con minor produzione di oociti di oociti immaturi e/o degenerati, e un maggiore recupero di oociti di classe MII che a loro volta sono in grado di generare embrioni di classe I e II, e che se fecondati portano a embrioni di altrettanta buona qualità;

- l'acido alfa-lipoico associato a mioinositolo può contribuire a diminuire i livelli di mtDNA, marker di stress ossidativo, a livello oocitario;

- l'inflammosoma NALP-3 è altamente attivato in donne con abortività ricorrente e si riduce in misura significativa dopo trattamento con combinazione di mioinositolo e acido alfa-lipoico rispetto alla popolazione di controllo;

- l'associazione mioinositolo e acido alfalipoico migliora il profilo clinico e le caratteristiche ormonali di pazienti con PCOS in sovrappeso/obese ed ancor più se iperinsulinemiche. Il miglioramento è tanto più evidente tanto maggiori sono le alterazioni pre-trattamento;
- le pazienti con PCOS e parenti diabetici non hanno mostrato modificazioni significative della risposta insulinica al test OGTT dopo trattamento con mioinositolo, mentre le pazienti con PCOS senza familiarità diabetica hanno presentato una marcata riduzione della risposta insulina al carico di glucosio;

- le pazienti con PCOS indipendentemente da avere o meno familiarità al diabete hanno tutte mostrato modificazioni significative della risposta insulinica al test OGTT dopo trattamento con la combinazione di mioinositolo e acido alfalipoico;

- nelle pazienti con PCOS la metformina agisce sulla componente metabolica (sensibilità insulinica) riducendo gli effetti negativi indotti dalla iperinsulinemia mentre il mioinositolo agisce sulla sensibilità insulinica ma anche sulla funzione ovulatoria migliorando l'anovulazione, spesso cronica;

- l'associazione "metformina, inositolo e acido lipoico" è una scelta terapeutica idonea per donne con PCOS obese e fertili che non vogliono assumere contraccettivi orali e che cercano il recupero della funzione ovulatoria, della ciclicità mestruale ed eventualmente della gravidanza. 